\title{
Lípidos y Feromonas de insectos plaga de granos almacenados
}

\author{
TESIS DOCTORAL \\ Lic. María Luciana Villaverde \\ Director: Dra. M. Patricia Juárez \\ Codirector: Dr. Horacio Heras \\ Facultad de Ciencias Naturales y Museo \\ Universidad Nacional de La Plata


El presente trabajo de tesis, para optar al grado de Doctora en Ciencias Naturales, fue realizado en el Instituto de Investigaciones Bioquímicas de La Plata (INIBIOLP), Facultad de Ciencias Médicas, UNLP, bajo la dirección de la Dra. M. Patricia Juárez y la codirección del Dr. Horacio Heras. 
A mis padres y a mis hijas, Celina y Ana 


\section{Mi Reconocimiento}

A la Dra. María J. Tacconi de Alaniz, por haberme permitido comenzar el presente trabajo en las instalaciones del INIBIOLP, como su directora.

Al actual director del INIBIOLP, Dr. Horacio Garda, por permitirme completar este trabajo.

A la Agencia Nacional de Promoción Científica y Tecnológica y al Consejo Nacional de Investigaciones Científicas y Técnicas, por las becas que me otorgaron oportunamente.

A las siguientes entidades que mediante los subsidios otorgados han financiado gran parte de este trabajo: Agencia Nacional de Promoción Científica y Tecnológica, PICT 2000 08-09653 y PICT 2004 20-25479; Consejo Nacional de Investigaciones Científicas y Técnicas, PIP 5172; Pan American Health Organization (PAHO) A20433. 


\section{Mi agradecimiento}

A la Dra. Patricia Juárez por su enorme paciencia y por haberme guiado en la realización de este trabajo.

Al Dr. Horacio Heras quien en forma desinteresada aceptó codirigir esta tesis.

A las Ing. Agr. Susana B. Padín y Cecilia Fusé por la provisión de los insectos utilizados. A ambas por su gran ayuda en la realización de los bioensayos $y$ por los gratos momentos compartidos.

A la Dra. Nora Eyler (Facultad de Ingeniería, Universidad Nacional del Centro, Olavarría) por facilitar el uso de las instalaciones de espectrometría de masa.

A todos los integrantes del INIBIOLP por la ayuda que me han prestado y por los buenos momentos compartidos.

A mis compañeros y Amigos del Lab. 12 por ayudarme en muchos experimentos de esta tesis y haber compartido tantas horas dentro y fuera del laboratorio.

A mis amigos y mi familia por alentarme, aconsejarme y estar siempre, en especial a Sole y flia por recibirme todos estos años.

A Bernardo, por soportar la distancia, por quererme y por el apoyo que me ha dado para que esta tesis llegue a su fin. 
"Hay una fuerza motriz más poderosa que el vapor, la electricidad y la energía atómica: la voluntad."

Albert Einstein

"Lo imposible, solo tarda un poco más" Nonpalidece 
Publicaciones en revistas científicas periódicas derivadas de este trabajo de tesis:

M.L Villaverde, M.P Juárez and S. Mijailovsky. 2007. Detection of Tribolium castaneum volatile defensive secretions by solid phase microextraction gas chromatography (SPME-CGC) analysis. Journal of Stored Products Research. 43: 540-545.

M.L Villaverde, J.R Girotti, S.J Mijailovsky, N Pedrini and M.P Juárez. 2009. Volatile secretions and epicuticular hydrocarbons of the beetle Ulomoides dermestoides. Compartive Biochemistry and Physiology. Part B: Biochemistry and Molecular Biology. 154: 381-386.

N Pedrini, M.L Villaverde, C.B Fusé, G.M Dal Bello and M.P Juárez. 2010. Beauveria bassiana infection alters colony development and defensive secretions of the beetles Tribolium castaneum and Ulomoides dermestoides (Coleoptera: Tenebrionidae). Journal of Economic Entomology. 103: 1094-1099.

R Crespo, M.L Villaverde, J.R Girotti, A Güerci, M.G de Bravo and M.P Juárez. 2011. Cytotoxic and genotoxic effects of defence secretion of Ulomoides dermestoides on A549 cells. Journal of Ethnopharmacology. 136: 204-209.

C.B Fusé, M.L Villaverde, S.B Padín, M De Giusto y M.P Juárez. 2013. Evaluación de la actividad insecticida de tierras de diatomeas de yacimientos argentinos. Revista de Investigaciones Agropecuarias (RIA). 39: 207-213. 


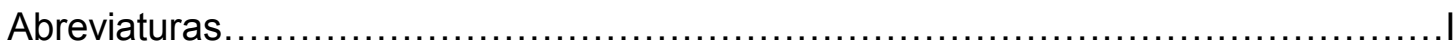

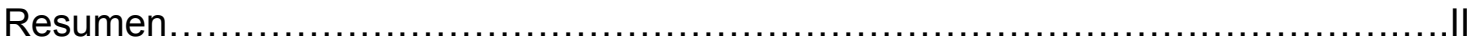

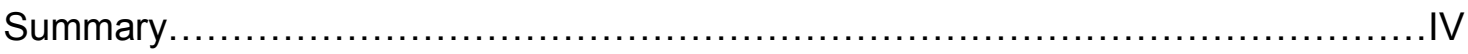

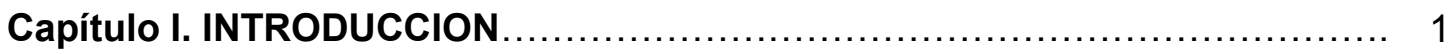

I.1.Generalidades de insectos plaga de granos almacenados..................... 2

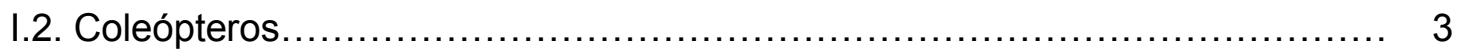

I.2.a. Tribolium castaneum................................................. 4

I.2.a.1.Clasificación taxonómica............................................ 4

I.2.a.2. Características generales..................................... 4

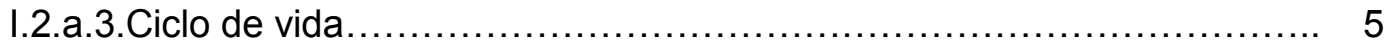

I.2.b.Ulomoides dermestoides.................................................. 7

I.2.b.1.Clasificación taxonómica......................................... 7

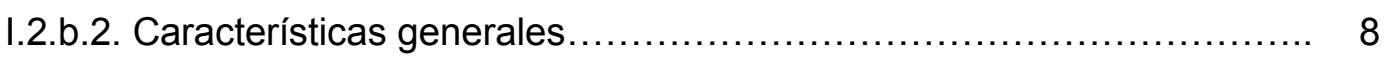

I.2.b.3.Ciclo de vida..................................................... 8

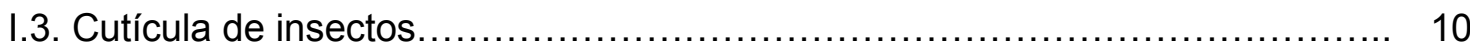

I.3.a. Hidrocarburos epicuticulares de insecto............................... 11

I.3.b. Biosíntesis de hidrocarburos y lípidos cuticulares......................... 14

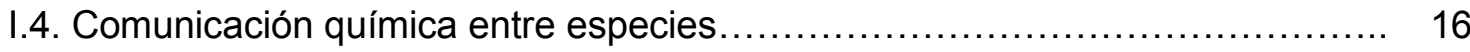

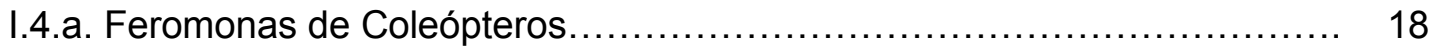

I.4.b. Compuestos orgánicos volátiles (VOC) liberados por T. castaneum........ 19

I.5. Métodos para el análisis de compuestos volátiles orgánicos................... 23

I.6. Control de insectos plaga de granos almacenados......................... 24

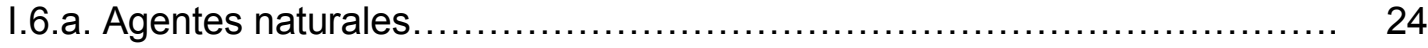

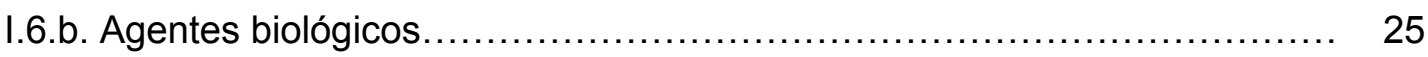

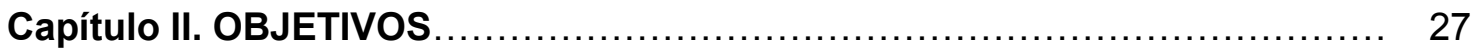

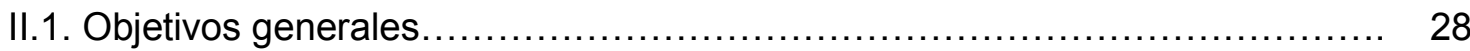

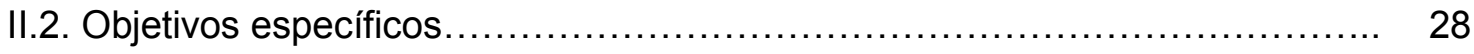

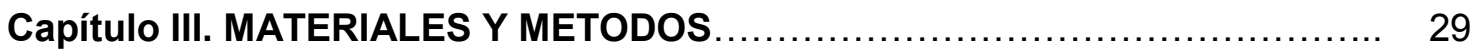

III.1. Reactivos, drogas, estándares, solventes y accesorios utilizados............ 30

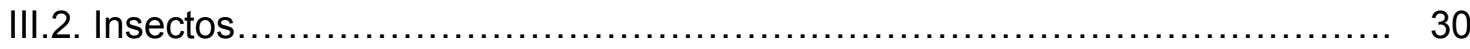


III.3. Análisis de lípidos de $T$. castaneum..................................... 31

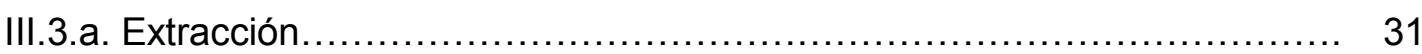

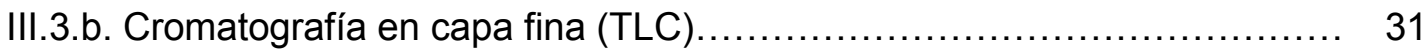

III.4. Análisis de hidrocarburos de T. castaneum .............................. 32

III.4.a. Extracción y purificación............................................ 32

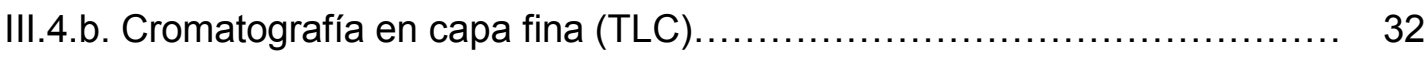

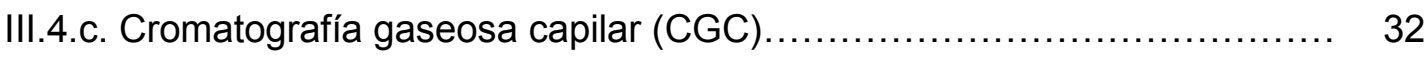

III.4.d. Cromatografía gaseosa capilar (CGC) acoplada a espectrometría de masas (MS).

III.5. Análisis de los VOC emitidos por T. castaneum y U. dermestoides............ 35

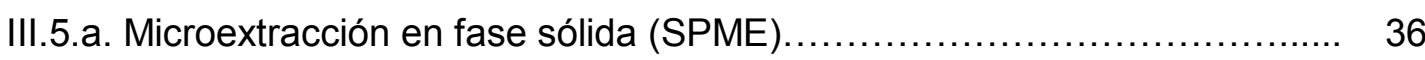

III.5.b. Análisis cualitativo mediante SPME- CGC acoplada a espectrometría de masa (MS).

III.5.b.1. Tribolium castaneum ....................................... 39

III.5.b.2. Ulomoides dermestoides..................................... 40

III.5.c. Análisis cuantitativo mediante SPME-CGC ......................... 41

III.5.c.1. Tribolium castaneum.......................................... 41

III.5.c.2. Ulomoides dermestoides.................................. 42

III.5.d. Análisis de las secreciones volátiles por extracción con solvente de $U$. dermestoides.

III.6. Metabolismo de lípidos en insectos plaga de granos almacenados.

III.6.a. Biosíntesis de novo de lípidos y secreciones volátiles en $T$. castaneum..

III.6.a.1. Extracción de los lípidos epicuticulares, totales y secreciones volátiles

III.6.a.2. Análisis de los lípidos epicuticulares, totales y secreciones volátiles por radio cromatografía en capa fina (radio-TLC).

III.6.b. Inhibición del metabolismo lipídico.

III.6.c. Incorporación de acetato en glándulas abdominales de $U$. dermestoides.

III.6.d. Biosíntesis de lípidos a partir de $\left[1-{ }^{14} \mathrm{C}\right]$ palmitato. Incubación de glándulas de $U$. dermestoides.

III.7. Efecto de inhibidores de la ácido graso sintasas (FAS) de insectos......... 46

III.7.a. Análisis de los VOC liberados mediante SPME-CGC ................. 47 
III.8. Efectos de agentes de control físico y biológico en la supervivencia y ciclo de vida de insectos plaga de granos almacenados

III.8.a. Bioensayos con agentes naturales................................. 47

III.8.b. Bioensayos con agentes biológicos..................................... 48

Capítulo IV. RESULTADOS ................................................. 49

IV.1. Análisis de lípidos de T. castaneum..................................... 50

IV.2. Análisis de hidrocarburos de T. castaneum............................... 52

IV.3. Análisis de los VOC emitidos por insectos plaga de granos almacenados

IV.3.a. Tribolium castaneum............................................ 58

IV.3.b. Ulomoides dermestoides.................................................. 64

IV.3.c. Análisis de las secreciones volátiles por extracción con solvente de $U$. dermestoides.

IV.4. Biosíntesis de novo de lípidos y secreciones volátiles.................... 67

IV.4.a. Tribolium castaneum............................................... 67

IV.4.b. Glándulas abdominales de U. dermestoides............................ 70

IV.5. Efecto de inhibidores de ácido graso sintasa (FAS) en la liberación de VOC en insectos plaga de granos almacenados...

IV.5.a. Tribolium castaneum................................................. 71

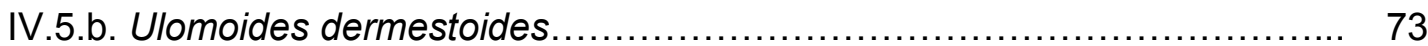

IV.6. Efecto de agentes naturales y biológicos en la supervivencia y ciclo de vida de insectos plaga de granos almacenados.

IV.6.a. Bioensayos con agentes naturales (Tierra de diatomeas) ................ 75

IV.6.b. Bioensayos con agentes biológicos (Beauveria bassiana)............... 76

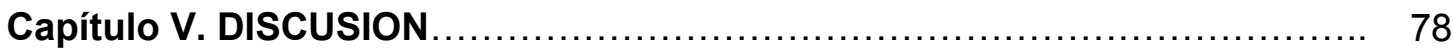

V.1. Hidrocarburos epicuticulares de $T$. castaneum ............................. 79

V.2. Compuestos orgánicos volátiles (VOC) de T. castaneum y U. dermestoides. 81

Análisis cuali-cuantitativo.................................................. 81

Biosíntesis de lípidos y secreciones volátiles en tenebriónidos.................... 84

V.3.Control físico y biológico de insectos plaga de granos almacenados.......... 86

Tierras de diatomeas.................................................... 86

Hongos entomopatógenos.......................................... 87 


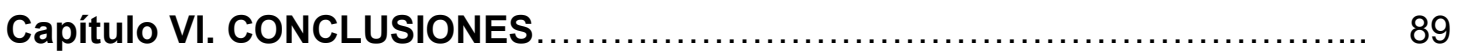

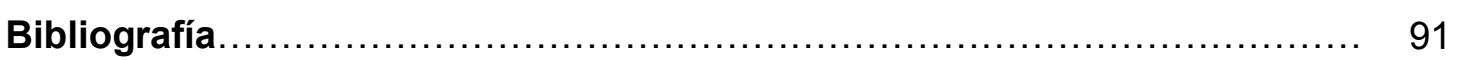




\section{Abreviaturas}

AGL Ácidos Grasos libres

$\mathrm{BQ} \quad$ Benzoquinona

CAR Carboxeno

CGC Cromatografía gaseosa capilar

cpm Cuentas por minuto

DCM Diclorometano

DG Diacilglicéridos

DVB Divinilbenceno

EBQ Etil-1,4-benzoquinona

EC Esteres de colesterol

FAS Ácido graso sintasa

FID Detector de ionización por llama

HC Hidrocarburos

$\mathrm{HQ} \quad$ Hidroquinona 5

HS Headspace

IK Indice de Kovats

MBQ Metil-1,4-benzoquinona

MS Espectrometría de masa

NADPH Nicotidamida adenina dinucleótido fosfato reducido

n-C15:1 1-pentadeceno

PDMS Polidimetilsiloxano

PHEP Fenil derivado del ácido propiónico

PM Peso molecular

RG Reservorios glandulares

$\mathrm{ROH} \quad$ Alcoholes grasos

TD Tierras de diatomeas

TG Triacilglicéridos

TLC Cromatografía en capa fina

VOC Compuestos orgánicos volátiles

W Ceras 


\section{Resumen}

La producción de granos es una de las principales actividades de nuestro país y por ende, es de suma importancia la preservación de su calidad durante el almacenamiento. La contaminación insectil es uno de los mayores problemas de los granos almacenados. Según estimaciones de la Organización de las Naciones Unidas para la Agricultura y la Alimentación (F.A.O), entre 10 y $30 \%$ de la producción agrícola mundial se pierde anualmente durante la última etapa de la comercialización por la acción de las plagas insectiles, cifra que se eleva a más del $50 \%$ en países subdesarrollados. Los insectos plaga pueden causar reducción del peso, calidad, valor comercial y poder germinativo de las semillas. En las etapas de almacenamiento, el método de control más utilizado es el químico, pero su aplicación debería ser rigurosamente controlada para evitar consecuencias negativas sobre el alimento del hombre y animales. Es allí donde la búsqueda de agentes de control natural, control biológico, nuevas técnicas de monitoreo, prácticas culturales adecuadas, mejoramiento genético y otras medidas terapéuticas de bajo impacto ambiental son necesarias.

Basado en estudios previos obtenidos en este laboratorio, en esta tesis se propuso avanzar en el conocimiento de la bioquímica de los hidrocarburos (HC) epicuticulares y las secreciones volátiles de origen lipídico de insectos tenebriónidos (Coleóptera); así como investigar métodos alternativos de bajo impacto para el control de estos insectos plaga de granos almacenados. Este conocimiento podrá contribuir al desarrollo de nuevas estrategias ecológicamente aceptables para el control de plagas.

En este trabajo se efectuó el análisis de los $\mathrm{HC}$ epicuticulares de adultos de Tribolium castaneum (Coleoptera: Tenebrionidae) empleando cromatografía gaseosa capilar (CGC) de alta resolución acoplada a espectrometría de masa (MS). Se detectaron 42 componentes lineales y ramificados. Comparada con las de otros órdenes de insectos, la composición de $\mathrm{HC}$ en $T$. castaneum es menos compleja; incluye estructuras saturadas y/o ramificadas con longitudes de 23 a 39 átomos de carbono, predominando $n-\mathrm{C} 27: 0$ y $n-\mathrm{C} 29: 0$.

Se identificaron y cuantificaron secreciones de defensa de Ulomoides dermestoides (Coleoptera: Tenebrionidae), extraídas del espacio de cabeza mediante la técnica de microextracción en fase sólida (HS-SPME) acoplada a CGC-MS. Los principales compuestos volátiles orgánicos (VOC) identificados fueron metil-1,4benzoquinona (MBQ), etil-1,4-benzoquinona (EBQ) y 1-pentadeceno ( $n$-C15:1); estos compuestos son semejantes a los reportados en Tribolium spp. El análisis cuantitativo de las secreciones liberadas por adultos vivos de ambas especies mostró que las 
benzoquinonas representan alrededor del $80 \%$ de las mismas en condiciones de estrés. Basado en el empleo de estas técnicas, se desarrolló una metodología para detectar VOC de insectos plaga en muestras de granos almacenados, que podría ser de utilidad como indicador de contaminación insectil. La técnica de HS-SPME acoplada a CGC permite detectar las secreciones volátiles de insectos vivos, en forma rápida, con alta sensibilidad y sin utilizar solventes. Este es el primer método químico que propone la detección de quinonas volátiles como un indicador de contaminación con tenebriónidos en granos almacenados.

En cuanto a su metabolismo, se demostró que la síntesis de n-C15:1 ocurriría vía de novo en la glándula a partir de $\left[1-{ }^{14} \mathrm{C}\right]$ acetato, o a partir de palmitato exógeno (incorporado a través del alimento, o sintetizado en integumento y/o cuerpo graso). Asimismo, se demostró síntesis de novo de $B Q$ en las glándulas. Estos ensayos se efectuaron empleando trazadores radiactivos y análisis por radiocromatografía en capa fina (radio-TLC).

En referencia a herramientas de bajo impacto para el control de insectos plagas de granos almacenados, se evaluó el potencial insecticida de tierras de diatomeas (TDs) de yacimientos locales, logrando seleccionar un yacimiento con capacidad insecticida similar a la de un producto comercial. Dentro de los coleópteros plaga de granos almacenados ensayados, T. castaneum fue la especie más tolerante. El empleo de esta metodología permitirá incorporar valor agregado a las TDs de yacimientos locales.

Finalmente, se evaluó el efecto del hongo entomopatógeno Beauveria bassiana en la supervivencia y ciclo de vida de $T$. castaneum y $U$. dermestoides. Ambos tenebriónidos mostraron una disminución significativa en la progenie, a pesar de los bajos índices de mortalidad observados. Es probable que la infección produzca un estado de aislamiento e inanición, alterando el desarrollo de las colonias de ambas especies.

Los resultados de este trabajo de tesis aportan al conocimiento de la bioquímica de los lípidos cuticulares y secreciones volátiles de tenebriónidos; asimismo proporcionan información de utilidad para el desarrollo de nuevas estrategias ecológicamente aceptables para el control de insectos plaga de granos almacenados 


\section{Summary}

Grain production is one of the main activities in our country and, therefore, its quality preservation during storage is extremely important. Insect contamination is one of the greatest problems of stored grains. According to estimations of the Food and Agriculture Organization of the United Nations (FAO), annually between 10 and $30 \%$ of the world agricultural production is lost during the last commercialization stage by the action of insect pests, an amount that increases over $50 \%$ in developing countries. Insect pests can cause reduction of weight, quality, commercial value and germinal power of seeds. In storage stages, the chemical control method is the most commonly used, but its application should be firmly controlled to avoid negative consequences on

the food of animals and human beings. Thus the search of natural and biological control tools, new monitoring techniques, adequate cultural practices, gene improvement and other therapeutic measurements of low environmental impact is needed.

Based on previous studies in our laboratory, in the present thesis the purpose was to advance in the knowledge of the biochemistry of epicuticular hydrocarbons $(\mathrm{HC})$ and lipid volatile secretions of tenebrionid insects (Coleoptera), as well as to investigate low impact alternative methods for the control of these insect pests of stored grains. This knowledge will contribute to the development of new ecologically friendly strategies for pest control.

In the present work, an analysis of the epicuticular $\mathrm{HC}$ of adult Tribolium castaneum (Coleoptera: Tenebrionidae) was performed employing capillary gas chromatography (CGC) of high resolution coupled to mass spectrometry (MS). More than forty linear and branched components were detected. Compared to other insect orders, $\mathrm{HC}$ composition in $T$. castaneum is relatively less complex; include saturated and/or branched structures with lengths from 23 to 39 carbon atoms, $n-\mathrm{C} 27: 0$ and $n$ C29:0 were predominant.

The defense secretions of Ulomoides dermestoides (Coleoptera: Tenebrionidae) were identified and quantitative after headspace extraction using solid phase microextraction (HS-SPME) coupled to CGC-MS. The main volatile organic compounds (VOC) identified were methyl-1,4-benzoquinone (MBQ), ethyl-1,4benzoquinone (EBQ) and 1-pentadecene (n-C15:1); these compounds are similar to those reported in Tribolium spp. The quantitative analysis of the secretions released by living adults of both species showed that benzoquinones account for approximately $80 \%$ of the VOC under stress conditions. By using these techniques, a methodology 
was developed to detect VOC of insect pests in of stored grain samples, which could be useful as indicator of insect contamination. The HS-SPME technique coupled to CGC allow detect volatile secretions of live insects, this is a fast, solvents less and high sensitivity technique. This is the first chemical method proposing for the detection of volatile quinones as an indicator of contamination with tenebrionids in stored grain.

Regarding its metabolism, it was shown that the biosynthesis of $n-C 15: 1$ would occur via de novo from $\left[1-{ }^{14} \mathrm{C}\right]$ acetate in the gland, or from exogenous palmitate (incorporated through the food or synthesized in integument and/or fat body). Also, de novo synthesis of $\mathrm{BQ}$ was demonstrated in the glands. These assays were performed using radioactive markers and analysis by radio thin layer chromatography (radio-TLC).

In reference to low-impact tools for controlling insect pests of stored grain, the insecticidal potential of diatomaceous earth (DE) of local deposits was evaluated, allowing to select a deposit with insecticide efficacy similar to that of a commercial product. Among tested the coleopteran pests of stored grains $T$. castaneum was the most tolerant. Using this methodology would allow incorporating an added value to DE obtained from of local deposits

Finally, it was evaluated the effect of the entomopathogenous fungus Beauveria bassiana in the survival and life cycle of $T$. castaneum and $U$. dermestoides. Both tenebrionids showed a significant decrease in its progeny, despite low indexes of mortality observed. It is likely that the infection may produce an isolation and starvation condition, thus altering the development of the colonies of both species.

The results of the present thesis work contribute to the knowledge of cuticular lipids and volatile secretions of tenebrionids, as well as provide useful information for the development of new ecologically friendly strategies for the control of insect pests of stored grains 


\section{I.1. Generalidades de insectos plaga de granos almacenados}

El cultivo y explotación de cereales constituye uno de los principales soportes de la economía nacional, cuyo éxito está relacionado estrechamente con la preservación de la calidad del producto durante el transporte y almacenamiento (Deschamps y col., 2004; Cassini y col., 2005). El daño causado por los insectos, es uno de los mayores problemas de los granos almacenados. Existen unas 1.000 especies de insectos que infestan los productos almacenados, siendo las de mayor importancia económica las que se encuentran dentro de los Ordenes Coleoptera y Lepidoptera (Viñuela y col., 1993; Rees, 2004; Dal Bello y Padín, 2006; Nerio y col., 2009). Los insectos plaga se clasifican en plagas de infestación primaria o secundaria de acuerdo con su posibilidad de atacar grano sano o partido, respectivamente (Rees, 2004). Las plagas de infestación primaria son aquellas capaces de desarrollarse en granos sanos; producen el llamado picado de los granos y pueden colocar sus huevos, según la especie, dentro o fuera de los mismos. Es decir que existe la posibilidad que una partida de mercadería que en la recepción sea considerada libre de insectos, en realidad esté infestada (infestación oculta). En este grupo se incluyen al gorgojo del trigo o de los granos (Sitophilus granarius, Coleoptera: Curculionidae), al gorgojo del arroz (S. oryzae) (Fig.I.1.A), al gorgojo del maíz (S. zeamais), al taladrillo de los cereales (Rhyzopertha dominica, Coleoptera: Bostrichidae) (Fig.I.1.B), la palomita de los cereales (Sitotroga cerealella, Lepidoptera: Gelechiidae), y al gorgojo de la judías o porotos (Acanthoscelides obtectus, Coleoptera: Bruchidae) (Fig.I.1.C), entre las más importantes (Fields, 1992; Padín y col., 2002). Las larvas de este tipo de plaga se alimentan del interior del grano y abren las puertas para el ataque de las plagas de infestación secundaria. Estas últimas necesitan para su desarrollo que el grano almacenado esté dañado, ya sea por un insecto de infestación primaria o debido a condiciones de cosecha, manipuleo o acondicionamiento. A este grupo pertenecen la carcoma dentada de los granos (Oryzaephilus surinamensis, Coleoptera: Cucujidae) (Fig.l.1.D), el gorgojo castaño de la harina (Tribolium castaneum, Coleoptera: Tenebrionidae), el gorgojo falso de la harina ( $T$. confusum) (Fig.l.1.E), la carcoma achatada (Cryptolestes pusillus, Coleoptera: Cucujidae) (Fig.I.1.F), y la polilla de la harina (Ephestia kuehniella, Lepidoptera: Pyralidae), entre otras. Los insectos plaga de los granos almacenados ocasionan daños directos por el consumo y contaminación del producto, e indirectos, tales como el calentamiento del grano, desarrollo de hongos y micotoxinas (Lord, 2005; Dal Bello y col., 2011). 


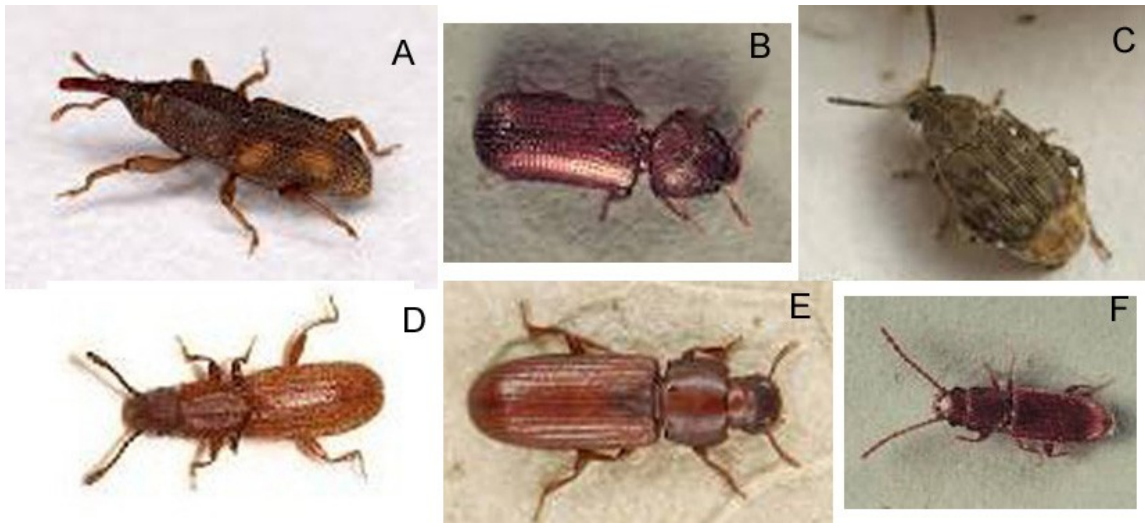

Fig.I.1. Insectos plaga de granos almacenados. A: Sitophilus oryzae, B: Rhyzopertha dominica, C: Acanthoscelides obtectus, D: Oryzaephilus surinamensis, E: Tribolium confusum, F: Cryptolestes pusillus.

\section{I.2. Coleópteros}

Los coleópteros (Coleoptera), (del griego, koleos: "caja o estuche", pteron: "ala") son un orden de insectos con unas 375.000 especies. Algunos nombres vulgares con los que se los conocen son: escarabajos, gorgojos, barrenillos, etc. Los coleópteros presentan una gran diversidad morfológica (Ruppert y Barnes, 1996). Son insectos mayoritariamente terrestres y pocos (relativamente) han conquistado el medio acuático (básicamente agua dulce) (Ruppert y Barnes, 1996). El primer par de alas de los escarabajos están transformadas en duros escudos, llamados élitros. Éstos forman una armadura que protege la parte posterior del tórax, incluido el segundo par de alas, y el abdomen. Las alas anteriores no son usadas en el vuelo, pero deben (en la mayoría de las especies) ser levantadas para poder usar las alas traseras. La mayoría de los escarabajos pueden volar, pero pocos alcanzan la destreza de otros grupos, y muchas especies vuelan sólo si es imprescindible (Ruppert y Barnes, 1996).

Los coleópteros son insectos holometábolos o endopterigotos, ya que sufren una metamorfosis completa con estados de huevo, larva, pupa y adulto (Ruppert y Barnes, 1996).

La mayoría de los coleópteros son fitófagos, y muchas especies pueden ser plagas de los cultivos, siendo las larvas las que causan la mayor parte de los daños agrícolas y forestales. Las especies de las familias Anobiidae, Bostrichidae, Bruchidae, Cucujidae, Curculionidae, Dermestidae, Lathridiidae, Tenebrionidae y Trogositidae, son las más comunes atacando el arroz, maíz, trigo, poroto, harina, etc (Rees, 2004). 


\section{I.2.a. Tribolium castaneum}

\section{I.2.a.1. Clasificación taxonómica}

Phylum: Arthropoda

Clase: Insecta

Orden: Coleoptera

Familia: Tenebrionidae

Género: Tribolium

Especie: Tribolium castaneum

\section{I.2.a.2. Características generales}

Los adultos y las larvas de Tribolium castaneum (Herbst, 1797) se alimentan de harina, granos partidos (plaga secundaria), y otros productos almacenados, ocasionando graves daños económicos (Fedina y Lewis, 2007). Esta especie, a pesar de que prefiere granos partidos o dañados, es capaz de multiplicarse en granos de trigo enteros cuando la humedad es elevada, alimentándose primero del germen y después del endospermo. T. castaneum produce grandes cantidades de polvo que impide la respiración de semillas, esto contribuye al sobrecalentamiento, excesiva humedad y el crecimiento de hongos y bacterias. A pesar de los enormes esfuerzos dedicados a nivel internacional, no hay aún disponibles moléculas ecológicamente aceptables de eficacia demostrada para su control. En Argentina, los insectos presentes en granos almacenados en postcosecha producen pérdidas que se estiman entre el 7 y el 10\% de la producción total (Viale, 1995, Deschamps y col., 2004). La legislación vigente establece el rechazo de toda mercadería con hasta un solo insecto y/o ácaro vivo, en cualquier etapa de la comercialización (Resolución №1975/94, Secretaria de Agricultura, Ganadería, Pesca y Alimentos, 2007).

Actualmente, luego de la secuenciación del genoma de $T$. castaneum (Tribolium castaneum Genome Project, 2012) existen muchas bases de datos genéticas y genómicas disponibles para su estudio (http://beetlebase.org). La secuenciación fue realizada por un equipo de más de 200 científicos de 14 países (Tribolium Genome Sequencing Consortium, Richard y col., 2008). El análisis del genoma $T$. castaneum proporciona una base para la identificación, organización y función de genes y familias de genes también en otros tenebriónidos. La secuencia completa del genoma de $T$. castaneum también es un recurso importante para estudios de ecología química tanto en Tribolium como en otros insectos. El análisis del genoma permitirá comprender los mecanismos de resistencia a insecticidas (Beeman 
y Nanis, 1986; Beeman y Stuart, 1990; Beeman y col., 1992, Beeman y col., 2010; Merzendorfer y col., 2012), y ayudará al mejoramiento de métodos de control químico y biológico.

\section{I.2.a.3. Ciclo de vida}

T. castaneum posee metamorfosis completa: huevo; larva, pupa y adulto. El adulto (Fig.I.2.a.3.a) mide de 3 a $4 \mathrm{~mm}$ de ancho y posee el cuerpo ligeramente plano, de color rojizo a castaño.

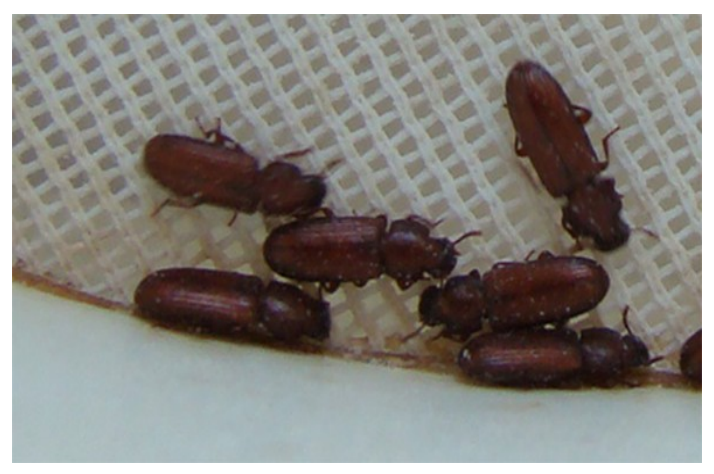

Fig.I.2.a.3.a. Adultos de T. castaneum

La hembra pone de 300 a 500 huevos en el exterior de los granos (Fig. I.2.a.3.b). Los huevos, luego de 5 a 12 días, dan origen a pequeñas larvas delgadas, cilíndricas, móviles, de color blanco, que llegan a medir $5 \mathrm{~mm}$, presentando 5 estadios larvales (Fig.I.2.a.3.c).

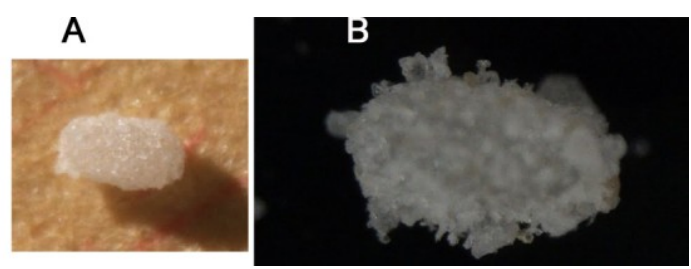

Fig.l.2.a.3.b. Huevos de T.castaneum.

En el último estadio larval, antes de iniciarse la fase de pupa, la larva detiene su crecimiento, disminuye su actividad y toma una posición a manera de la letra c, quedando como tal entre 2 a 4 días. Esta puede ser denominada la fase de pre-pupa. 


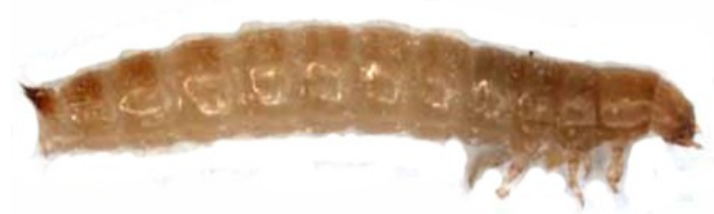

Fig.I.2.a.3.c. Larva de T.castaneum

Luego se inicia el estado de pupa libre (Fig.l.2.a.3.d), la cual dura entre 4 a 5 días.

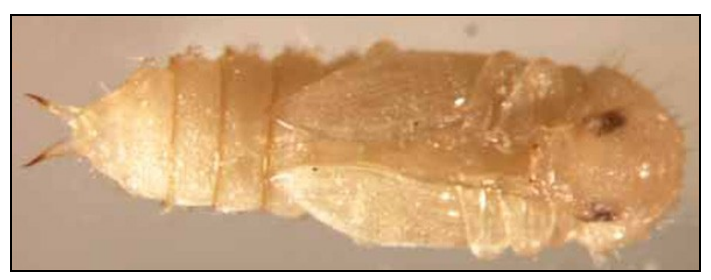

Fig.I.2.a.3.d. Pupa de T.castaneum.

En el estado pupal se facilita la diferenciación de los sexos, debido a que la hembra presenta papilas genitales (urogonfos) en su parte caudal. Estas papilas son dos proyecciones cónicas características (Fig.I.2.a.3.e.A), en cambio el futuro macho las exhibe en forma de una placa cóncava de apariencia delicada y brillante (Fig.I.2.a.3.e.B).
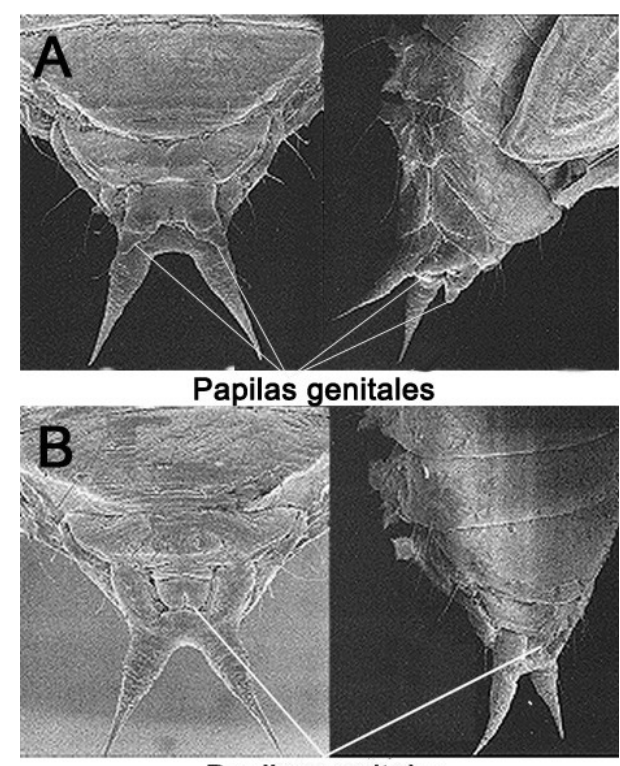

Papilas genitales

Fig.l.2.a.3.e.A. Extremo caudal de una pupa hembra de T. castaneum. B. Extremo caudal de una pupa macho de T. castaneum. Modificado a partir de Agricultural Reserach Service, USA (www.ars.usda.gov). 
En los adultos también se puede observar dimorfismo sexual, debido a que los machos presentan un pequeño parche de cerdas cortas en el primer patas (Fig.l.2.a.3.f).

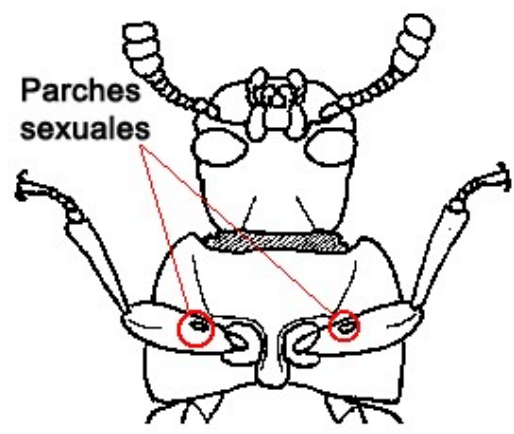

Fig.l.2.a.3.f. Parches sexuales en un adulto macho de $T$. castaneum. Modificado a partir de Agricultural Reserach Service, USA (www.ars.usda.gov)

El desarrollo, desde el huevo hasta el adulto, dura 30 a 35 días en condiciones favorables (Tabla I.2.a.3). El tiempo de vida reproductiva en las hembras es de 3-4 meses y de los machos de 4-6 meses.

Tabla I.2.a.3. Ciclo de vida de T. castaneum, en diferentes rangos de temperatura.

\begin{tabular}{cccc}
\hline & \multicolumn{3}{c}{ Temperatura } \\
\cline { 2 - 4 } Estados & $25^{\circ} \mathrm{C}$ & $30{ }^{\circ} \mathrm{C}$ & $35{ }^{\circ} \mathrm{C}$ \\
\hline Huevo & 7 días & 3 días & 2 días \\
Larva & 31 días & 20 días & 15 días \\
Pupa & 10 días & 4 días & 3 días \\
Maduración reproductiva & 6 días & 5 días & 4 días \\
\hline Fuente Agricultural Reserach Service, USA (www.ars.usda.gov)
\end{tabular}

\section{I.2.b. Ulomoides dermestoides}

\section{I.2.b.1. Clasificación taxonómica}

Phylum: Arthropoda

Clase: Insecta

Orden: Coleoptera

Familia: Tenebrionidae

Género: Ulomoides

Especie: Ulomoides dermestoides

\section{I.2.b.2. Características generales}


U. dermestoides (Fairmaire, 1893) posee metamorfosis completa: huevo, larva, pupa y adulto. Fue introducida en Brasil por los inmigrantes que utilizaban los escarabajos para el tratamiento del asma, la artritis, y otras enfermedades (Buzzi y Miyazaki, 1999; Costa-Neto, 2002). Actualmente es plaga secundaria del maní en Costa Rica. En la Argentina fue introducida para el tratamiento de diferentes enfermedades; se ha registrado atacando pan de trigo y silos de granos, lo que la convierte en una plaga de los productos almacenados (Flores y col., 2002).

\section{I.2.b.3. Ciclo de vida}

Las hembras ponen los huevos sobre los residuos del alimento, las posturas se encuentran en grupos de 3 a 9 huevos, oviponiendo aproximadamente 210 huevos durante su ciclo. El huevo (Fig.I.2.b.3.a) recién depositado está recubierto de una fina película mucilaginosa, en la cual se adhieren residuos de harina y/o excrementos. Luego de 16 a 18 días emergen las larvas (Fig.l.2.b.3.b) de gran movilidad, presentando un color blanco. El tamaño varía de acuerdo con los estadios, siendo el mínimo de $1 \mathrm{~mm}$ y el máximo de $11 \mathrm{~mm}$. El número de estadios que presenta $U$. dermestoides, es variable y depende de factores como temperatura, humedad, capacidad y tipo de alimento (Marinoni y Ribeiro-Costa, 2001).

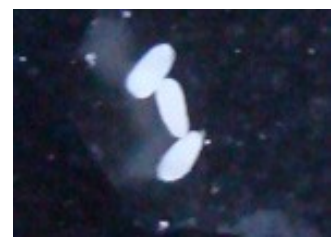

Fig.l.2.b.3.a. Huevos de U. dermestoides

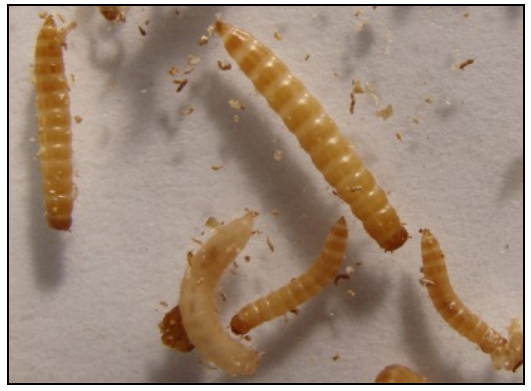

Fig.I.2.b.3.b. Larvas de U. dermestoides

Luego de 40 días la larva en su último estadio detiene su crecimiento y se transforma en pupa. La pupa (Fig.I.2.b.3.c) es de tipo libre y de color banco y luego se transforma en color café. Al igual que T. castaneum, en este estado se puede lograr la diferenciación de sexos, ya que la hembra presenta en su parte caudal, dos 
proyecciones laterales, con terminales esclerotizados y en el último segmento o extremo posterior del abdomen presenta un par de urogonfos con sus terminales endurecidas.

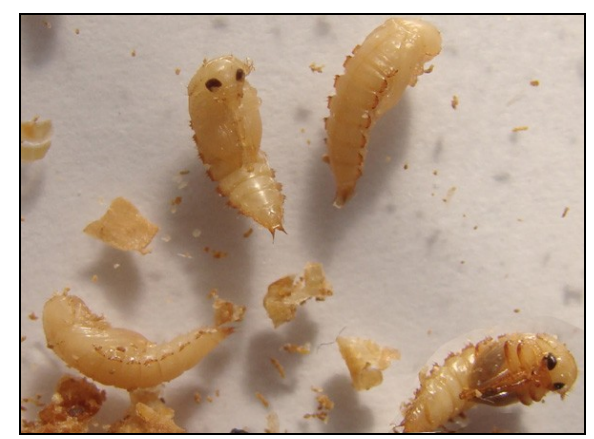

Fig.l.2.b.3.c. Pupas de U. dermestoides

Los adultos pueden medir entre $5,0 \mathrm{~mm}$ y $1,0 \mathrm{~mm}$ (Fig.l.2.b.3.d). Las antenas poseen once artejos bien diferenciados y miden aproximadamente lo mismo que el ancho del cuerpo. La forma del cuerpo es oblonga, aplanada, la cabeza es tipo prognata, con ojos compuestos prominentes, fácilmente diferenciables en cualquier posición de los adultos. Poseen fuertes mandíbulas. Los élitros presentan surcos 0 estrías longitudinales, formados por las punturas que son correspondientes a las venas longitudinales. Son activos, móviles, de gran capacidad de dispersión.

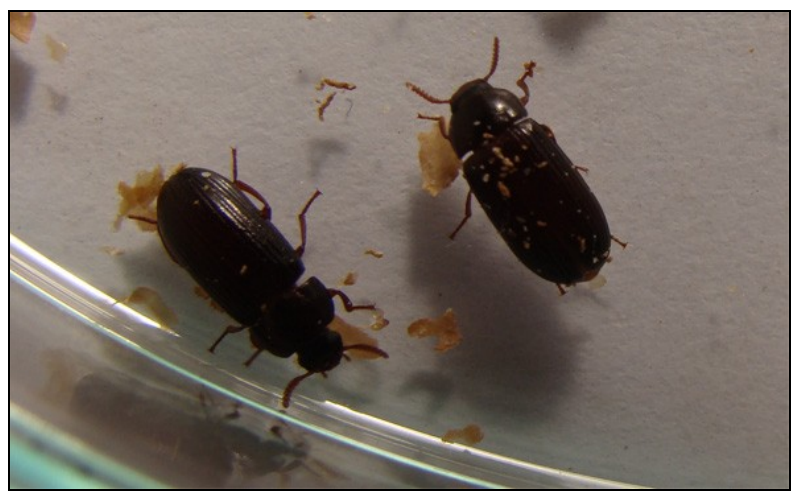

Fig.l.2.b.3.d. Adultos de U. dermestoides

\section{I.3. Cutícula de los insectos}


Parte de la fisiología de los insectos depende de la naturaleza de su cutícula, la misma está formada por varias capas, que de afuera hacia adentro son: la epicutícula, la exocutícula, la endocutícula (Fig.l.3.a). La epicutícula usualmente tiene un espesor de hasta $3 \mu \mathrm{m}$, es una estructura muy compleja y su naturaleza varía entre diferentes insectos (Wigglesworth, 1934). Si bien los componentes mayoritarios de la cutícula son proteínas y quitina (constituida por polímeros de N-Acetilglucosamina) (Neville, 1975), la epicutícula está compuesta de una mezcla compleja de lípidos no polares. Predominan hidrocarburos $(\mathrm{HC})$ lineales y ramificados de muy largas cadenas (entre 20 y 40 átomos de carbono), alcoholes grasos, ceras, glicéridos y ácidos grasos libres de variadas estructuras (Blomquist y Jackson, 1979; Juárez y col., 1984; Blomquist y Dillwith, 1985; Juárez y Brenner, 1985; Blomquist y col, 1987; Lockey, 1988; Nelson y Blomquist, 1995; Juárez y Calderón, 2007).

En la figura I.3.a se muestra un corte transversal del integumento de insectos en la que se observa la disposición de sus componentes principales (cemento, ceras, epicutícula, exocutícula, endocutícula, epidermis, glándulas dermales y membrana basal).

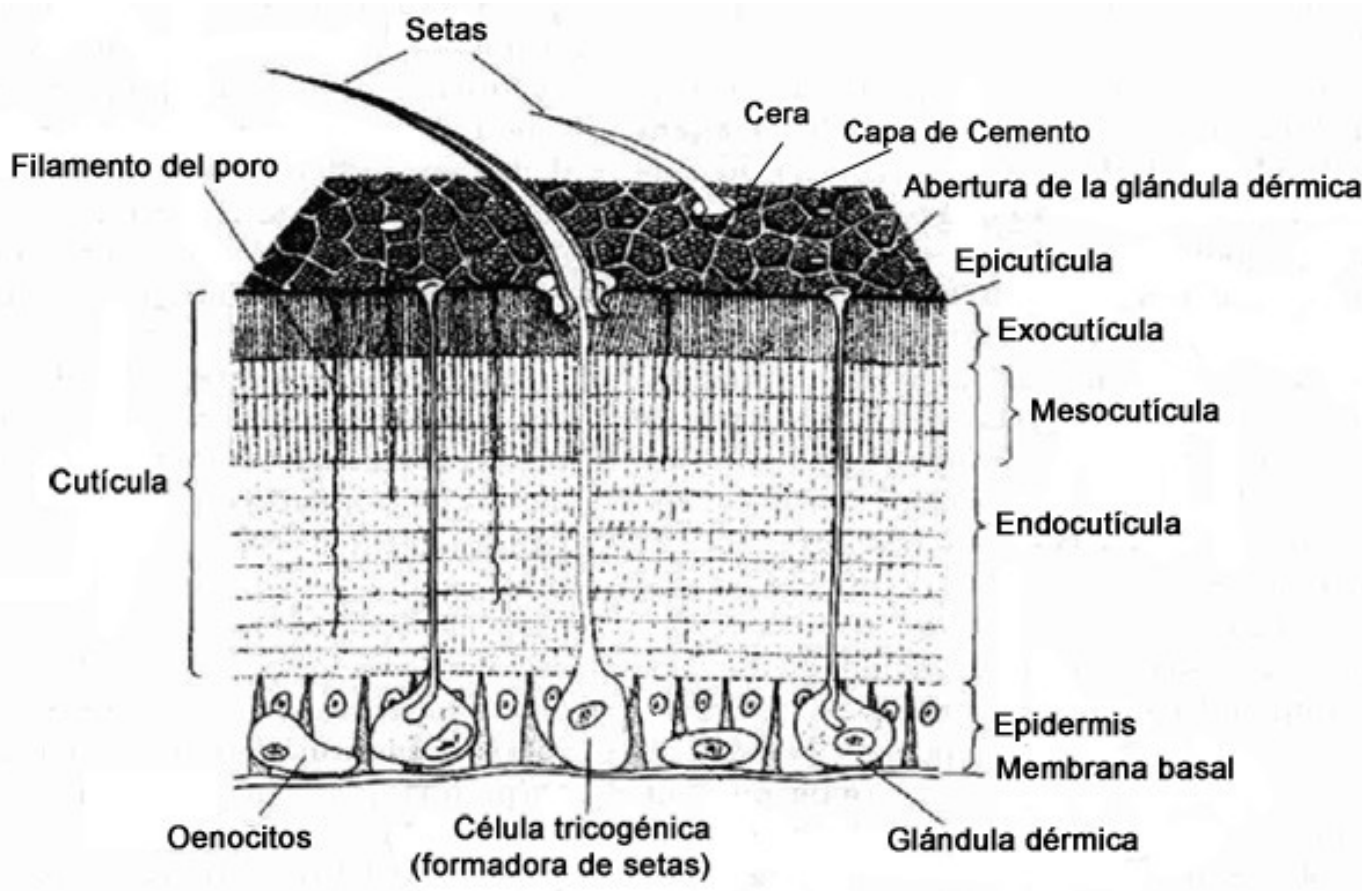

Fig.l.3.a. Esquema de un corte transversal del integumento de insectos. Modificado a partir de Hackman, R.H, 1971. Chemical Zoology Vol. VI, Academic Press, NY

Para el desarrollo/mejoramiento de nuevas técnicas de monitoreo y control es necesario conocer aspectos biológicos y bioquímicos del insecto plaga. En insectos, la superficie más externa de la cutícula constituye la primera barrera de protección contra 
agentes externos (químicos, físicos o biológicos) (Wigglesworth, 1942; Juárez, 1994a, 1995; Napolitano y Juárez, 1997, Crespo y col., 2000, Crespo y col., 2002, Crespo, 2006, Pedrini y col, 2007, Pedrini y col., 2009). La epicutícula está formada por una delgada capa de lípidos (hidrocarburos, ácidos grasos, ceras, alcoholes, etc.) una de cuyas principales funciones es restringir la pérdida de agua, evitando la desecación (Wigglesworth, 1945, 1985; Hadley, 1984), controlar la absorción de sustancias químicas, actuar como barrera para la actividad de microorganismos y actuar en procesos de comunicación química (Blomquist y col., 1987; Juárez, 1994b; Blomquist y Howard, 2003; Blomquist y Bagnéres, 2010).

\section{I.3.a. Hidrocarburos epicuticulares de insecto}

Los hidrocarburos $(\mathrm{HC})$, principalmente $n$-alcanos, y alquenos de cadenas lineales o metil-ramificadas, son los lípidos epicuticulares más estudiados. Las longitudes de cadena usuales varían de 20 a 50 átomos de carbono. Sus funciones, demostradas experimentalmente o inferidas, son muchas. Entre ellas se destacan ser los principales responsables del rol de barrera para impedir la pérdida de agua, ya que la gran relación superficie/volumen de los insectos resulta en un alto potencial para la desecación; en este sentido, las características hidrofóbicas de los HC contribuyen significativamente al balance hídrico del insecto (Hadley, 1984; Gibbs, 1995). Diversos experimentos han demostrado que la abrasión de la cutícula con sustancias capaces de dañar la capa de lípidos, o la remoción de la misma tienen efectos drásticos en la supervivencia de los insectos debido a la pérdida de agua (Beamont 1945, Wigglesworth 1945, Locke 1965, Sponsler y Appel 1990, Juárez 1994a,b). Los lípidos cuticulares contribuirían además a modular la tasa de ingreso de insecticidas (Juárez 1994a; Juárez, 1995; Juárez y col., 2010). Con respecto al ingreso de microorganismos, se ha demostrado en Triatoma infestans (Hemiptera: Reduviidae) y en algunos insectos plaga de granos almacenados, que los lípidos cuticulares y en particular los $\mathrm{HC}$, pueden actuar como fuente de carbono para el desarrollo de las primeras etapas de crecimiento y penetración de hongos entomopatógenos como Beauveria bassiana y Metarhizium anisopliae (Napolitano y Juárez, 1997; Crespo y col., 2000; Crespo y col., 2002; Crespo, 2006; Pedrini, 2006). También los lípidos cuticulares actuarían en procesos de comunicación química. En particular, los HC sirven como señal de reconocimiento entre individuos de la misma especie o enemigos, así como suelen ser clave para el apareamiento; en insectos solitarios esta capacidad es vital para la reproducción y supervivencia (Hölldobler y Michener, 1980; Howard y Liang, 1993). En muchas especies y órdenes, los HC son especie- 
específicos, y a menudo sexo-específicos, es así que los insectos pueden reconocerse por simple contacto de sus cutículas, como se ha demostrado para el HC monometil 7C23:1 en la mosca de la fruta (Drosophila melanogaster, Diptera: Drosophilidae) o el monometil 9-C23:1 en la mosca doméstica (Musca domestica, Diptera: Muscidae) (Nelson y col., 1981; Caputo y col., 2005), participando diversos componentes no solo como feromonas sexuales sino como afrodisíacos, antiafrodisíacos, etc (Carlson y col., 1971; Bartlet y col., 1986; Jallon y David, 1987; Cobb y Jallon, 1990). HC de estructuras similares (C23:1 con insaturaciones en diferentes posiciones) juegan complejos roles en el apareamiento de escarabajos (Coleoptera) (Peschke y Metzler, 1987; Tillman y col., 1999; Blomquist y Howard, 2003).

Por su alta especificidad de especie, el patrón de $\mathrm{HC}$ se ha utilizado con excelentes resultados como marcador taxonómico (quimiotaxonomía), contribuyendo en la diferenciación de géneros, complejos, especies, subespecies y aún de diferentes poblaciones en dípteros y hemípteros (Carlson y Service, 1979; Juárez y Brenner, 1986; Carlson y col., 1993; Etges y Jackson, 2001; Juárez y col., 2002; Caputo y col., 2007; Calderón y col., 2011).

Los $n$-alcanos son comunes a la mayoría de los insectos; sus proporciones en la epicutícula varían desde trazas en la mosca tsetse (Glossina sp. Diptera: Glossinidae) (Blomquist y col., 1985, Jackson y Bartelt 1986) hasta casi el $100 \%$ en ciertos coleópteros (Lockey, 1985; Nelson y col., 1984).

Los $n$-alquenos se hallan en muchos insectos. Dentro de este tipo de compuestos son más importantes los mono-insaturados, la mayoría de éstos se detectan mediante CGC como picos multicomponentes que contienen entre 3 y 6 isómeros, en tanto que los di- y tri-insaturados son componentes menores de la cutícula. En el caso de los dienos hay mezclas de isómeros de posición y en pocos insectos se han reportado compuestos conjugados (Howard y col., 1978; Warthen y Uebel, 1980; Nelson y col., 1984; Villaverde y col., 2009).

Los HC metil ramificados son característicos de insectos, siendo los mono y dimetil ramificados los más abundantes; mientras que los tri- y tetrametil derivados se encuentran en cantidades importantes en la mosca tsetse y en algunos triatominos (Nelson y Carlson, 1986; Nelson y col., 1988; Juárez y Blomquist, 1993; Juárez y col., 2001; Juárez y Calderón, 2007; Calderón y col., 2011 a, b). También se han detectado HC penta-metilramificados (Blomquist y Bagnéres, 2010).

Tabla I.3.a. Composición de hidrocarburos epicuticulares. 
Hidrocarburos epicuticulares

\begin{tabular}{|c|c|c|c|c|}
\hline Insecto & $n$-alcanos & metil-alcanos & $n$-alquenos & Referencia \\
\hline \multicolumn{5}{|l|}{ Coleoptera } \\
\hline Leptinotarsa decemlineata & ++++ & + & + & Nelson y col., 2003 \\
\hline Rhyzopertha dominica & ++++ & ++ & - & Howard y Liang, 1993 \\
\hline Sitophylus oryzae & ++ & + & ++++ & Baker y col., 1984 \\
\hline Tenebrio monitor & +++ & ++ & ++ & Lockey, 1978 \\
\hline Tribolium castaneum & + & + & ++++ & Baker y col., 1978 \\
\hline Ulomoides dermestoides & + & + & ++++ & Villaverde y col., 2009 \\
\hline \multicolumn{5}{|l|}{ Dictyoptera } \\
\hline Blattella germanica & ++ & +++ & - & Augustynowicz y col., 1987 \\
\hline \multicolumn{5}{|l|}{ Diptera } \\
\hline Aedes aegypti & +++ & ++ & + & Horne y Priestman, 2002 \\
\hline Anopheles gambiae & +++ & ++ & + & Caputo y col., 2005 \\
\hline Glossina morsitans & - & ++++ & + & Nelson y Carlson, 1986 \\
\hline Musca domestica & +++ & +++ & + & Nelson y col., 1981 \\
\hline \multicolumn{5}{|l|}{ Hemiptera } \\
\hline Nezara viridula & ++++ & - & - & Sosa-Gómez y col., 1997 \\
\hline Rhodnius prolixus & +++ & +++ & - & $\begin{array}{c}\text { Juárez y col., } 2001 \\
\text { Juárez y Blomquist, } 1993\end{array}$ \\
\hline Triatoma infestans & +++ & +++ & - & $\begin{array}{l}\text { Calderón y col.,2011b } \\
\text { Calderón y col., 2005, }\end{array}$ \\
\hline T. dimidiata & +++ & +++ & - & $2011 \mathrm{a}$ \\
\hline \multicolumn{5}{|l|}{ Homoptera } \\
\hline Brevicoryne brassicae & +++ & ++ & - & Szafranek y col., 2001 \\
\hline Hyalopterus pruna & +++ & ++ & - & Szafranek y col., 2001 \\
\hline Sitobion avenae & +++ & + & - & Hebanowska y col., 1989 \\
\hline \multicolumn{5}{|l|}{ Hymenoptera } \\
\hline \multicolumn{5}{|l|}{ Isoptera } \\
\hline Coptotermes formosanus & ++++ & + & - & Haverty y col., 1996 \\
\hline \multicolumn{5}{|l|}{ Lepidoptera } \\
\hline Manduca sexta & ++++ & ++ & - & Nelson y col., 1981 \\
\hline Lymantria dispar & ++++ & ++ & - & Jurenka y Subchev, 2000 \\
\hline Diatrea saccharalis & + & + & ++++ & Girotti y col., 2012 \\
\hline \multicolumn{5}{|l|}{ Orthoptera } \\
\hline Locusta migratoria & +++ & ++ & - & Lockey, 1976 \\
\hline Melanoplus sanguinipes & ++++ & ++ & - & Soliday y col., 1974 \\
\hline Schistocerca gregaria & +++ & ++ & - & Lockey, 1976 \\
\hline
\end{tabular}

En la tabla I.3.a se detallan algunos órdenes de insectos de los cuales se conoce la composición de los HC epicuticulares. 
La presencia, ausencia o abundancia relativa de $\mathrm{HC}$ específicos se relaciona con la presencia, ausencia o la actividad de las enzimas involucradas en su biosíntesis (Page y col., 1997; Dallerac y col., 2000; Takahashi y col., 2001; Juárez y Calderón, 2007). Estudios en varios órdenes de insectos aportan fuertes evidencias de que la mezcla de HC es específica de la especie (Carlson y col., 1971; Juárez y Brenner, 1985; Page y col., 1997; Etges y Jackson, 2001; Mullen y col., 2007; Juárez y Calderón, 2007; Dapporto y col.; 2009).

\section{I.3.b. Biosíntesis de hidrocarburos y lípidos cuticulares}

En insectos, plantas y mamíferos la biosíntesis de $\mathrm{HC}$ se inicia a partir de la síntesis de ácidos grasos y su posterior elongación. Kolattukudy y col (1976) demostraron que el ácido palmítico (C16:0) producido por una ácido graso sintetasa citosólica, es elongado por acil-CoA elongasas asociadas a la membrana del retículo endoplasmatico, generando un acil-CoA de muy larga cadena, el cual es decarbonilado para obtener un HC con un átomo de carbono menos (Qui y col., 2012) (Fig.I.3.b.1).

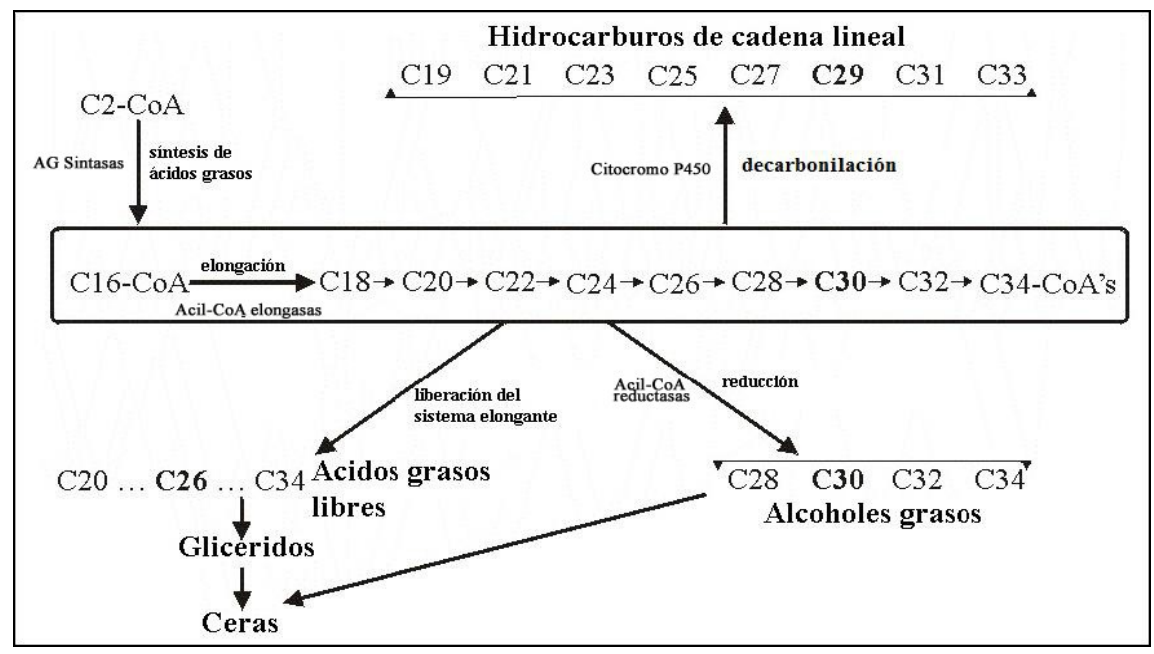

Figura I.3.b.1. Esquema de formación de hidrocarburos de cadenas lineales en insecto.

\section{Modificado a partir de Juárez y Calderón, 2007.}

En insectos, la biosíntesis de los ácidos grasos de muy larga cadena (AGMLC) en el integumento, fue descripta por primera vez en $T$. infestans y ocurre también a través de la acción de una ácido graso sintetasa acoplada a acil-CoA elongasas relacionadas a la membrana del retículo endoplasmatico (Juárez y Brenner, 1989; Juárez, 1995; Juárez y col., 1996). Estos estudios demostraron que las tres especies lipídicas principales de la cutícula de este insecto, $\mathrm{HC}$, alcoholes grasos y ácidos grasos libres o esterificados, están relacionadas biosintéticamente; y que los ácidos 
grasos de $26,28,30,32$ y 34 carbonos en la cadena lineal son los sustratos para la síntesis de los principales HC (n-C25, n-C27, n-C29, n-C31 y n-C33). En Blattella germanica (Blattodea: Blattellidae) y $T$. infestans se demostró la síntesis de ácidos grasos saturados lineales y metil ramificados de 16 a 18C, por acción de dos ácido graso sintetasas de localización citosólica y microsomal, respectivamente (Juárez y col., 1992, Juárez y col., 1996). Estas se acoplan a un sistema elongante que produce AGMLC de hasta 34C, que se incorporan en las fracciones de ácidos grasos libres y acilglicéridos de la epicutícula (Juárez y Brenner, 1989, Juárez y col., 1992, Juárez y col., 1996; Juárez y Calderón, 2007). Los productos de elongación comprenderían ácidos grasos lineales y metil ramificados de 20C a más de $30 \mathrm{C}$, los precursores de los HC mayoritarios en este insecto. El mecanismo de la etapa final de formación de los $\mathrm{HC}$ cuticulares de insectos fue un tema de controversia por más de 20 años. El grupo del Dr. Blomquist ha logrado demostrar que una enzima citocromo P450 (familia CYP4G), convertiría las acil-coAs de muy largas cadenas en HC, mediante una reacción de decarbonilación oxidativa, previa conversión en aldehído por acción de una acil-CoA reductasa (Qiu y col., 2012).

Los metilalcanos se forman por sustitución de metilmalonil-CoA en lugar de malonil-CoA en posiciones específicas durante la elongación de la cadena (Fig.l.3.b.2). Según los estudios de Dillwith y col, (1982) y Chase y col, (1990), la metilmalonil-CoA se incorpora en los pasos iniciales de la elongación de la cadena en insectos por acción de una ácido graso sintasa (FAS) (de Renobales y col, 1989) de localización microsomal (Juárez y col., 1992, Juárez y col., 1996).

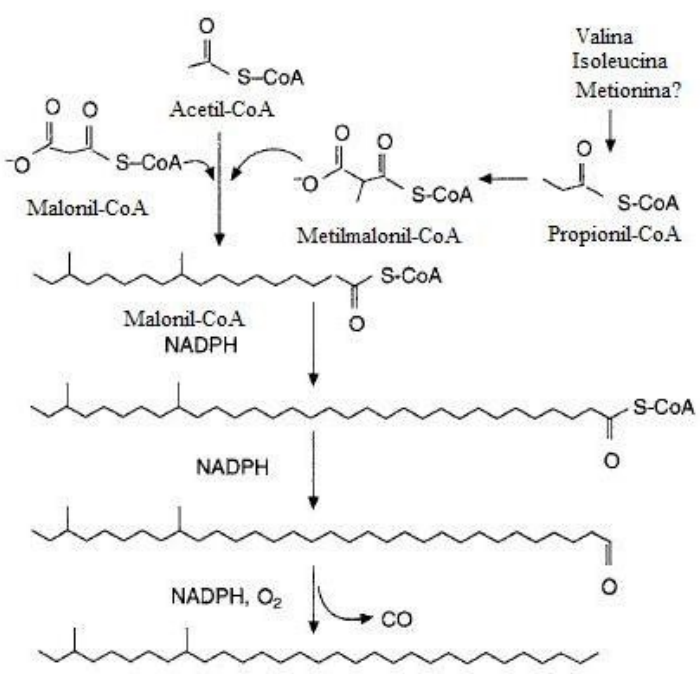

Figura I.3.b.2. Ejemplo de etapas en la biosíntesis de HC metil ramificados. Modificado a partir de Juárez y Calderón, 2007. 
Dada la importancia y enorme complejidad del rol de los $\mathrm{HC}$ en insectos, y su especificidad, la disponibilidad del genoma de numerosos insectos (www.beetlebase.org, www.beebase.org, www.butterflies.org, www.vectorbase.org, etc) facilitará la identificación de genes conservados, así como avanzar en la comprensión de los mecanismos asociados con el metabolismo, y el transporte de lípidos y feromonas, entre otros aspectos. Además de los aspectos básicos, este conocimiento es relevante en referencia al control de plagas, dado podría permitir el diseño de inhibidores específicos y ecológicamente aceptables de diversas plagas.

\section{I.4. Comunicación química entre especies}

La comunicación química en insectos está asociada a la reproducción, protección y búsqueda de alimentos. El término "feromona" se aplica a aquellos compuestos químicos que permiten una comunicación entre ejemplares de una misma especie (Karlson y Butenandt, 1959). Estas sustancias pueden ser volátiles, (de bajo peso molecular) y, en su gran mayoría, derivadas de ácidos grasos y terpenos. Existen además feromonas no volátiles (de alto peso molecular) que requieren contacto directo para ser percibidas.

Según su modo de acción, las feromonas se dividen en dos grandes grupos: "primer": producen cambios fisiológicos, los que a su vez inducirán una respuesta en la conducta. Su acción está bajo la influencia del sistema endocrino.

"releaser": son las de respuesta inmediata y actúan a través del sistema nervioso. En este grupo se encuentran las más conocidas, como las de atracción sexual, de alarma, de reclutamiento y de agregación.

Las feromonas sexuales son los semioquímicos más estudiados, especialmente por su utilidad en programas de control integrado de plagas (Phillips, 1997). En insectos, los sistemas de comunicación por feromonas sexuales son altamente sensibles y específicos. La especificidad viene dada por la singularidad de la estructura química (posición y/o geometría del doble enlace, quiralidad, etc.) y por una mezcla determinada de componentes de la feromona (multicomponentes). Los compuestos más usuales son ácidos grasos libres y esterificados, cetonas, alcoholes e hidrocarburos. Para analizar su estructura, isomería geométrica y configuración, en el pasado se necesitaba gran cantidad de insectos; p.ej. para aislar e identificar la feromona sexual del gusano de seda (10E, 12Z)- hexadecadien-1-ol se utilizaron 500.000 hembras (Butenandt y col., 1959). En la actualidad, debido a los avances en las técnicas y a la sofisticación de los equipos de nueva generación, el número de insectos utilizados es notablemente menor, p.ej, para aislar la feromona sexual de 
Parastizopus transgariepinus (Coleoptera: Tenebrionidae), se emplearon grupos de 3 machos (Geiselhardt y col., 2008). Las feromonas sexuales se pueden dividir en feromona sexual de largo alcance, liberada por un individuo para atraer al sexo opuesto a distancia, o en feromonas sexuales de contacto (corta distancia), incitando una conducta de cortejo y/o copulación en el sexo opuesto. Generalmente las feromonas sexuales de largo alcance son altamente volátiles, y percibidas mediante el sistema olfativo, mientras que las feromonas de contacto poseen una baja volatilidad y se ha sugerido que son percibidas como estímulos gustativos (Nojima y col., 2007). A la fecha, la mayoría de las feromonas sexuales estudiadas corresponden a feromonas sexuales de largo alcance, especialmente de insectos plaga; por esto el estudio de feromonas de contacto fue relegado a un segundo plano, probablemente debido a su supuesto bajo potencial para ser utilizadas en programas de control de plagas. Sin embargo, ambos tipos de feromonas pueden ser importantes para el apareamiento, y en algunas especies de insectos, ambos tipos son usadas secuencialmente (ejemplo, B. germanica, Nojima y col., 2005). En T. infestans, se demostró en este laboratorio que los alcoholes grasos de las hembras resultaron esenciales para desencadenar los intentos de cópula de los machos (Cocchiararo y col., 2011).

Las feromonas de alarma muestran menor quimioespecificidad que la feromona sexual y su selectividad se basa principalmente en su volatilidad, más que en sus características estructurales. Predominan en insectos sociales, como las hormigas, en las que se han aislado sustancias terpenoides, HC y cetonas (Blum, 1969).

Las feromonas de reclutamiento también son características de insectos sociales. En abejas, una mezcla de geraniol, neral, genarial y ácido nerólico, actuarían para marcar la colmena y las fuentes de alimento (Free y col., 1981; Le Conte y col., 1990).

Las feromonas de agregación, pueden conducir a sitios de alimentación y/o de reproducción. Su liberación puede provocar una infestación masiva. Se han aislado en hemípteros, como en $T$. infestans (Lorenzo y col., 2009), dípteros como en $D$. melanogaster (Bartelt y col., 1985) y mayoritariamente en coleópteros siendo características de insectos plaga de granos almacenados, como $R$. dominica (Khorramshahi y Burkholder, 1981), S. oryzae, S. zeamais (Schumuff y col., 1984), T. castaneum, T. confusum (Suzuki y Sugawara, 1979), O. surinamensis (Pierce y col., 1985). 


\section{I.4.a. Feromonas de coleópteros}

La diversidad biológica de los coleópteros, alrededor de 375.000 especies, distribuidas en 150 familias, se refleja también en la diversidad estructural de las feromonas sexuales producidas por estos insectos (Tillman y col., 1999; Seybold y Vanderwel, 2003). Estas van desde simples estructuras, como por ejemplo HC de cadenas lineales o ramificados, a estructuras complejas, tales como lactonas, heterociclos de oxígeno, derivados de aminoácidos o compuestos aromáticos (Vanderwel y Oehlschlager, 1987) (Tabla I.4.a).

Tabla.l.4.a. Diversidad estructural de feromonas sexuales en coleópteros.

\begin{tabular}{|c|c|c|c|}
\hline Especie & Familia & Compuestos & Emisor \\
\hline Xylotrechus pyrrhoderus & Cerambycidae & $\begin{array}{l}\text { (2S,3S)-octan-2,3-diol } \\
\text { (2S)-2-hidroxioctan-3-ona }\end{array}$ & Macho \\
\hline $\begin{array}{l}\text { Anthrenus flavipes } \\
\text { Gnathotrichus sulcatus }\end{array}$ & $\begin{array}{l}\text { Dermestidae } \\
\text { Curculionidae }\end{array}$ & $\begin{array}{l}\text { Ácido (3Z)-decenoico } \\
\text { (2S) y }(2 R) \text {-6-metil-5-hepten-2-ol }\end{array}$ & $\begin{array}{l}\text { Hembra } \\
\text { Macho }\end{array}$ \\
\hline Sitophilus oryzae & Curculionidae & $\begin{array}{l}\text { (4S,5R)-5-hidroxi-4-metilheptan- } \\
\text { 3-ona }\end{array}$ & Hembra \\
\hline Diabrotica virgifera & Chrysomelidae & $\begin{array}{l}\text { Propionato de } \quad(1 R, 7 R)-1,7- \\
\text { dimetildecilo }\end{array}$ & Hembra \\
\hline Lasioderma serricorne & Anobiidae & $\begin{array}{l}\text { (4S,6S,7S)-7-hidroxi-4,6- } \\
\text { dimetilnonan-3-ona }\end{array}$ & Hembra \\
\hline Holotrichia parallela & Scarabaeidae & $\begin{array}{l}(2 S, 3 S)-2 \text {-amino-3- } \\
\text { metilpentanoato de metilo }\end{array}$ & Hembra \\
\hline Exomala orientalis & Scarabaeidae & 7-(Z) y 7-(E)-tetradecen-2-ona & Hembra \\
\hline
\end{tabular}

Estas feromonas pueden producirse a través de modificaciones en la ruta biosintética de ácidos grasos, compuestos isoprenoides y metabolismo de aminoácidos. Estas modificaciones a menudo incluyen formación estereoespecífica de los productos finales. La abundancia de centros quirales en los componentes de las feromonas de coleópteros incrementa su complejidad y diversidad (Blomquist y Vogt, 2003).

Un tema a dilucidar en la síntesis de feromonas es determinar el origen de sus componentes, específicamente establecer si son sintetizados de novo o son derivados precursores obtenidos de la dieta, y utilizados directamente, o son alterados por el sistema enzimático de los insectos. Por ejemplo, es posible que el escarabajo Dendroctonus pseudotsugae (Coleoptera: Curculionidae) obtenga su feromona, el limoneno, desde su hospedador Pseudotsuga menziesii, durante la alimentación. (Rudinsky y col., 1977).

Otros estudios reportaron la biosíntesis de feromonas derivadas de terpenos, por modificación de los compuestos provenientes de hospederos. Por ejemplo machos de Cryptolestes ferrugineus (Coleoptera: Laemophloeidae), alimentados con farnesol 
marcado radioactivamente incorporaron la marcación en uno de los componentes de su feromona de agregación (4-E,8-E-4,8-dimetildecadien-10-olido) (Tillman y col., 1999).

Las feromonas de coleópteros, que se generarían por síntesis de novo, son aquellas de origen isoprenoide, y las derivadas de ácidos grasos. Por ejemplo, la producción de ipsdienol y E-mircenol en machos de Ips duplicatus (Curculionidae) ocurre de novo, mediante la ruta isoprenoide (Ivarsson y col., 1993). Estudios realizados por Seybold y col (1995), también demostraron que la síntesis de la feromona de agregación de Ips pini y Ips paraconfusus utilizando $\left[1-{ }^{14} \mathrm{C}\right]$-acetato y $[1$ $\left.{ }^{14} \mathrm{C}\right]$-mevalolactona, ocurre de novo mediante la vía del mevalonato. Los precursores de feromonas también pueden ser ácidos grasos, como por ejemplo ocurre en hembras de Tenebrio molitor, la síntesis de la feromona sexual, (4-metil-1- nonanol) ocurre de novo a través de una modificación en la biosíntesis de ácidos grasos. La iniciación de la ruta con una unidad de propionato genera una cadena con número impar de carbono. La incorporación de una nueva unidad de propionato durante la elongación de la cadena introduce la metil ramificación; finalmente la reducción del ácido metilnonanoico produce la feromona (Islam y col., 1999). También se ha estudiado la biosíntesis de la feromona de agregación en $T$. castaneum, el 4,8dimetildecanal (4,8-DMD) (Suzuki y Sugawara, 1979; Suzuki 1980), que es producida por los machos adultos. La biosíntesis de la feromona ocurre de novo a través de una modificación en la biosíntesis de ácidos grasos, mediante la secuencia de acetatopropionato-acetato-propionato-acetato (Kim y col., 2005).

\section{I.4.b. Compuestos orgánicos volátiles liberados por Tribolium castaneum}

El sistema de defensa química de los tenebriónidos es uno de los más estudiados entre los insectos. Más de 200 especies se han estudiado hasta ahora (Tschinkel 1975b; Howard 1987; Brown y col., 1992). Las secreciones son principalmente quinonas, metil y etil- 1,4 benzoquinonas, acompañadas generalmente por hidrocarburos insaturados de diversas longitudes de cadena, además de cantidades menores de otros compuestos como, monoterpenos (Brown y col., 1992; Geiselhart y col., 2006) y cetonas (Tschinkel 1975a). Los compuestos de defensa liberados por los insectos se secretan durante el estrés causado por los depredadores (Tschinkel, 1975b). Los adultos de T. castaneum liberan abundantes secreciones de defensa (repelentes e irritantes) (Roth, 1943; Eisner, 1966; Tschinkel, 1975b; Ruther y col., 2001) Estas sustancias son liberadas en gran cantidad cuando los insectos infestan depósitos de granos y sus derivados almacenados, modificando las 
propiedades de los alimentos a los cuales contaminan y confieren un olor desagradable. Los principales compuestos orgánicos volátiles (VOC) emitidos por esta especie son la metil-1,4-benzoquinona (MBQ) y la etil-1,4-benzoquinona (EBQ) (Blum, 1981; Attygalle y col., 1991, 1993; Eisner y col., 1998) (Fig.l.4.b.1.A), junto con el HC, 1-pentadeceno ( $n$ C15:1) (Alexander y Barton, 1943; Happ, 1968; Suzuki y col., 1975) (Fig.l.4.b.1.B).

Fig.l.4.b.1. Estructuras de los VOC. A: Benzoquinonas (BQ): $\mathrm{R}_{1}=\mathrm{CH}_{3}, \mathrm{R}_{2}=\mathrm{H}$ (Metil-1, 4 benzoquinona (MBQ)), $\mathrm{R}_{1}=\mathrm{C}_{2} \mathrm{H}_{5}, \mathrm{R}_{2}=\mathrm{H}$ (Etil-1,4 benzoquinona (EBQ)). B: 1-pentadeceno $(n-$ C15:1)

Las benzoquinonas $(B Q)$, son almacenadas en los reservorios glandulares (RG) y liberadas por estos insectos a través de las glándulas protorácicas y abdominales (Fig.l.4.b.2 y 3 ).

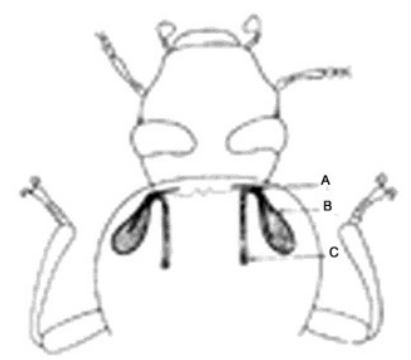

Fig.l.4.b.2. Esquema de la ubicación de las glándulas protorácicas. A: orificio de salida de los compuestos. B: Reservorio Glandular (RG). C: Musculo retráctil de la glándula. Modificado a partir de Tschinkel, 1975b.

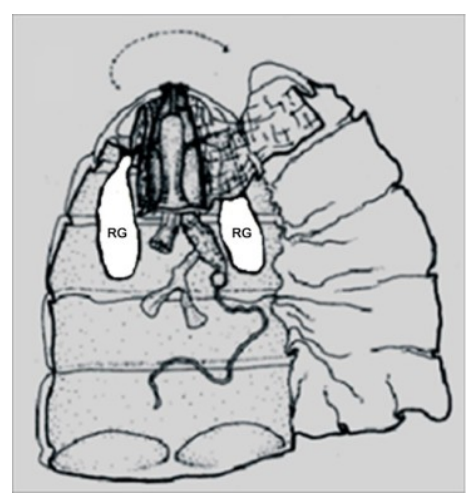


Fig.I.4.b.3. Esquema del abdomen de insecto donde se resaltan los RG. Modificado a partir de Tschinkel y Doyen.1980.

Estas sustancias son tóxicas debido principalmente a que facilitan la formación de especies reactivas del oxígeno, se unen covalentemente a macromoléculas (Bolton y col., 2000; Monks y Jones, 2002) o alteran el metabolismo del $\mathrm{Ca}^{++}$afectando en forma potente la respuesta inmune por inhibición de las funciones de macrófagos (Pfeifer e Irons, 1983). Las BQ también son tóxicas para el propio insecto, de manera que son almacenadas en las mencionadas glándulas como su precursor atóxico, hidroquinona $(\mathrm{HQ})$, y al momento de ser secretadas son trasformadas a $B Q$ mediante una reacción con $\mathrm{H}_{2} \mathrm{O}_{2}$ catalizada por una peroxidasa (Happ, 1968). El n-C15:1 actuaría como disolvente de las BQ en el cuerpo del escarabajo (Peschke y Eisner, 1987). Los machos producen la feromona de agregación, el 4,8-DMD (Suzuki y Sugawara, 1979; Suzuki, 1980), que atrae a ambos sexos y conduce a sitios de alimentación y/o de reproducción, provocando generalmente una infestación masiva. Estudios posteriores revelaron que el 4,8-DMD sería también una feromona de agregación producida por los machos de otras especies del género Tribolium ( $T$. castaneum, $T$. confusum y $T$. freemani) (Suzuki y col., 1987). La localización de la glándula productora de esta feromona no está definida; Faustini y col. (1981) reportaron su ubicación en los fémures de las patas, sin embargo Qazi y col. (1998), demostraron que las patas no eran los principales sitios de producción ya que machos sin sus patas continuaban liberando importantes cantidades de 4,8-DMD. Actualmente se ha demostrado que $T$. castaneum libera una mezcla de isómeros de 4,8-DMD (Lu y col, 2011).

Dada la importancia económica de esta plaga, una variedad de métodos sofisticados y complejos se han utilizado para analizar las principales secreciones volátiles de $T$. castaneum (Unruh y col., 1998). En la Tabla I.4.b se muestran ejemplos de las distintas metodologías utilizadas para de su análisis. La gran variación en el contenido de quinonas reportado se debe, en parte a los distintos procedimientos empleados, y también a la falta de información sobre la edad de los insectos utilizados en los ensayos.

Tabla.I.4.b. Análisis de benzoquinonas de T. castaneum

\begin{tabular}{|c|c|c|}
\hline Método & Resultado & Referencia \\
\hline $\begin{array}{l}\text { Sublimación de } 500-1000 \text { insectos por } \\
\text { ensayo con etanol frío, solvente } \\
\mathrm{NaHSO}_{3} \text {. Insectos de edad y sexo } \\
\text { desconocido. Pruebas químicas y } \\
\text { análisis UV. }\end{array}$ & $\begin{array}{l}\text { No hay datos de cuantificación de } \\
\text { quinonas Total de la secreción } 2,3 \\
-4,5 \mu \mathrm{g} / \text { insecto }\end{array}$ & $\begin{array}{l}\text { Alexander y } \\
\text { Barton (1943) }\end{array}$ \\
\hline $\begin{array}{l}\text { Sublimación de } 25000-74000 \text { insectos } \\
\text { por ensayo con éter y éter dietílico. } \\
\text { Insectos de edad y sexo desconocido. }\end{array}$ & $\begin{array}{l}\text { Total de quinonas } \sim 16,2 \\
\mu \mathrm{g} / \mathrm{insectos} .10-20 \% \text { de } \mathrm{MBQ}, 80- \\
90 \% \text { de } \mathrm{EBQ},<1 \% \text { de } 2 \text { metoxi } 1-4\end{array}$ & $\begin{array}{l}\text { Loconti y Roth } \\
\text { (1953) }\end{array}$ \\
\hline
\end{tabular}


Pruebas químicas

Secreciones de defensa y extractos metanólicos celulares, analizados por TLC. Método de extracción no descripto.

Insectos de edad y sexo desconocido. Disección de glándulas y pruebas químicas realizadas con tejidos fijados.

Lavado y homogeneizado de 10-200 insectos por ensayo con metanol. Insectos de edad y sexo desconocido. Análisis por LC/UV/MS.

Homogenato de 1-4 insecto por ensayo con solución acuosa de metanol 10\%, HCl 10 mM, ácido ascórbico $25 \mathrm{mM}$.

Insectos de edad y sexo conocido. Análisis LC/UV/EC
$B Q$

No hay datos cuantificación de quinonas. La secreción y extracto celular ambos contenían sustancias fenólicas, mezcla de $H Q$, MHQ y EHQ. El extracto celular contenía b-glucósido.

Quinonas de superficie: 0,3 Pappas y $\mu \mathrm{g} /$ insecto. Quinonas totales: 25 Wardrop (1996) $\mu \mathrm{g} /$ insecto (MBQ: $38 \%$, EBQ: $62 \%$, $\mathrm{MHQ}$ y $\mathrm{EHQ}$ fueron detectadas pero no cuantificadas).

† de 40 días posteclosión: $M B Q$ y Unruh y col MHQ: $20,4 \pm 1,5 \mu \mathrm{g} / \mathrm{insecto}$; EBQ y

EHQ: $32,0 \pm 2,7 \mu \mathrm{g} /$ insecto.

$\widehat{o}$ de 40 días posteclosión: $\mathrm{MBQ}$ y

MHQ: $15,5 \pm 3,0 \mu \mathrm{g} / \mathrm{insecto}$; EBQ y EHQ: $22,2 \pm 4,3 \mu \mathrm{g} /$ insecto.

En 1941, Roth y Howland aislaron la secreción de T. confusum pasando aire sobre el insecto. La secreción se condensó en una trampa de hielo seco, dando cristales de color amarillo-marrón. A temperatura ambiente la sustancia recogida era un líquido volátil con un olor acre. Como ha señalado Roth (1943), las glándulas secretoras sobre el abdomen y tórax del adulto de $T$. castaneum, $T$. confusum y $T$. destructor contienen un líquido irritante picante. En 1943, Alexander y Barton informaron sobre secreciones liberadas por T. castaneum. En 1971, Von Endt y Wheeler aislaron un nuevo compuesto, $n$-C15:1, además de las benzoquinonas; el $n$ C15:1 facilitaría la absorción de las quinonas cuando los insectos son atacados por depredadores. Howard (1987) realizó un análisis de las secreciones de defensa de la familia Tenebrionidae, incluyendo a $T$. confusum y $T$ castaneum. El autor determinó la presencia de 15 hidrocarburos, de los cuales se encontraron cinco en todos los insectos estudiados, incluyendo también a la metil-1,4-benzoquinona y la etil-1,4benzoquinona. Los niveles de las secreciones volátiles pueden variar en cantidades casi indetectables justo después de la eclosión del adulto, a niveles cada vez mayores como ocurre en los adultos maduros. Se ha reportado en hembras de Tribolium spp. de 30 días de edad, concentraciones de 35-46 $\mu$ g de benzoquinona y 14-24 $\mu \mathrm{g}$ de $n$ C15:1 (Wirtz y col., 1978). En un estudio realizado por Yezerski y col., (2004) se cuantificaron las dos principales quinonas secretadas, usando cromatografía líquida de alta resolución (HPLC) empleando cepas genéticamente distintas de $T$. confusum. Los valores medios detectados fueron de alrededor de $0,4 \mu \mathrm{g} /$ insecto de $\mathrm{MBQ}$ y 2 $\mu \mathrm{g} /$ insecto de $E B Q$, mientras que las cantidades internas (glandulares) eran alrededor de 10 y $15 \mu \mathrm{g} /$ insecto, respectivamente en las cepas "de alta-producción" y "bajaproducción". 


\section{I.5. Métodos para el análisis de compuestos volátiles orgánicos}

Modernas metodologías permiten el análisis directo de volátiles liberados. El método más simple es tomar muestras del espacio gaseoso de una muestra con una jeringa para gases directamente del espacio de cabeza (HS-headspace-) e inyectarla directamente en un cromatógrafo de gases. Es un procedimiento poco eficiente para extracción, pero es utilizable en caso de alta producción de volátiles.

Alternativamente, los compuestos volátiles de una muestra pueden ser transportados por un gas carrier (aire purificado generalmente) a una trampa sólida de polímeros porosos (por ejemplo, Tenax TA, Porapak Q, Chromosorb 102) donde los analitos son adsorbidos y preconcentrados, luego pueden ser liberados o bien a través de la extracción con disolventes orgánicos (Fontán y col., 2002) o mediante desorción térmica (Lima y col., 2001). Los compuestos volátiles pueden ser adsorbidos mediante muestreo difusivo del espacio de cabeza o por purga y captura activa de gases del espacio de cabeza (Seitz y col., 1999; Hatami y col., 2011).

En 1989 Belardi y Pawliszyn describieron el método de microextracción en fase sólida del espacio de cabeza (Headsapce-Solid Phase Micro Extraction-HS- SPME), utilizando microfibras recubiertas de material adsorbente para la toma de muestra de volátiles seguida por la inyección directa en una unidad de desorción térmica en el cromatógrafo de gases.

Otra alternativa es el reciente desarrollo de sensores electrónicos que responden a los compuestos volátiles específicos, dando lugar al desarrollo de la nariz electrónica (e.n -electronic nose-), surgiendo así nuevas maneras de detectar el daño de los insectos en los granos almacenados (Stetter y col., 1993; Hu, 2006; Zhang y Wang, 2007; Zhang y Wang, 2008; Zhou y Wang, 2011).

\section{I.6. Control de insectos plaga de granos almacenados}

La agricultura sustentable requiere de nuevas alternativas de control que permitan reducir o eliminar la aplicación de insecticidas tradicionales basados en el uso de fumigantes y productos químicos persistentes con alto impacto ambiental. Las tendencias actuales en el manejo integrado de plagas (MIP) se orientan hacia la 
preservación del ambiente junto al uso de métodos de bajo impacto y pesticidas naturales de escasa toxicidad.

\section{I.6.a. Agentes naturales}

El uso de polvos desecantes o abrasivos como agentes insecticidas se conoce desde hace mucho tiempo, sin embargo, su actual nivel de comercialización es relativamente escaso. Las tierras de diatomeas (TD) son de origen sedimentario y están formadas por los restos fósiles de algas unicelulares de origen lacustre o marino (Korunic, 1997; 1998; Lord, 2001; Dal Bello y col., 2006). Estos sedimentos están formados principalmente por las paredes celulares de las diatomeas (frústulos), compuestas por sílice amorfa. Según la clasificación de la Organización Mundial de la Salud, la TD amorfa pertenece a la Clase III (WHO, 2009), considerada no tóxica para mamíferos (Quarles, 1992) y su uso en alimentos almacenados está autorizado por la Agencia de Protección Ambiental de los Estados Unidos de América (USA Federal Register, 1981).

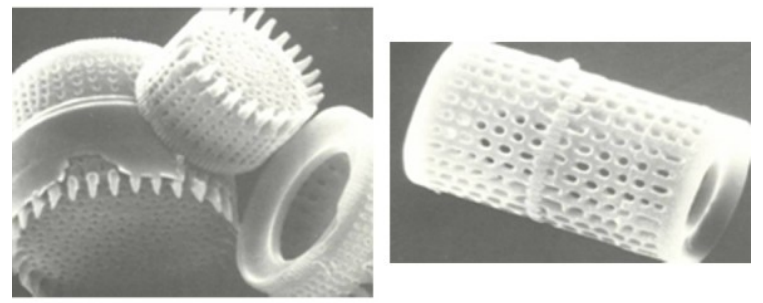

Fig.I.6.a. M.E de barrido de TD (Modificado de Permaguard)

El uso de TD como insecticida está registrado en varios países para la protección de granos almacenados, así como para su uso doméstico y en invernaderos. Una de las ventajas en su aplicación es que no deja residuos tóxicos, por lo cual es apta para la producción orgánica y tiene un alto poder residual que es superior al de muchos insecticidas químicos. El mecanismo de acción insecticida de la TD es por abrasión y adsorción de los lípidos cuticulares del insecto que produce su muerte por desecación (Korunic, 1998; Subramanyan y Roesli, 2000). También tienen una participación importante en la absorción de sustancias químicas, en la penetración de microorganismos y alterarían procesos de comunicación química (Juárez, 1994; Juárez y Calderón, 2007; Pedrini y col., 2007; Blomquist y Banegeres., 2010). El grado de susceptibilidad del insecto está relacionado con la capacidad de las distintas TD para adsorber los lípidos cuticulares, lo cual a su vez se relaciona con la estructura 
cuticular, hábitos y fisiología del insecto blanco (Akbar y col., 2004; Korunic y Fields, 2006; Dal Bello y col., 2006; Athanassiou y Korunic, 2007).

En este sentido, la reciente detección de depósitos de diatomitas locales en las cercanías de la localidad de Ingeniero Jaccobaci (Provincia de Río Negro) con capacidad insecticida, tanto en forma individual como combinadas con $B$. bassiana (Dal Bello y col., 2006), abre un importante campo de aplicación de este producto en el país ya que hasta el momento, la totalidad de las TD usadas comercialmente son importadas.

\section{I.6.b. Agentes biológicos}

Una rama del control biológico, es el control microbiano. Los microorganismos más utilizados son bacterias, hongos, virus. Las principales ventajas de su utilización respecto del control químico residen en que no contaminan el ambiente ni son tóxicos para el hombre, así como la escasa probabilidad de aparición de resistencia en los insectos blanco, como a sus múltiples modos de acción. Además, al multiplicarse y dispersarse dentro del agroecosistema se puede lograr un efecto a largo plazo una vez que logran introducirse y colonizar el mismo. Una desventaja con el control químico es que al tratarse de organismos vivos, son sensibles a las condiciones climáticas (temperatura, humedad relativa, luminosidad, etc.) y requieren mayores cuidados en su almacenamiento para evitar pérdidas de su patogenicidad o disminución de su virulencia. La variada especificidad de hospedadores hace posible que se puedan seleccionar cepas que presenten selectividad o baja mortalidad para otros enemigos naturales como parasitoides o predadores. Los hongos entomopatógenos han sido exitosamente utilizados como enemigos naturales de varias especies de artrópodos (insectos y ácaros). La extensa lista de hospedadores incluye moscas, mosquitos, tucuras, escarabajos, gorgojos, chinches, hormigas y mariposas. Aunque existen más de cien especies de hongos patógenos de insectos, los más usados en estrategias de control biológico son los deuteromicetes debido a que poseen ciclo de vida simple, se producen a gran escala con relativa facilidad y poseen un amplio rango de insectos hospedadores (Charnley, 1991; Lacey y col., 2001). Aprovechando esta propiedad bioinsecticida, así como la fácil disponibilidad y desarrollo de estos hongos en el laboratorio, Beauveria bassiana y Metarhizium anisopliae son utilizadas como micoinsecticidas en distintas regiones del mundo. La capacidad insecticida de $B$. bassiana ha sido demostrada sobre diferentes coleópteros plaga de granos almacenados (Fig.l.8.b) (Adane y col., 1996; Padín y col., 1997; 2002; Hidalgo y col., 1998; Moino y col., 1998; Smith y col., 1998; Rice y Cogburn, 1999; Dal Bello y col., 
2001; Pedrini y col., 2001; Crespo y col., 2002, Dal Bello y col., 2006, Pedrini y col.,2010), siendo uno de los potenciales candidatos para el control biológico en este sector donde es evidente la necesidad de reducir la aplicación de pesticidas químicos a su mínima expresión.

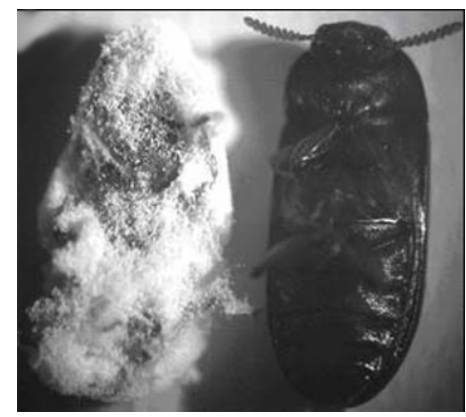

Fig.l.6.b. Ejemplar adulto de $U$. dermestoides muerto por $B$. bassiana, luego de 3-4 días de incubación en cámara húmeda: A la derecha del insecto infectado se muestran un ejemplar no tratado. Aumento: 4x. Tomado de Pedrini 2006.

El empleo de nuevas estrategias de control ecológicamente aceptables, como métodos alternativos a los pesticidas químicos tradicionales, es indispensable y urgente. Los hongos entomopatógenos tienen un gran potencial como agentes bioinsecticidas. Es por esto que para un resultado exitoso, no es suficiente la detección y aplicación de cepas virulentas, sino que es esencial utilizar herramientas biotecnológicas que optimicen su funcionamiento. 


\section{II.1.Objetivos generales}

- Avanzar en el conocimiento de la bioquímica de los lípidos cuticulares de insectos, tomando como modelo a insectos plaga de granos almacenados.

- Estudiar las secreciones volátiles de origen lipídico de estos insectos.

- Estudiar la interacción entre insectos plaga de granos almacenados y agentes de control que producen bajo impacto ecológico.

\section{II.2.Objetivos específicos}

- Analizar la composición cuali/cuantitativa de los hidrocarburos de $T$. castaneum.

- Desarrollar un método de alta sensibilidad para el análisis de compuestos volátiles orgánicos (VOC) emitidos por T. castaneum.

- Caracterizar y analizar los VOC liberados por U. dermestoides.

- Iniciar el estudio del metabolismo de los lípidos cuticulares y secreciones volátiles derivadas, en $T$. castaneum y $U$. dermestoides.

- Evaluar la capacidad insecticida de tierras de diatomeas locales en $T$. castaneum, $R$. dominica y $S$. oryzae.

- Evaluar el efecto de hongos entomopatógenos, en la supervivencia y ciclo de vida de $U$. dermestoides y $T$. castaneum. 


\section{III.1. Reactivos, drogas, estándares, solventes y accesorios utilizados}

Los solventes utilizados (hexano, etanol, diclorometano, éter etílico, acetona, cloroformo, metanol, acetonitrilo, tetrahidrofurano, dimetil sulfóxido) fueron grado proanálisis de las marcas Merck (Darmstadt, Alemania) y Carlo Erba (Milán, Italia).

Se emplearon las siguientes placas para cromatografía en capa fina (TLC): de ácido silícico (Aldrich, Milwaukee, USA), de silica gel Polygram Sil G/UV ${ }_{254}$ (MachereyNagel, Düren, Alemania), y las placas de alta resolución (HPTLC Silicagel 60, Merck Darmstadt, Alemania). El ácido silícico utilizado como relleno de columnas de purificación fue Biosil A (Bio-Rad Lab, Richmond, Canadá) y Supelcosil ${ }^{\mathrm{TM}}$ A (Supelco, Bellefonte, USA)

Los estándares de ácidos grasos, 1-pentadeceno, hidroquinona y 1,4benzoquinona fueron obtenidos de Sigma- Aldrich (St. Louis, USA).

Las fibras de microextracción en fase sólida se adquirieron en Supelco (Bellefonte, USA). El porapak $Q$ utilizado para relleno de las trampas de volátiles se adquirió de Waters Assoc., Inc. (Massachussets, USA).

Los trazadores radiactivos utilizados, $\left[{ }^{14} \mathrm{C}\right]$ acetato $(56 \mathrm{mCi} / \mathrm{mmol})$ y $\left[{ }^{14} \mathrm{C}\right]$ palmitato $(57,5 \mathrm{mCi} / \mathrm{mmol})$ de New England Nuclear (Boston, USA). El líquido de centelleo utilizado fue Optiphase Hisafe 2 de Perkin Elmer Life Sciences, (Boston, USA).

\section{III.2. Insectos}

Se utilizaron ejemplares de insectos plaga de granos almacenados, $T$. castaneum (Fig.III.2.A), R. dominica, S. oryzae y U. dermestoides (Fig.III.2.B), provenientes de colonias pertenecientes a la Cátedra de Terapéutica Vegetal, Facultad de Ciencias Agrarias y Forestales, UNLP. Los insectos fueron criados en frascos de vidrio de $500 \mathrm{ml}$ cubiertos con una red fina de tela y mantenidos en cámara de cría a $27 \pm 2{ }^{\circ} \mathrm{C}$ y $70 \pm 5 \%$ de humedad relativa, fotoperíodo de $12 \mathrm{~h} / 12 \mathrm{~h}$ luz: oscuridad, excepto $U$. dermestoides que fue mantenido a $25^{\circ} \mathrm{C}$ y en oscuridad.

Se alimentaron con dietas consistente en grano de trigo entero para $S$. oryzae y $R$. dominica; pan de salvado, salvado de trigo y maní para $U$. dermestoides y una mezcla de harina de trigo (85\%), levadura de cerveza (5\%), germen de trigo $(5 \%)$ y leche descremada en polvo (5\%) para T. castaneum. 


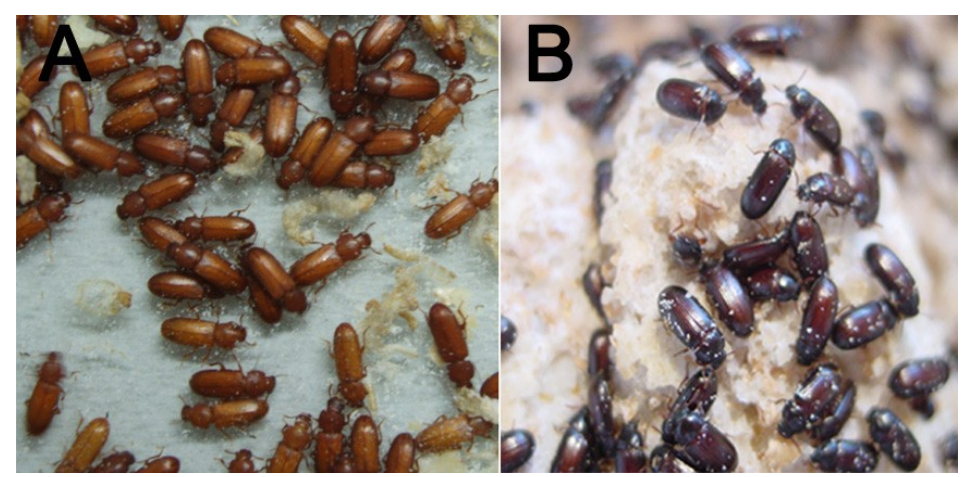

Fig. III.2: Ejemplares adultos de T. castaneum (A) y U. dermestoides (B)

\section{III.3. Análisis de los lípidos de T. castaneum}

\section{III.3.a. Extracción}

Ejemplares adultos de T. castaneum fueron lavados con agua bidestilada para remover restos de alimento, luego secados en papel por $10 \mathrm{~min}$, transferidos a viales de $4 \mathrm{ml}$, y sumergidos en $n$-hexano destilado ( $6 \mathrm{ml} / \mathrm{gr}$ de insecto), realizando tres extracciones de $5 \mathrm{~min}$, y colectando en un vial el extracto conteniendo los lípidos cuticulares (Juárez y col, 2001).

\section{III.3.b. Cromatografía en capa fina (TLC)}

El extracto obtenido como se explica en la sección anterior (III.3.a.) se concentró con un gas inerte $\left(\mathrm{N}_{2}\right)$ y se analizó en placas de silica gel de $4 \times 8 \mathrm{~cm}$ (Macherey-Nagel, Düren, Alemania), las muestras se sembraron en bandas o puntos, y su desarrollo se efectuó en cubas de vidrio utilizando dos sistemas de desarrollo:

1- $n$-hexano (100\%), para separar compuestos de muy baja polaridad

2- $n$-hexano:éter etílico:ácido acético (80:20:1 v/v), para la separación de los lípidos neutros.

Las corridas cromatográficas se desarrollaron en cubas previamente saturadas con los vapores de la mezcla de solventes correspondiente. El revelado de las muestras se realizó mediante los siguientes métodos:

1) Con vapores de iodo $\left(\mathrm{I}_{2}\right)$. Se colocó la placa desarrollada y seca en una cuba conteniendo iodo bisublimado (Carlo Erba, Italia) durante $10 \mathrm{~min}$. Este método cualitativo permite visualizar las zonas con lípidos ya que el iodo (colorante inespecífico) los tiñe de un color parduzco. El iodo se fija a los dobles enlaces, la intensidad de la mancha se correlaciona con insaturaciones. 
2) Por calcinación. Se realizó la inmersión de la placa cromatográfica en una solución de ácido sulfúrico $\left(\mathrm{H}_{2} \mathrm{SO}_{4}\right)$ en etanol $(5 \%)$ y posteriormente se colocó en estufa a $180^{\circ} \mathrm{C}$ durante $15 \mathrm{~min}$. Es un método destructivo, inespecífico, con una alta sensibilidad, que produce la carbonización de los compuestos que se observan como manchas negras. La intensidad de color de la mancha se correlaciona con la cantidad de lípido. Los hidrocarburos se identificaron por comparación con estándares analizados en condiciones similares

\section{III.4. Análisis de hidrocarburos de T. castaneum}

\section{III.4.a. Extracción y purificación}

Para la extracción de los lípidos epicuticulares, los insectos adultos de $T$. castaneum fueron sumergidos durante $5 \mathrm{~min}$ en $n$-hexano destilado $(6 \mathrm{ml} / \mathrm{gr}$ de insecto). Los hidrocarburos totales (en su mayoría provenientes de hemolinfa e integumento) se extrajeron de forma similar pero luego de $48 \mathrm{~h}$ de inmersión. Los hidrocarburos se purificaron del extracto lipídico total en una mini columna de Biosil de $2,5 \mathrm{~cm} \times 0,5 \mathrm{~cm}$, eluyendo con $n$-hexano destilado (6 ml/mg de lípido), y luego se concentraron bajo atmósfera de $\mathrm{N}_{2}$.

\section{III.4.b. Cromatografía en capa fina (TLC)}

Los extractos se analizaron en las mismas condiciones que las descriptas para los lípidos. Adicionalmente, para estudiar la presencia de hidrocarburos insaturados, la muestra se desarrolló por:

-TLC en placas de silica gel previamente impregnadas con $\mathrm{NO}_{3} \mathrm{Ag}(20 \%$ en acetonitrilo), usando como solvente $n$-hexano (100\%), el revelado de las muestras se realizó por inmersión de la placa cromatográfica en una solución de ácido sulfúrico en etanol $(5 \%)$ y posteriormente se colocó en estufa a $180^{\circ} \mathrm{C}$ durante $15 \mathrm{~min}$.

\section{III.4.c. Cromatografía gaseosa capilar (CGC)}

La técnica de CGC permite la separación y cuantificación de compuestos volátiles. Se inyecta una pequeña cantidad de la muestra a separar en una corriente de un gas inerte transportador a elevada temperatura, esta corriente de gas, atraviesa una columna cromatográfica que separará los componentes de la muestra. Los componentes serán diferencialmente arrastrados por el gas transportador hacia el 
detector. El detector realizará un registro de la cromatografía en la forma de un cromatograma.

Se utilizó un cromatógrafo Hewlett Packard 6890 con detector de ionización por llama (FID) operado a $320^{\circ} \mathrm{C}$ y equipado con una columna capilar no polar DB-5 (J \& W Scientific, Folson, USA, de $30 \mathrm{~m}$ de longitud $\times 0,32 \mathrm{~mm}$ de diámetro interno y 0,5 $\mu \mathrm{m}$ de fase estacionaria). Como gas transportador se utilizó He a 11.36 psi con una velocidad lineal de $39 \mathrm{~cm} / \mathrm{seg}$. El inyector se operó en modo (sin deriva) a $280{ }^{\circ} \mathrm{C}$, y el horno se programó con una temperatura inicial de $50{ }^{\circ} \mathrm{C}$ por $1 \mathrm{~min}$, y luego con rampas de temperatura de $50{ }^{\circ} \mathrm{C} / \mathrm{min}$ hasta $200{ }^{\circ} \mathrm{C}$ y $3{ }^{\circ} \mathrm{C} / \mathrm{min}$ hasta $300{ }^{\circ} \mathrm{C}$ permaneciendo finalmente a esa temperatura por $10 \mathrm{~min}$. El sistema fue operado, y los datos colectados, con el programa HP ChemStation. La longitud de cadena se estimó en base a los índices de Kovats (IK) (Kovats, 1965) calculados a partir de los tiempos de retención de $n$-alcanos de 10 a 44 átomos de carbono analizados en idénticas condiciones, utilizando la siguiente fórmula:

$$
\mathrm{IK}=100\left[n+(N-n) \frac{\log t_{r}^{\prime}(\text { desconocido })-\log t_{r}^{\prime}(n)}{\log t_{r}^{\prime}(N)-\log t_{r}^{\prime}(n)}\right]
$$

Donde $\mathrm{n}$ es el número de carbonos del alcano más corto; $\mathrm{N}$ es el número de átomos de carbono del alcano más largo; $t_{r}^{\prime}(n)$ es el tiempo de retención ajustado del alcano más corto; y t ' $(\mathrm{N})$ el tiempo de retención ajustado del alcano más largo.

Para el cálculo del IK, se inyectaron estándares de hidrocarburos de longitud de cadena conocida en las mismas condiciones cromatográficas de las muestras, y luego se graficó el tiempo de elución versus la longitud de cadena. De esta manera, por interpolación del tiempo de elución un hidrocarburo de número de carbonos desconocido en la ecuación obtenida a partir del gráfico, se obtuvo su valor de IK. Los $\mathrm{KI}$ de los distintos componentes se calcularon, aplicando la siguiente fórmula:

$\mathrm{KI}=100 *\left(\mathrm{Ca}+(\mathrm{Cb}-\mathrm{Ca}){ }^{*}((\operatorname{tr} \mathrm{X}-\operatorname{tra}) /(\operatorname{trb}-\operatorname{tra}))\right)$

donde: Ca: número de carbonos del estándar que eluye anteriormente

$\mathrm{Cb}$ : número de carbonos del estándar que eluye posteriormente

trX: tiempo de retención del hidrocarburo incógnita

tra: tiempo de retención del estándar que eluye anteriormente

trb: tiempo de retención del estándar que eluye posteriormente.

III.4.d. Cromatografía gaseosa capilar (CGC) acoplada a espectrometría de masa (MS)

La cromatografía de gases (GC) acoplada a espectrometría de masas (MS) 
tiene gran aplicación para la identificación y caracterización de compuestos ya que combina el alto poder de resolución que da la cromatografía de gases con la alta sensibilidad suministrada por el espectrómetro de masas. En la MS de impacto electrónico $(\mathrm{EI})$, los hidrocarburos son fragmentados e ionizados por una corriente de electrones generando un patrón de fragmentos que es específico de cada molécula; en la fragmentación se forman grupos metileno por ruptura de las uniones carbonocarbono de la cadena principal. En los HC de cadena lineal, la intensidad de los fragmentos disminuye en forma continua, el peso molecular del compuesto se puede determinar en base al ion molecular $(\mathrm{M})^{+}$. En la figura III.4.d.1, se muestra un espectro típico de un $n$-alcano en este caso el $n$-nonacosano, su $(\mathrm{M})^{+}$es 408 .

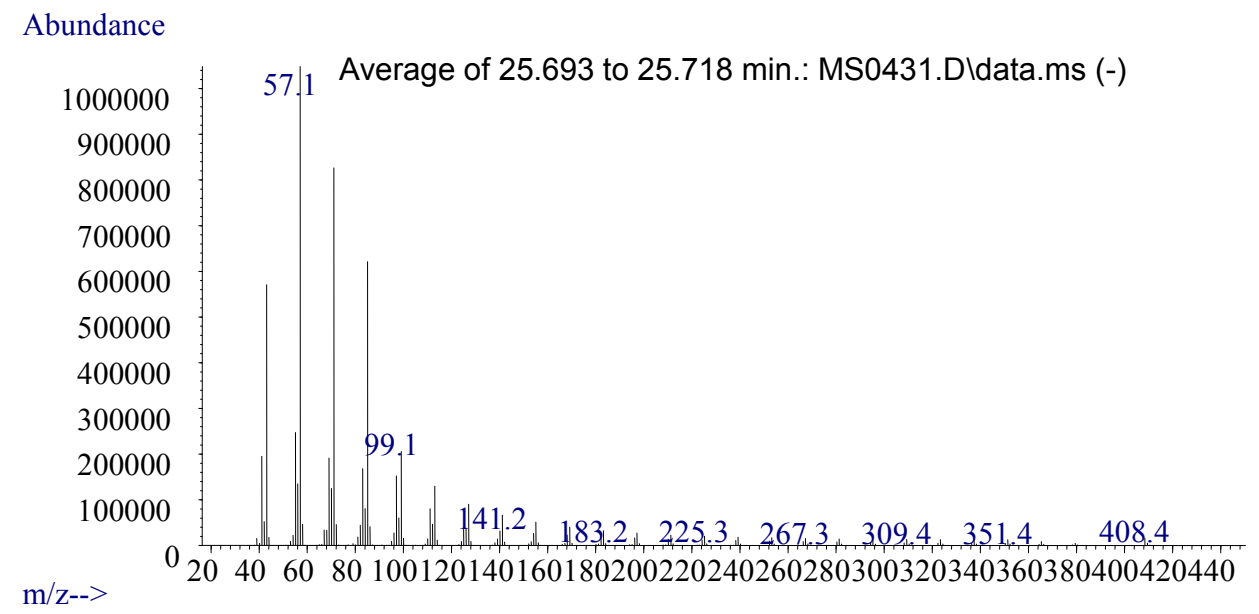

Figura III.4.d.1. Espectro de masa típico de un HC saturado lineal, ejemplo $n$-nonacosano.

Los metilalcanos se fragmentan preferencialmente a ambos lados de la ramificación, y muestran un incremento en la intensidad del ion $\mathrm{M}-15$ como resultado de la ruptura al nivel de la ramificación metilo. En los monometilalcanos terminales, la liberación de un grupo isopropilo en la fragmentación de los 2-metilalcanos y de un grupo etilo en la de los 3-metilalcanos, da como resultado un incremento del ion M-43 y M-29 respectivamente, que resultan de una intensidad similar al del M-15. En los monometilalcanos internos los M-43, M-29 y M-15 forman un grupo de iones de intensidad creciente el cual ayuda a determinar la ubicación del $\mathrm{M}^{+}$y por lo tanto contribuye a la identificación del compuesto. Una característica de la fragmentación de los monometilalcanos internos, es la formación de un fragmento iónico de masa par debido a la pérdida de un átomo de hidrógeno tanto en el fragmento que porta la ramificación como en el fragmento lineal (McCarthy y col., 1968), de tal manera que en el espectro aparecen una serie de dobletes iónicos; por ejemplo, la ruptura en el lado 
interno de la ramificación del 9-metil-C29, generará un par de iones de masa 140 y 141 (donde el 140 es resultado de la pérdida de un hidrógeno del 141) junto al par 280 y 281, mientras que la ruptura en el lado externo generará los pares 308 y 309 junto al par 112 y 113. La formación del ion de masa par queda suprimida cuando en la cadena se encuentra más de una ramificación (McCarthy y col., 1968, Blomquist y col., 1987).

En la figura III.4.d.2 se ve el espectro generado por El del 7-metilnonacosano, no se ve el ion molecular $(M)^{+} 422$, si se observa el $M-15$ con m/z 407. $Y$ los iones diagnostico que se generan por las rupturas que se muestran en la misma figura.

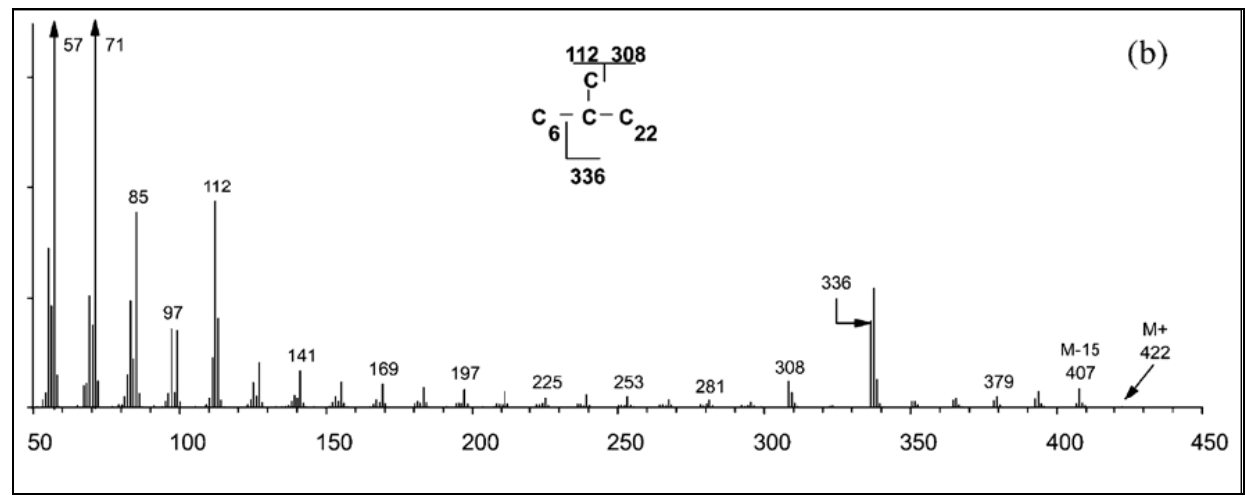

Figura III.4.d.2. Espectro del 7-metilnonacosano (Tomado de Juárez y Blomquist, 1993)

El análisis GC-MS de las muestras de $\mathrm{HC}$ de adultos de $T$. castaneum se realizó en un equipo Hewlett-Packard 6890 con una columna capilar HP-5MS (30 m x $0.25 \mathrm{~mm}$ I.D., F.T. $0.25 \mu \mathrm{m})$. El equipo se programó como en el ítem III.4.c pero esta vez acoplado a un detector selectivo de masa (MSD) Agilent 5975C VL. EI MSD fue operado en el modo SCAN con un rango de masas de 35 a 650 u.m.a.; en modo impacto electrónico a $70 \mathrm{eV}$; línea de transferencia a $320^{\circ} \mathrm{C}$; temperatura de cámara de ionización a $230{ }^{\circ} \mathrm{C}$ y cuadrupolo a $150{ }^{\circ} \mathrm{C}$. Los $\mathrm{HC}$ se identificaron por interpretación de sus espectros de fragmentación (Blomquist y col., 1987; Juárez y col., 2001).

\section{III.5. Análisis de los VOC emitidos por T. castaneum y U. dermestoides}

Este grupo de insectos posee un complejo sistema de comunicación química, liberando gran cantidad de compuestos. Previamente se realizó la puesta a punto de técnica de microextracción en fase sólida (SPME) para el análisis cuali y cuantitativo de los compuestos volátiles liberados por insectos vivos. El análisis cuantitativo del espacio de cabeza (HS) se efectuó por HS-SPME acoplada a CGC, empleando fibras de distinta polaridad mediante la técnica de muestreo de la fase vapor en equilibrio, 
utilizando patrones apropiados para calibración. Para el análisis cualitativo se aplicó SPME-CGC acoplada MS.

\section{III.5.a. Microextracción en fase sólida (SPME)}

La microextracción en fase sólida es una técnica no destructiva que permite extraer compuestos químicos para su posterior análisis e identificación. Esta técnica novedosa y relativamente económica, se puede implementar tanto en el laboratorio como en el campo, es rápida y no requiere el uso de solventes (Pawliszyn, 1997; Vas y Vékey, 2004). Además, el umbral de detección puede estar en el orden de partes por trillón (ppt). La técnica consiste en la extracción de los analitos de la matriz de la muestra, sólida o líquida, mediante una fibra de sílice fundida que está recubierta de un material adsorbente, seguida de la desorción de los analitos mediante temperatura o un disolvente orgánico. El pequeño tamaño de la fibra y su geometría cilíndrica permiten incorporarla en una jeringa. De esta forma, se facilita su manipulación y al mismo tiempo se protege la fibra cuando no se utiliza, ya que ésta permanece dentro de la aguja de la jeringa. Un esquema del dispositivo comercial o holder de SPME se muestra en la Figura III.5.a.1 y 2.

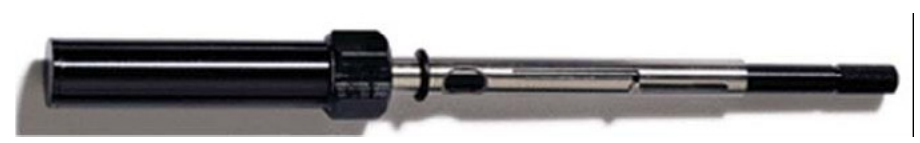

Figura III.5.a.1. Holder de SPME.

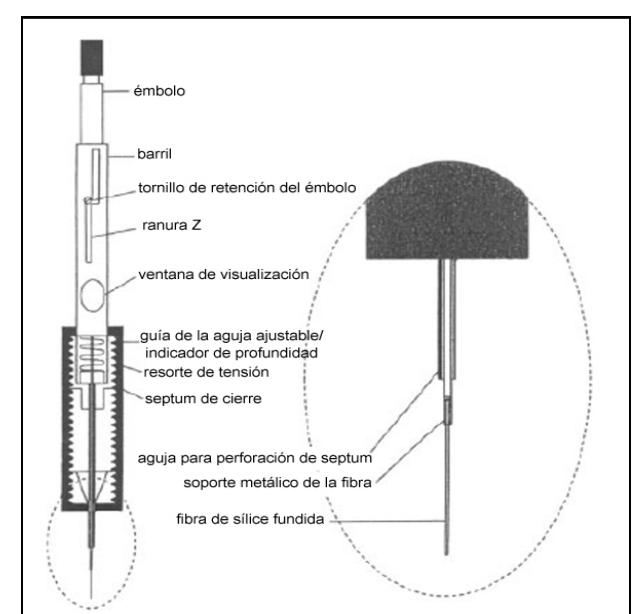

Figura III.5.a.2. Diagrama esquemático del holder y la fibra de SPME.

También está disponible comercialmente un dispositivo de SPME diseñado para realizar análisis de campo que presenta algunas pequeñas diferencias con el 
dispositivo convencional. Esas diferencias están enfocadas básicamente a proteger la fibra durante el transporte desde el lugar de muestreo al laboratorio.

Las fibras están protegidas por una aguja metálica que permite introducirlas a través de los septum que sellan los viales o recipientes donde se halla la muestra a analizar y el puerto de inyección de un cromatógrafo de gases, Para ser utilizadas, las fibras deben ser previamente acondicionadas de acuerdo con las recomendaciones del fabricante (Supelco, Bellefonte, PA, USA). La polaridad de las fibras depende del material de recubrimiento empleado, y pueden extraer diferentes tipos de moléculas, volátiles o no volátiles, a partir de diferentes medios, en fase líquida o gaseosa (Tabla III.5.a).

Tabla III.5.a. Tipos de recubrimientos de SPME.

\begin{tabular}{lccc}
\hline \multicolumn{1}{c}{ Tipo de recubrimiento } & Polaridad & Compuestos a analizar & Acondicinamiento \\
\hline Polidimetilsiloxano (PDMS) & no polar & volátiles & $0,5 \mathrm{~h}$ a $250^{\circ} \mathrm{C}$ \\
PDMS-divinilbenceno (DVB) & bipolar & volátiles polares & $0,5 \mathrm{~h} \mathrm{a} 250{ }^{\circ} \mathrm{C}$ \\
Carboxeno (CAR)-PDMS & bipolar & gases y volátiles & $1-2 \mathrm{~h} \mathrm{a} 300^{\circ} \mathrm{C}$ \\
DVB-PDMS-CAR & bipolar & olores y sabores & $1 \mathrm{~h} \mathrm{a} 270^{\circ} \mathrm{C}$ \\
Poliacrilato (PA) & polar & semivolátiles polares & $2 \mathrm{~h} \mathrm{a} 300^{\circ} \mathrm{C}$ \\
Carbowax (CW)-DVB & polar & analitos polares & \\
CW-resina templada (TPR) & polar & (alcoholes) & $0,5 \mathrm{~h} \mathrm{a} 220^{\circ} \mathrm{C}$ \\
\hline
\end{tabular}

El principio en el que se basa la SPME es la partición de los analitos entre la matriz de la muestra y el recubrimiento de fibra. Así, el transporte de los analitos desde la matriz de la muestra hasta la fibra comienza cuando la fibra entra en contacto con la muestra y la extracción se considera completa cuando la concentración de analito ha alcanzado el equilibrio de distribución entre la muestra y la fibra. Los analitos extraídos pueden analizarse posteriormente por cromatografía gaseosa (GC) y espectrometría de masa (MS) (Figura III.5.a.3).

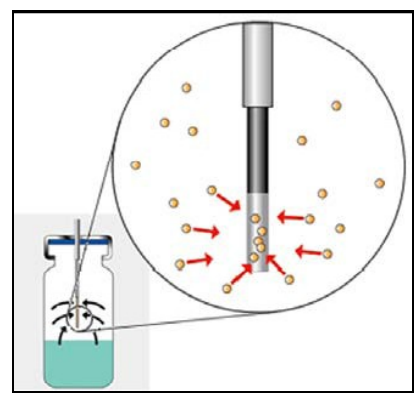

Fig.III.5.a.3. Las moléculas son extraídas por la fibra de SPME. 
El procedimiento de extracción de VOC implica sellar o tapar en forma hermética el vial o recipiente donde se encuentra la muestra, dicho sello o tapa debe poseer un septum a través del cual se introduce la aguja. Los VOC son liberados por la muestra y se acumulan en el espacio libre del vial o recipiente, este espacio se denomina espacio de cabeza. Una vez traspasado el septum con la aguja, se baja la fibra de SPME para que entre en contacto con los VOC que serán captados por el absorbente (Fig.III.5.a.4). La cantidad de moléculas extraídas por la fibra es proporcional a su concentración en la muestra, esto depende de que se alcance el equilibrio termodinámico.

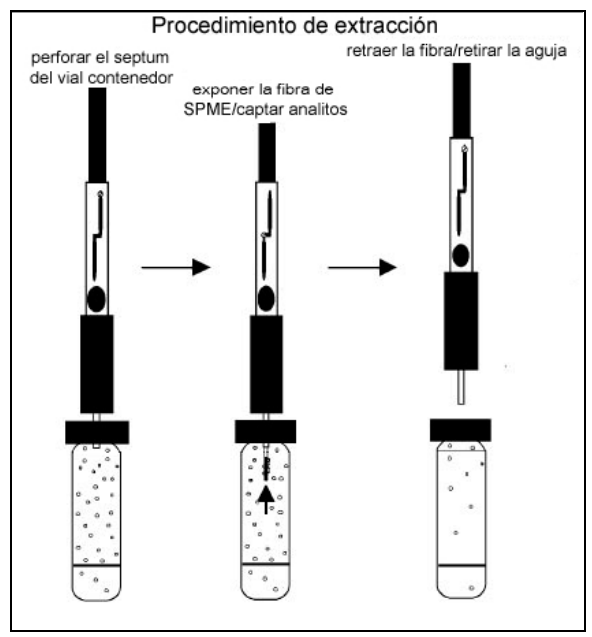

Fig. III.5.a.4. Proceso de adsorción.

El segundo paso es la desorción de los compuestos extraídos en el paso previo para su posterior análisis. Luego de la extracción, la fibra de SPME es transferida al puerto de inyección del cromatógrafo gaseoso (CG), donde la desorción de las moléculas tiene lugar (Figura III.5.a.5).

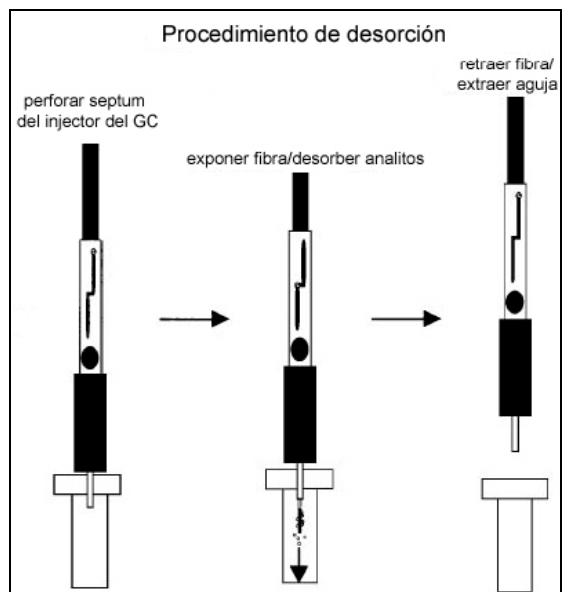

Fig. III.5.a.5. Proceso de desorción de VOC. 


\section{III.5.b. Análisis cualitativo mediante SPME-CGC acoplada a espectrometría de masa (MS)}

El análisis cualitativo hace referencia a la determinación de la identidad química de los compuestos contenidos en una muestra; el método más difundido es la CGC acoplada a MS (CGC-MS). La identificación se realizó por interpretación de sus espectros de fragmentación (ver inciso III.4.d) y/o por comparación con la biblioteca de MS.

\section{III.5.b.1. Tribolium castaneum}

Los insectos adultos fueron despolvados suavemente para quitar el exceso de harina, la muestra a analizar consistió en colocar cinco insectos/vial de $4 \mathrm{ml}$, con septum para SPME y tapa perforada, y se mantuvieron en los viales en cámara de cría por $24 \mathrm{~h}$. Se realizaron tres mediciones sobre una misma muestra sometida a distintos tratamientos:

1- La muestra a temperatura ambiente.

2- La muestra (1) fue agitada fuertemente durante $30 \mathrm{seg}$ a temperatura ambiente, para estimular la liberación de los VOC y analizada por SPMECGC.

3- Luego del tratamiento (2), la muestra fue calentada a $90{ }^{\circ} \mathrm{C}$ durante $15 \mathrm{~min}$, con fin de estimular la liberación total de los VOC, y analizada nuevamente por SPMECGC.

En todos los tratamientos los VOC fueron colectados durante $15 \mathrm{~min}$, se utilizaron 3 fibras de SPME, fibra polidimetilsiloxano (PDMS) $(100 \mu \mathrm{m})$, fibra PDMS/divinilbenceno (PDMS/DVB) (65 $\mu \mathrm{m})$, y fibra carboxeno/PDMS (CAR/PDMS) $(75 \mu \mathrm{m})$, con distinta capacidad de absorción y polaridad creciente. Las fibras fueron acondicionadas previamente siguiendo las indicaciones del proveedor (Supelco, Bellefonte, PA, USA). Se utilizaron como control viales conteniendo harina libre de contaminación. El tiempo que transcurría entre cada tratamiento era de $2 \mathrm{~h}$ aproximadamente.

El análisis de los VOC liberados se realizó en un cromatógrafo Hewlett Packard 6890 (Fig.III.5.b.1) con detector FID utilizando una columna capilar no polar DB-5 (30 $\mathrm{m}$.; $0,32 \mathrm{~mm}$ y $0,25 \mu \mathrm{m}$ de espesor). El inyector se operó en modo sin deriva a $250{ }^{\circ} \mathrm{C}$, el programa de temperatura del horno fue de $40{ }^{\circ} \mathrm{C}$ durante $3 \mathrm{~min}, 5^{\circ} \mathrm{C} / \mathrm{min}$ hasta 80 ${ }^{\circ} \mathrm{C}, 20^{\circ} \mathrm{C} / \mathrm{min}$ hasta $150{ }^{\circ} \mathrm{C}$ y $30^{\circ} \mathrm{C} / \mathrm{min}$ hasta $250{ }^{\circ} \mathrm{C}$ permaneciendo por 10 min a esa 
temperatura. La temperatura del detector de ionización de llama (FID) se fijó en 280 ${ }^{\circ} \mathrm{C}$.

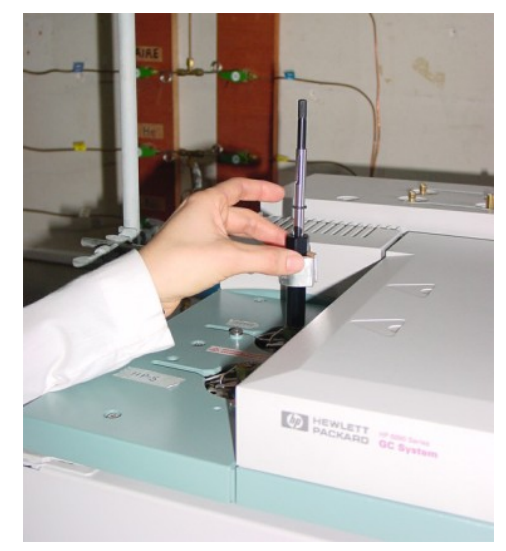

Fig.III.5.b.1. Inyección de la muestra de los VOC de T.castaneum en el CGC.

La identidad de los compuestos se confirmó por SPME-CGC-MS en un equipo Finnigan Polaris Q con trampa iónica (Facultad de Ingeniería, Universidad Nacional del Centro, Olavarría), operado en similares condiciones a las descritas para CGC. La identificación se realizó por interpretación de sus espectros de fragmentación y por comparación con la biblioteca de MS (NIST/EPA/NIH, NIST 98).

\section{III.5.b.2. Ulomoides dermestoides}

Los insectos a analizar se separaron por sexos, a diferencia de T. castaneum, $U$. dermestoides presenta mayor tamaño, por lo que se colocaron los insectos individualmente en viales de $4 \mathrm{ml}$ con septum para SPME y tapa perforada (Fig.III.5.b.2). Cada vial fue agitado fuertemente durante $30 \mathrm{seg}$., para permitir la liberación de los compuestos de defensa y ser analizados por SPME-CGC. Como control se emplearon viales con salvado de trigo y maní. En base a los resultados anteriores (III.5.b.1), se utilizó la fibra bipolar de PDMS/DVB (65 $\mu \mathrm{m})$, Los VOC fueron colectados durante $15 \mathrm{~min}$.

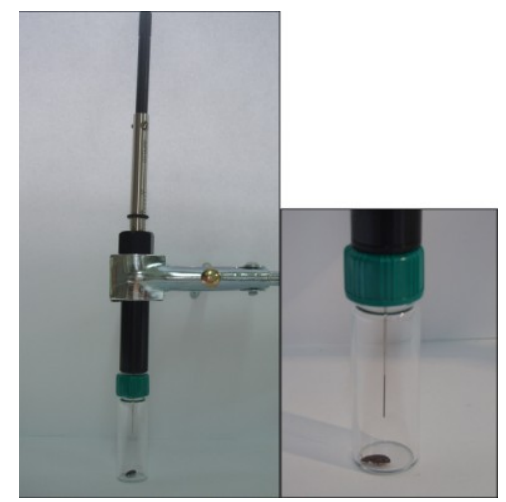

Fig.III.5.b.2. Toma de muestra de VOC de U. dermestoides mediante técnica HS-SPME. 
La identificación de los VOC se realizó empleando un detector selectivo de masa (MSD) HP 5975C VL Agilent acoplado al CGC. EI MSD se operó en el modo de impacto electrónico a $70 \mathrm{eV}$, con la línea de transferencia a $300{ }^{\circ} \mathrm{C}$, la cámara de ionización a $230{ }^{\circ} \mathrm{C}$, y el cuadrupolo a $150{ }^{\circ} \mathrm{C}$. Los VOC fueron identificados por la interpretación del espectro de fragmentación de masa; por comparación con los datos de las bibliotecas de espectros de MS (NIST/EPA/NIH, 2005), y sus índices de retención de Kovats $(\mathrm{KI})$.

\section{III.5.c. Análisis cuantitativo mediante SPME- CGC}

La cuantificación de un compuesto mediante CGC se basa en que el área de los picos registrados en el cromatograma es proporcional a la masa del compuesto inyectado; de esta manera, el procedimiento general de un análisis cuantitativo por CGC involucra la obtención del cromatograma de la muestra, la medida del área de los picos de interés y el cálculo de la masa correspondiente a cada uno de los picos. Este cálculo se hace empleando una curva de calibración basada en la inyección de un estándar de concentración conocida. El cálculo posterior del área obtenida a partir del estándar permite correlacionar valores de área con valores de masa.

\section{III.5.c.1. Tribolium castaneum}

Para calcular las cantidades de VOC colectados de los insectos durante 15 min a temperatura ambiente, se emplearon cantidades conocidas de 1-pentadeceno ( $n$ C15:1) y de 1,4-benzoquinona (BQ) sintéticos. El $n$-C15:1 fue disuelto en $1 \mu \mathrm{l}$ de hexano y la $B Q$ en $1 \mu \mathrm{l}$ de diclorometano (DCM) dentro de viales de SPME, la muestra fue analizada en un cromatógrafo Hewlett Packard 6890 como se describió anteriormente utilizando la fibra CAR/PDMS, y se trazó una curva de calibración con el n-C15:1 y BQ sintéticos.

Para efectuar la curva de calibración a $90{ }^{\circ} \mathrm{C}$, se emplearon réplicas de diferentes concentraciones conocidas de BQ y de $n$-C15:1 sintético ( $1 \mu$ l de cada uno) en viales de SPME, y los compuestos volatilizados se recogieron con la fibra CAR/PDMS a $90{ }^{\circ} \mathrm{C}$ durante $15 \mathrm{~min}$ con el fin de simular las condiciones fijadas (tratamiento 3, inciso III.5.b.1) de extracción de los VOC liberados por los insectos. 


\section{III.5.c.2. Ulomoides dermestoides}

El análisis se realizó en un cromatógrafo Hewlett Packard 6890, en las mismas condiciones empleadas para $T$. castaneum. Las cuantificación de los VOC liberados por los insectos durante 15 min se calculó a partir de los datos de la curva de calibración descripta en el inciso III.5.c.1. Cada muestra fue analizada como se describió anteriormente utilizando la fibra CAR/PDMS.

\section{III.5.d.Análisis de las secreciones volátiles por extracción con solventes de $U$. dermestoides}

Para cuantificar el contenido total de VOC, liberados por los adultos de $U$. dermestoides, se emplearon cinco insectos adultos que fueron sumergidos en $300 \mu \mathrm{l}$ de $\mathrm{DCM}$, por $15 \mathrm{~min}$ o $48 \mathrm{~h}$. Los extractos fueron trasvasados a otro vial, se concentraron bajo atmósfera de $\mathrm{N}_{2}$, y se analizaron por CGC. El inyector se operó en el modo sin deriva a $290{ }^{\circ} \mathrm{C}$, la temperatura del horno fue de $40{ }^{\circ} \mathrm{C}$ durante $3 \mathrm{~min}, 5$ ${ }^{\circ} \mathrm{C} / \mathrm{min}$ hasta $150{ }^{\circ} \mathrm{C}, 20{ }^{\circ} \mathrm{C} / \mathrm{min}$ hasta $250{ }^{\circ} \mathrm{C}$ y $30{ }^{\circ} \mathrm{C} / \mathrm{min}$ hasta $310{ }^{\circ} \mathrm{C}$, permaneciendo por $15 \mathrm{~min}$ a esa temperatura. La temperatura del detector de ionización de llama (FID) se fijó en $310^{\circ} \mathrm{C}$. La cuantificación se realizó por comparación con curvas de calibración construidas por la inyección de cantidades conocidas de $n$-C15:1 y BQ sintético.

\section{III.6. Metabolismo de lípidos en insectos plaga de granos almacenados}

La metodología más aceptada para el estudio del metabolismo lipídico en general, es emplear trazadores radiactivos (marcadores), es decir moléculas con igual o similar estructura que el precursor putativo, que contiene isótopos marcados, por lo general, $-{ }^{13} \mathrm{C},{ }^{2} \mathrm{H},{ }^{3} \mathrm{H}-,{ }^{14} \mathrm{C}-,{ }^{32} \mathrm{P}$ o con la marcación en posiciones específicas que ayudan a seguir las rutas biosintéticas, tanto in vivo como in vitro. El análisis más simple para el estudio de los lípidos cuticulares de insecto es mediante el estudio in vivo, inyectando o incorporando al alimento un precursor apropiado de ácido graso (es decir, acetato marcado) a un cierto número de insectos de la especie en estudio, siguiendo el transporte de los lípidos marcados en la cutícula a intervalos de tiempo seleccionados. Luego, utilizando un solvente de extracción, los lípidos pueden ser lavados de la superficie epicuticular (o los del conjunto del tegumento por una disección previa), seguido de la concentración, fraccionamiento y análisis, para obtener así la información sobre la cantidad total y las clases de lípidos formados. Generalmente se emplean diversos tipos de detectores de radiactividad y métodos, 
como el recuento de líquido de centelleo, el cual es una mezcla que contiene solvente, emulsificador y flúor, dicha mezcla sirve para convertir la energía de la partícula emitida durante el proceso de decaimiento radiactivo $(\beta)$, la cual es detectada por el contador de centelleo, con el que se determina la cantidad total del metabolito producido en las condiciones experimentales del ensayo, o por radiocromatografía de capa fina (Radio-TLC) que permite determinar el tipo de lípidos producido.

Para iniciar el estudio del metabolismo de los lípidos epicuticulares y secreciones volátiles derivadas, en $T$. castaneum y $U$. dermestoides, se emplearon como precursores radiactivos $\left[1-{ }^{14} \mathrm{C}\right]$ acetato $(56 \mathrm{mCi} / \mathrm{mmol})$ y $\left[1-{ }^{14} \mathrm{C}\right]$ palmitato $(57,5$ $\mathrm{mCi} / \mathrm{mmol}$ ) New England Nuclear (Boston, USA).

\section{III.6.a. Biosíntesis de novo de lípidos y secreciones volátiles en $T$. castaneum}

Se realizaron ensayos in vivo en adultos de ambos sexos de $T$. castaneum de 30 días, mantenidos en ayuno por 6 días. En un kitasato (Fig. Ill.6.a) se colocó el alimento previamente delipidizado, con una solución etanólica de $\left[1-{ }^{14} \mathrm{C}\right]$ acetato $\left(8^{*} 10^{6}\right.$ cpm); luego de evaporar completamente el solvente se colocaron cincuenta insectos (hembras y machos por separado). La colección de los compuestos volátiles orgánicos (VOC) emitidos por los insectos se realizó por arrastre con aire comprimido, los VOC fueron colectados en una columna rellena de Porapak $Q$. Los especímenes se mantuvieron en estas condiciones por 10 días. Se realizaron cuatro repeticiones del tratamiento.

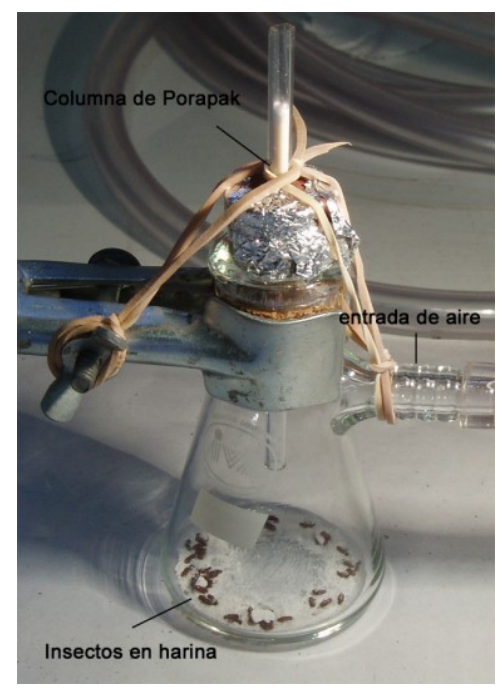

Fig. III.6.a. Adultos de T. castaneum alimentándose con harina marcada con $\left[1-{ }^{14} \mathrm{C}\right]$ acetato. 


\section{III.6.a.1. Extracción de los lípidos epicuticulares, totales y secreciones volátiles}

Los lípidos epicuticulares se extrajeron mediante la inmersión de los insectos en $n$-hexano ( 3 lavados de 5 min cada uno), el procedimiento se repitió dos veces. Los extractos lipídicos se concentraron bajo atmosfera de $\mathrm{N}_{2}$ (Juárez y col., 2001).

Los lípidos neutros totales (provenientes principalmente de cuerpo graso, hemolinfa e integumento) se extrajeron por inmersión de los insectos durante $48 \mathrm{~h}$ en $n$-hexano destilado. Los extractos lipídicos se concentraron bajo atmósfera de $\mathrm{N}_{2}$. Los hidrocarburos se purificaron por fraccionamiento del extracto lipídico total en una minicolumna de Supelcosil A (Supelco, Bellefonte, USA) de 2,5 cm $\times 0,5 \mathrm{~cm}$, eluyendo con $n$-hexano (6 ml/mg de lípido), y luego se concentraron bajo atmósfera de $\mathrm{N}_{2}$.

Por otra parte, los VOC retenidos en la columna de Porapak $Q$, fueron eluidos con $2 \mathrm{ml}$ de DCM, y concentrados bajo atmósfera de $\mathrm{N}_{2}$

\section{III.6.a.2. Análisis de los lípidos epicuticulares, totales y secreciones volátiles por radio cromatografía en capa fina (radio-TLC)}

Se determinó la radiactividad incorporada en cada una de las fracciones (lípidos epicuticulares e internos y secreciones volátiles) utilizando un contador de centelleo líquido (CCL) Beckman LS 1701. Alícuotas de $200 \mu \mathrm{l}$ de las muestras a analizar, se colocaron en viales descartables de material plástico con $3 \mathrm{ml}$ de líquido de centelleo. La distribución de la radiactividad se analizó en placas de sílica gel Polygram Sil G/UV ${ }_{254}$ de $4 \times 8 \mathrm{~cm}$ y 20 × $20 \mathrm{~cm}$ (Macherey-Nagel, Düren, Alemania), utilizando dos sistemas de desarrollo: primero n-hexano (100\%) y luego n-hexano:éter etílico:ácido acético $(80: 20: 1 \mathrm{v} / \mathrm{v})$. Los lípidos se identificaron por comparación con estándares sembrados en forma simultánea en la misma placa. El análisis de los hidrocarburos se realizó mediante placas de silica previamente impregnadas en $\mathrm{AgNO}_{3}$ (20\% acetonitrilo) y desarrolladas en hexano:éter etílico (95:5). El análisis de las secreciones volátiles se realizó en placas de silica gel utilizando primero n-hexano $(100 \%)$ y luego n-hexano:éter etílico:ácido acético (80:20:1v/v). La visualización y cuantificación de radiactividad incorporada luego del desarrollo cromatográfico, se realizó empleando un escaner óptico, Storm 840 (Amersham), este equipo genera imágenes digitales de muestras radiactivas. Las placas de TLC fueron expuestas durante un tiempo determinado dentro de un cassette de exposición a una pantalla de almacenamiento (Storage Phosphor), que colecta las imágenes de las muestras radiactivas, luego la pantalla fue escaneada y la imagen digital obtenida fue analizada con el programa de análisis de imágenes (ImageQuant TL). Para las zonas detectadas 
con radiactividad, se calculan los $\mathrm{R} f$ (distancia recorrida por el soluto/distancia recorrida por el solvente) correspondientes, y se refirieren a estándares sembrados y desarrollados en similares condiciones.

\section{III.6.b. Inhibición del metabolismo lipídico}

Los ácidos de cadena corta, lineales o ramificados fenilsustituidos actúan como agentes inhibidores de la síntesis de lípidos en otros insectos (Juárez y Napolitano, 2000).

Se estudio el efecto de un fenil derivado del ácido propiónico (PHEP), sobre el metabolismo de lípidos de $T$. castaneum. Este compuesto inhibe la actividad de la ácido graso sintasas (FAS) interrumpiendo la formación de lípidos, (Juárez y Napolitano, 2000). Para este experimento, los insectos fueron separados a partir del estado pupal por sexo bajo lupa y mantenidos individualmente. Luego de la muda, los adultos se colocaron en placas de Petri a $-4{ }^{\circ} \mathrm{C}$ durante $5 \mathrm{~min}$, luego se topicaron con soluciones etanólicas $(1 \mu \mathrm{l})$ de dosis subletales de PHEP $(2 \mathrm{mM})$. La topicación fue realizada con jeringa Hamilton de $10 \mu \mathrm{l}$ punta roma, empleando un aplicador automático. Luego, los insectos fueron colocados en un kitasato (cada sexo por separado), alimentados y mantenidos como se explica en la sección III.6.a. Como control se utilizaron machos y hembras topicados con $1 \mu \mathrm{l}$ de etanol. Se realizaron cuatro repeticiones por tratamiento y sexo. Posteriormente se realizó la extracción y análisis de los lípidos epicuticulares, totales y VOC liberados como se describió en la secciones III.6.a.1 y III.6.a.2.

\section{III.6.c. Incorporación de acetato en glándulas abdominales de $U$. dermestoides}

Se realizaron ensayos in vitro en $U$. dermestoides, sus glándulas abdominales son muy pequeñas y se encuentran junto a reservorios glandulares (RG), que se encargan de almacenar la producción glandular. Los insectos se colocaron en placas de Petri, a $-4{ }^{\circ} \mathrm{C}$ durante $5 \mathrm{~min}$. Luego se extrajeron las glándulas abdominales y sus RG (Fig. III.6.c.1). La disección se realizó sumergiendo los insectos en PBS, a $4{ }^{\circ} \mathrm{C}$, luego se incubaron con $\left[1-{ }^{14} \mathrm{C}\right]$ acetato acuoso $\left(2.10^{6} \mathrm{cpm}\right)$, durante $4 \mathrm{~h}$ a $30{ }^{\circ} \mathrm{C}$ las glándulas junto a los RG, y por separado cuerpo y cabeza. Luego se detuvo la incubación agregando al medio $2 \mathrm{ml}$ de hexano y se mantuvo en heladera durante 24 h. A la mezcla obtenida se agregó la quinta parte de agua destilada, la separación de la fase superior orgánica (hexano) de la fase inferior acuosa (agua), se realizó por centrifugación a 2000xg durante $15 \mathrm{~min}$. La fase orgánica se concentró por 
evaporación con un gas inerte $\left(\mathrm{N}_{2}\right)$ y la distribución de la radiactividad se analizó en placas de silica gel, utilizando dos sistemas de desarrollo como se explica en la sección III.6.a.1. Los lípidos se identificaron por comparación con estándares sembrados en forma simultánea en la misma placa. La radiactividad incorporada se evaluó en un escáner Storm 840.

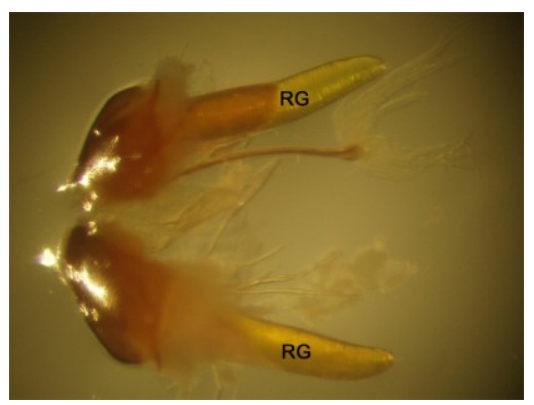

Fig.III.6.c.1. Fotografía de las glándulas y RG de U. dermestoides mantenidos en PBS.

\section{III.6.d.Biosíntesis de lípidos a partir de $\left[1-{ }^{14} \mathrm{C}\right]$ palmitato. Incubación de glándulas de $U$. dermestoides}

Se utilizó como precursor radiactivo $\left[1-{ }^{14} \mathrm{C}\right]$ palmitato $(57.5 \mathrm{mCi} / \mathrm{mmol})$. Dado que éste por su insolubilidad en medios acuosos, no puede ser transportado por la hemolinfa, fue necesario vehiculizarlo ligado a albúmina (Rimoldi y col., 1985).

La obtención de las glándulas y sus RG, se realizó como se explica en el Item III.6.c. Las glándulas y sus $R G$, se incubaron durante $2 \mathrm{~h}$ a $30{ }^{\circ} \mathrm{C}$, con $\left[1-{ }^{14} \mathrm{C}\right]-$ palmitato, buffer fosfato $0.1 \mathrm{M} \mathrm{pH} \mathrm{7,8} \mathrm{y} 2 \mathrm{mM}$ de NADPH. Luego el medio se acidificó con $100 \mu \mathrm{l}$ de ácido sulfúrico $\left(\mathrm{H}_{2} \mathrm{SO}_{4}\right)$ al $50 \%$, el $\left[{ }^{14} \mathrm{C}\right] \mathrm{CO}_{2}$ producido fue capturado por arrastre a través de minicolumnas de PVC en viales de $4 \mathrm{ml}$ que contenían 2,5 $\mathrm{ml}$ de solución acuosa de hidróxido de potasio $\mathrm{K}(\mathrm{OH})$ al 10\%. La determinación de la radiactividad se cuantificó mediante $\mathrm{CCL}$.

\section{III.7. Efecto de inhibidores de ácido graso sintasa (FAS) de insectos}

Para los ensayos se utilizaron adultos de $U$. dermestoides y $T$. castaneum (hembras y machos). Se utilizaron soluciones etanólicas de ácido octanoico (20 mM) y de PHEP (2 mM). Los insectos fueron topicados individualmente en el abdomen con 1 $\mu \mathrm{l}$ de diferentes concentraciones de las respectivas soluciones, como se explica en la sección III.4.b.4. Luego se colocaron machos y hembras de T. castaneum por separado (cinco insectos/vial), y un insecto/vial de $U$. dermestoides, que fueron mantenidos en cámara de cría. Se analizaron los VOC a las 24 h. Como controles se emplearon insectos topicados con $1 \mu \mathrm{l}$ de etanol. 


\section{III.7.a. Análisis de los VOC liberados mediante SPME-CGC}

Cada vial conteniendo los insectos tratados con los inhibidores fue agitado fuertemente durante $30 \mathrm{seg}$, para permitir la liberación de los compuestos de defensa. Los VOC fueron colectados durante $15 \mathrm{~min}$, utilizando la fibra bipolar de CAR/PDMS (75 $\mu \mathrm{m})$, y analizados por SPME-CGC. El análisis de los VOC liberados se realizó en un cromatógrafo Hewlett Packard 6890 con detector FID utilizando una columna capilar no polar DB-5 (30 m; 0,32 mm, 0,25 $\mu \mathrm{m}$ de espesor). El inyector se operó en modo sin deriva a $250{ }^{\circ} \mathrm{C}$, el programa de temperatura del horno fue de $40{ }^{\circ} \mathrm{C}$ durante $1 \mathrm{~min}$, y $20{ }^{\circ} \mathrm{C} / \mathrm{min}$ hasta $250{ }^{\circ} \mathrm{C}$ permaneciendo finalmente por $10 \mathrm{~min}$ a esa temperatura. La temperatura del detector de ionización de llama (FID) se fijó en 280 ${ }^{\circ} \mathrm{C}$.

\section{III.8. Efectos de agentes de control físico y biológico en la supervivencia y ciclo de vida de insectos plaga de granos almacenados}

\section{III.8.a. Bioensayos con agentes naturales}

Se evaluó la capacidad insecticida de tierras de diatomeas (TD), obtenidas de yacimientos locales, mediante bioensayos de mortalidad en $R$. dominica, S. oryzae y $T$. castaneum. Las TDs fueron obtenidas de tres yacimientos ubicados en el área de Ingeniero Jacobacci, provincia de Rio Negro, a $41^{\circ} 18^{\prime}$ de Latitud y $69^{\circ} 35^{\prime}$ de Longitud (La Josefina (LJ), RN 1 y RN 2). Los bloques de TD se redujeron en tamaño hasta 2 $\mathrm{cm}$ y fueron pasados a través de una malla $18(1 \mathrm{~mm})$. Luego se secaron a $110{ }^{\circ} \mathrm{C}$ hasta peso constante. A continuación, las TD se procesaron sobre tamíz malla 325 (43 $\mu \mathrm{m})$, deslizándolas y desmenuzándolas con un pincel de cerdas blandas. Por último se estimó el tamaño de las partículas por microscopía electrónica de barrido (De Giusto comunicación personal). La TD de San Juan es un producto comercial (donado por Agrominera Mercomen Group, S.A.), mientras que la TD Permaguard $\AA$ es una tierra ampliamente utilizada, de origen lacustre (donado por Permaguard $\AA$, USA) y empleada en nuestro país como insecticida natural.

Los bioensayos se realizaron en frascos de vidrio de $250 \mathrm{ml}$ con tapa perforada, se colocaron $20 \mathrm{~g}$ de trigo mezclado con la TD en la proporción a ensayar, luego se incorporaron veinte insectos adultos de cada especie por frasco de sexo desconocido (cinco réplicas por tratamiento); los frascos se mantuvieron a $27 \pm 2{ }^{\circ} \mathrm{C}$ y $40 \%$ de H.R. La mortalidad se evaluó a los 7 y 14 días post-tratamiento. Las aplicaciones se efectuaron mediante la técnica de espolvoreo sobre granos de trigo entero a dos diferentes concentraciones (700 y 1500 ppm). Cada muestra fue agitada 
en forma manual durante $1 \mathrm{~min}$. Las dosis de TD fueron seleccionadas de acuerdo a Korunic (1997). Para la corrección de los resultados de mortalidad obtenidos se empleó la fórmula de Schneider - Orelli, derivada de la fórmula de Abbott (Costa y col., 1974):

$$
\% \text { corregido }=\frac{\% \text { mortalidad en tratados }-\% \text { mortalidad en testigo }}{100-\% \text { mortalidad en testigo }}
$$

\section{III.8.b. Bioensayos con hongos entomopatógenos}

Se estudió el efecto en el ciclo de desarrollo de $T$. castaneum y $U$. dermestoides por infección con un hongo entomopatógeno (Beauveria bassiana). Se utilizó la cepa Bb GHA, obtenida de Laverman International (Butte, MT, USA). Los insectos se separaron por sexo en el estado de pupa y 15 días después de la muda, los adultos de sexo conocido se trataron por inmersión durante 6 seg en una suspensión de $1 \times 10^{9}$ conidios $/ \mathrm{ml}$, conteniendo $0,01 \%$ de Tween 80 en agua estéril (Pedrini y col., 2010). Luego ocho machos y ocho hembras de cada especie, fueron colocados en un frasco de $250 \mathrm{ml}$ con $5 \mathrm{~g}$ de la dieta correspondiente ( $T$. castaneum fue alimentado con harina de trigo y $U$. dermestoides con pan de salvado y maní). Para quitar el exceso de humedad después del tratamiento, fueron colocados en los frascos un día después. A los 15 días, se contaron y se retiraron los adultos vivos y muertos (P1). El conteo de la descendencia (pupas y adultos) se realizó cada 4 días durante 3 meses. Se realizaron seis repeticiones por insecto. Los insectos muertos fueron separados, sumergidos por $1 \mathrm{~min}$. en etanol 95\%, lavados con agua destilada estéril, secados y mantenidos cinco días en cámara húmeda $\left(27 \pm 2{ }^{\circ} \mathrm{C}\right)$. Se registraron como infectados los insectos que mostraron crecimiento hifal característico de hongos entomopatógenos. Los controles fueron insectos tratados de forma similar con agua destilada conteniendo $0,01 \%$ de Tween 80 . 


\section{IV.1. Análisis de lípidos de T. castaneum.}

El análisis de los lípidos no polares de larva, pupa y ejemplares adultos de $T$. castaneum, reveló diferencias cualitativas entre los diferentes estadios. Los lípidos fueron extraídos por inmersión en $n$-hexano y analizados mediante la técnica de TLC.

En pupas y adultos no se observaron diferencias en función del sexo. En la Fig.IV.1.a.A se observa tanto la presencia de hidrocarburos $(\mathrm{HC})$, ceras $(\mathrm{W})$, ésteres de colesterol $(E C)$, triacilglicéridos (TG), benzoquinonas $(B Q)$, ácidos grasos libres $(A G)$, alcoholes grasos $(\mathrm{ROH})$, esteroles/colesterol (Col), hidroquinonas $(\mathrm{HQ})$ y lípidos polares (LP).

En larvas se observó que los TG son los compuestos mayoritarios, luego siguen los AG y en menor proporción EC/W; Col y ROH. (Fig.IV.1.a.A). En pupas se observó menor cantidad de lípidos totales respecto a larvas y adultos, presentando EC/W, TG, AG, como compuestos mayoritarios; y menores cantidades de Col, ROH (Fig.IV.1.a.A y B). En los lípidos totales de adultos predominan los TG y AG, siendo más importantes los TG, le siguen en proporción los $\mathrm{HC}$, luego los W/EC y $B Q$. (Fig.IV.1.a.A y B).

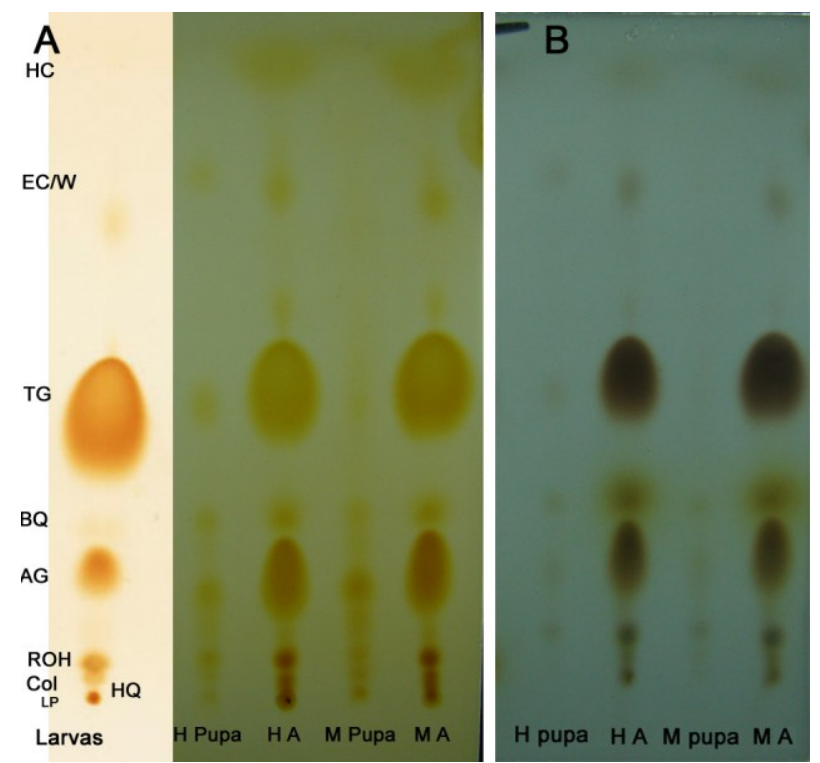

Fig.IV.1.a.A. Cromatografía en capa fina (TLC) de los lípidos totales de larvas, pupas y adultos de T. castaneum. Fig.IV.1.a.B. TLC de los lípidos totales de pupas y adultos de T. castaneum, revelado con $\mathrm{H}_{2} \mathrm{SO}_{4}$ /calor. Los sistemas de desarrollo utilizados fueron primero hexano (100\%) y luego en hexano:éter etílico:ácido acético (80:20:1). H pupa: Hembra pupa, H A: Hembra Adulto, M pupa: Macho pupa, y M A: Macho Adulto. HC: hidrocarburo, EC: ester de colesterol, W: cera, TG: triacilglicéridos, $\mathrm{BQ}$ : benzoquinona, $\mathrm{AG}$ : ácido graso, $\mathrm{ROH}$ : alcohol; Col: colesterol, LP: lípidos polares, $\mathrm{HQ}$ : hidroquinona. Revelado con $\mathrm{I}_{2}$ 
En la Fig.IV.1.a.B los lípidos totales de pupas y adultos fueron revelados por el método de calcinación. La diferencia con el modo de revelado con I 2 (Fig.IV.1.a.A) se basa en que la técnica por $\mathrm{I}_{2}$ tiñe con mayor intensidad a los compuestos que presentan insaturaciones, debido a adición del $I_{2}$ a los dobles enlaces, por consiguiente la intensidad de las manchas no se corresponde necesariamente con la cantidad de cada fracción lipídica. En el caso del revelado por calcinación, la intensidad de las manchas obtenidas está relacionada con el contenido de carbono de la muestra.

Los lípidos epicuticulares de adultos y pupas de $T$. castaneum fueron analizados por TLC (Fig.IV.1.b). En los lípidos de la superficie de la cutícula de la pupa se observa que los $\mathrm{HC}$ son los componentes mayoritarios, también se observan W/EC, $\mathrm{TG}, \mathrm{BQ}, \mathrm{AG}, \mathrm{Col}, \mathrm{ROH}$ e HQ. Los adultos muestran una mayor proporción de HC y un incremento en el resto de los lípidos respecto de lo que se observa en la pupa.

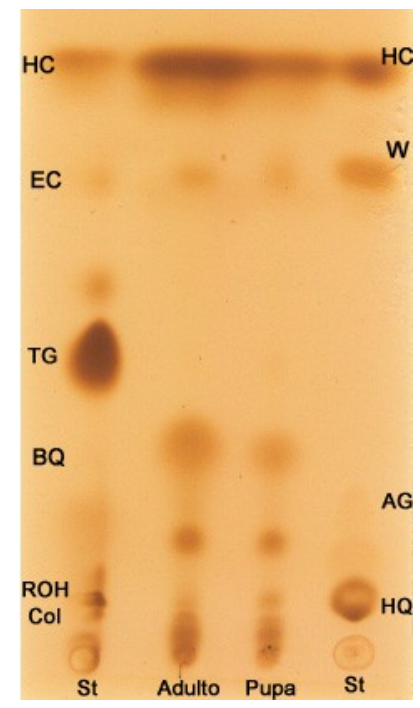

Fig.IV.1.b. Cromatografía en capa fina (TLC) de los lípidos epicuticulares de adultos y pupas de T. castaneum. Los sistemas de desarrollo utilizados fueron primero hexano (100\%) y luego en hexano:éter etílico:ácido acético (80:20:1). HC: hidrocarburo, EC: ésteres de colesterol, W: cera, TG: triacilglicéridos, $\mathrm{BQ}$ : benzoquinona, AG: ácido graso, $\mathrm{ROH}$ : alcohol; Col: colesterol, LP: lípidos polares, $\mathrm{HQ}$ : hidroquinona. St: estándares. Revelado con $\mathrm{I}_{2}$.

Los lípidos epicuticulares de adultos de $T$. castaneum también fueron analizados por TLC, en la Fig.IV.1.c se observa los lípidos extraídos con dos solventes de distinta polaridad, hexano y diclorometano (DCM), el DCM es un solvente algo más polar que el hexano, por lo tanto, contribuye a la extracción de compuestos relativamente más polares (Fig.IV.1.c). Luego de la extracción realizada con los 2 solventes, se realizó la TLC no se observan diferencias cualitativas; con ambos 
solventes los HC representan un porcentaje importante de la composición lipídica de la cutícula, y en menor cantidad benzoquinonas (BQ), ácidos grasos ( $A G)$ e hidroquinonas (HQ). Se observa que el diclorometano (DCM) favorece la extracción de los compuestos más polares como las $\mathrm{HQ}$, y fosfolípidos ( $F L)$.

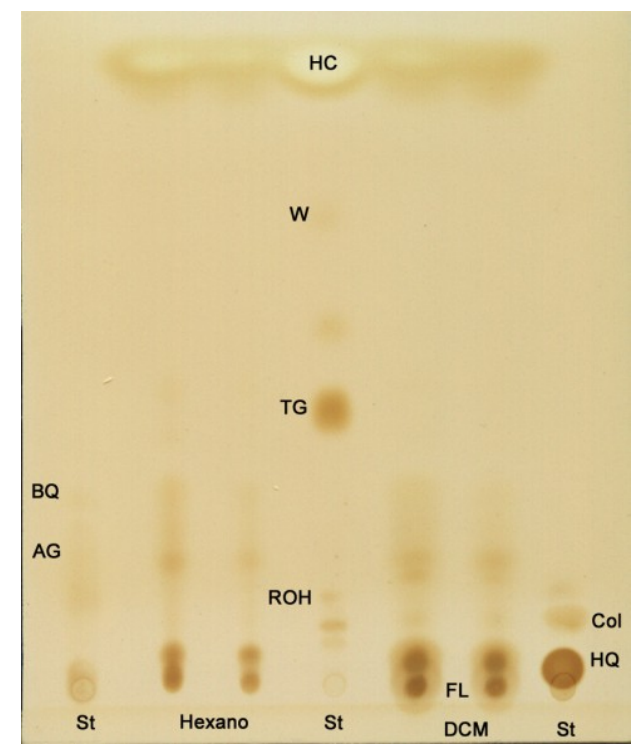

Fig.IV.1.c. Cromatografía en capa fina (TLC) de los lípidos epicuticulares de adultos de $T$. castaneum, utilizando 2 solventes de extracción, $n$-hexano y DCM. Los sistemas de desarrollo utilizados fueron primero hexano (100\%) y luego en hexano:éter etílico:ácido acético (80:20:1). Revelado con $\mathrm{I}_{2}$. $\mathrm{HC}$ : hidrocarburo, W: cera, TG: triacilglicéridos, BQ: benzoquinona, AG: ácido graso, $\mathrm{ROH}$ : alcohol; Col: colesterol, $\mathrm{HQ}$ : hidroquinona, FL: fosfolípidos, St: estándares. DCM: diclorometano. Revelado con $\mathrm{I}_{2}$.

\section{IV.2. Análisis de hidrocarburos de T. castaneum}

La fracción de HC de $T$. castaneum fue analizada por TLC en placas de sílica gel impregnadas con $\mathrm{AgNO}_{3}$ para diferenciar los compuestos saturados de los insaturados. En la Fig.IV.2.a fue posible separar las dos bandas de HC, observándose una mayor abundancia de $\mathrm{HC}$ insaturados (posiblemente el $n$-C15:1) 


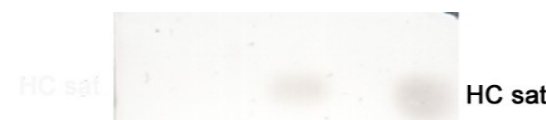

$\mathrm{HC}$ sat

$\mathrm{HC}$ insat

BQ

St:C15:1 Adulto St:C28

Fig.IV.2.a. TLC de los hidrocarburos epicuticulares de adultos de T. castaneum. La placa sílica gel fue impregnada en $\mathrm{AgNO}_{3}(20 \%$ de acetonitrilo), luego desarrollada en hexano. Revelado por calcinación.

Luego de realizada la extracción de los $\mathrm{HC}$, se realizó el análisis de los $\mathrm{HC}$ epicuticulares no volátiles de adultos de $T$. castaneum mediante CGC y CGC-MS mostrando una serie de $n$-alcanos con longitud de cadena entre los 23 y 33 carbonos. Analizando el perfil cromatográfico, es posible agrupar los $\mathrm{HC}$ en dos fracciones: la primera, que eluye con tiempos de retención menores a $15 \mathrm{~min}$, corresponde a HC insaturados de entre 13 y 17 átomos de carbono, en su mayoría compuestos volátiles de bajo PM, siendo el 1-pentadeceno ( $n$-C15:1) el compuesto más abundante (KI: 1492, Ion diagnóstico: 210), seguido por cantidades menores de 1,6 pentadecadieno (KI: 1472, Ion diagnóstico: 208), y trazas de 1-trideceno ( $n$-C13:1), 1-tetradeceno ( $n$ C14:1), 1-heptadeceno ( $n$-C17:1), no hay reportes de $\mathrm{HC}$ de bajo PM como componentes estructurales de la cutícula, por lo tanto, estos componentes no se incluyen en la tabla IV.2; mientras que el otro grupo, de mayor PM, incluye una gran variedad de estructuras saturadas y/o ramificadas, con longitudes de 23 a 39 átomos de carbono (Tabla IV.2 y Fig. IV.2.b). Predominaron HC con cadenas lineales de 27 y 29 átomos de carbono, siendo el componente más abundante el heptacosano $(15,60 \pm$ 0,51\%), seguido por el nonacosano (14,91 $\pm 0,82 \%)$ y el HC metil ramificado, 11-,13metil heptacosano $(14,12 \pm 0,81 \%)$. También fueron importantes los $\mathrm{HC}$ ramificados internos 11-,13-,15-metil nonacosano, 5-,11-metil heptacosano y el HC dimetil 3,11; 3,13-dimetil heptacosano.

Tabla IV.2. Composición porcentual de los HC epicuticulares de adultos de T. castaneum 
${ }^{a}$ Los números corresponden a los picos de la figura IV.2.b.

\begin{tabular}{|c|c|c|c|c|}
\hline $\mathrm{Pico}^{\mathrm{a}}$ & Hidrocarburo $^{\mathrm{b}}$ & $\begin{array}{c}\text { Indice de } \\
\text { Kovats } \\
\text { (IK) }\end{array}$ & $\begin{array}{l}\text { Abundancia } \\
(\% \pm D . E)^{c}\end{array}$ & Iones Diagnósticos \\
\hline 1 & $n-\mathrm{C} 23$ & 2300 & $\operatorname{Tr}$ & 324 \\
\hline 2 & $n-\mathrm{C} 24$ & 2400 & $\operatorname{Tr}$ & 338 \\
\hline 3 & $n-\mathrm{C} 25$ & 2500 & $0.62 \pm 0.07$ & 352 \\
\hline 4 & 11-;13-;9-metilC25 & 2535 & $\operatorname{Tr}$ & $\begin{array}{l}\text { 168/169;224/225;196/197;140/141;252/253;3 } \\
51\end{array}$ \\
\hline 5 & 5-metil C25 & 2547 & $\operatorname{Tr}$ & $84 / 85 ; 308 / 309 ; 351$ \\
\hline 6 & 3-metil C25 & 2557 & $\operatorname{Tr}$ & $56 / 57 ; 336 / 337 ; 351$ \\
\hline 7 & $n-\mathrm{C} 26$ & 2600 & $0.36 \pm 0.02$ & 366 \\
\hline 8 & 3,11-; 3,13-dimetilC25 & 2607 & $0.10 \pm 0.01$ & $56 / 57 ; 351 ; 224 / 225 ; 183 ; 196 / 197 ; 211$ \\
\hline 9 & 10-;12-;11-;13-metilC26 & 2634 & $0.98 \pm 0.06$ & $\begin{array}{l}\text { 154/155;252/253;182/183;224/225;168/169;2 } \\
38 / 239 ; 365\end{array}$ \\
\hline 10 & 6-metil C26 & 2643 & $0.13 \pm 0.01$ & $98 / 99 ; 308 / 309$ \\
\hline 11 & 5-metil C26 & 2650 & $0.11 \pm 0.02$ & $84 / 85 ; 322 / 323$ \\
\hline 12 & 4-metil C26 & 2658 & $0.30 \pm 0.01$ & $70 / 71 ; 336 / 337 ; 365$ \\
\hline 13 & 3-metil C26 & 2674 & $0.24 \pm 0.02$ & $56 / 57 ; 351$ \\
\hline 14 & 4,10-; 4,12-dimetilC26 & 2689 & $0.13 \pm 0.01$ & $70 / 71 ; 351 ; 252 / 253 ; 169 ; 224 / 225 ; 197 ; 379$ \\
\hline 15 & $n-\mathrm{C} 27$ & 2700 & $15.60 \pm 0.51$ & 380 \\
\hline 16 & 11-; 13-metilC27 & 2735 & $14.12 \pm 0.81$ & $168 / 169 ; 252 / 253 ; 196 / 197 ; 224 / / 225 ; 379$ \\
\hline 17 & 5-metilC27 & 2750 & $5.38 \pm 0.7$ & $84 / 85 ; 336 / 337 ; 379$ \\
\hline 18 & 3-metilC27 & 2774 & $6.59 \pm 0.6$ & $56 / 57 ; 365 ; 379$ \\
\hline 19 & 5,11-dimetilC27 & 2781 & $3.82 \pm 0.2$ & $84 / 85 ; 351 ; 252 / 253 ; 183 ; 393$ \\
\hline 20 & $n-\mathrm{C} 28$ & 2800 & $6.13 \pm 0.7$ & 394 \\
\hline 21 & 3,11-; 3,13-dimetilC27 & 2805 & $4.61 \pm 0.3$ & $56 / 57 ; 379 ; 252 / 253 ; 183 ; 224 / 225 ; 211$ \\
\hline 22 & 12-;10-;14-;11-;13-metilC28 & 2831 & $4.25 \pm 0.1$ & $\begin{array}{l}\text { 182/183;252/253;154/155;280/281;210/211;2 } \\
24 / 225 ; 393\end{array}$ \\
\hline 23 & 4-metilC28 & 2856 & $2.46 \pm 0.09$ & $70 / 71 ; 365 ; 393$ \\
\hline 24 & 3-metilC28 & 2872 & $0.92 \pm 0.06$ & $56 / 57 ; 379$ \\
\hline 25 & 4,12-; 4,14-; 4,16-dimetilC28 & 2887 & $0.72 \pm 0.11$ & $\begin{array}{l}\text { 70/71;379;252/253;197;224/225;225;196/197 } \\
; 253 ; 407\end{array}$ \\
\hline 26 & $n-C 29$ & 2900 & $14.91 \pm 0.82$ & 408 \\
\hline 27 & 11-;13-;15-metilC29 & 2931 & $6.72 \pm 0.35$ & $\begin{array}{l}\text { 168/169;280/281;196/197;252/253;224/225;4 } \\
07\end{array}$ \\
\hline 28 & 5-metilC29 & 2950 & $0.97 \pm 0.01$ & $84 / 85 ; 364 / 365 ; 407$ \\
\hline 29 & 11,15-dimetilC29 & 2955 & $0.88 \pm 0.04$ & $168 / 169 ; 295 ; 224 / 225 ; 239 ; 421$ \\
\hline 30 & 3-metilC29 & 2975 & $3.90 \pm 0.95$ & $56 / 57 ; 393$ \\
\hline 31 & $n-\mathrm{C} 30$ & 3000 & $0.64 \pm 0.15$ & 422 \\
\hline 32 & 3,11-; 3,13-dimetilC29 & 3005 & $1.23 \pm 0.11$ & $56 / 57 ; 407 ; 280 / 281 ; 183 ; 252 / 253 ; 211$ \\
\hline 33 & 12-;14-;13-;15-;11-metilC30 & 3030 & $0.67 \pm 0.08$ & $182 / 183 ; 280 / 281 ; 210 / 211 ; 252 / 253 ; 421$ \\
\hline 34 & 4-metilC30 & 3057 & $0.17 \pm 0.04$ & $70 / 71 ; 392 / 393 ; 421$ \\
\hline 35 & $n-\mathrm{C} 31$ & 3100 & $1.01 \pm 0.39$ & 436 \\
\hline 36 & 15-;13-;11-metilC31 & 3126 & $0.19 \pm 0.03$ & $\begin{array}{l}224 / 225 ; 252 / 253 ; 196 / 197 ; 284 / 285 ; 168 / 169 ; 308 / 30 \\
9 ; 435\end{array}$ \\
\hline 37 & 3-metil C31 & 3158 & $\operatorname{Tr}$ & $56 / 57 ; 420 / 421 ; 450$ \\
\hline 38 & C32 + 3,11-dimetil C31 & 3205 & $\operatorname{Tr}$ & $450+56 / 57 ; 435 ; 308 / 309 ; 183 ; 464$ \\
\hline 39 & $n-\mathrm{C} 33$ & 3300 & $0.17 \pm 0.01$ & 464 \\
\hline 40 & 9-;11-;13-;15-metil C33 & 3331 & $\operatorname{Tr}$ & $\begin{array}{l}140 / 141 ; 364 / 365 ; 168 / 169 ; 336 / 337 ; 196 / 197 ; 308 / 30 \\
9 ; 224 / 225 ; 280 / 281 ; 478\end{array}$ \\
\hline 41 & 13-;15-metil C38 & $\mathrm{NI}$ & $\operatorname{Tr}$ & $196 / 197 ; 378 / 379 ; 224 / 225,350 / 351 ; 548$ \\
\hline 42 & 11-;13-metil C39 & $\mathrm{NI}$ & $\operatorname{Tr}$ & $196 / 197 ; 392 / 393 ; 1687169 ; 406 / 407 ; 562$ \\
\hline
\end{tabular}


${ }^{\mathrm{b}}$ Los HC se identificaron en base a sus IK y a sus patrones de fragmentación por CGC-MS.

${ }^{c}$ Los valores representan las medias de tres repeticiones de cinco insectos cada uno \pm D.E.

Tr: Trazas. NI: No identificado.

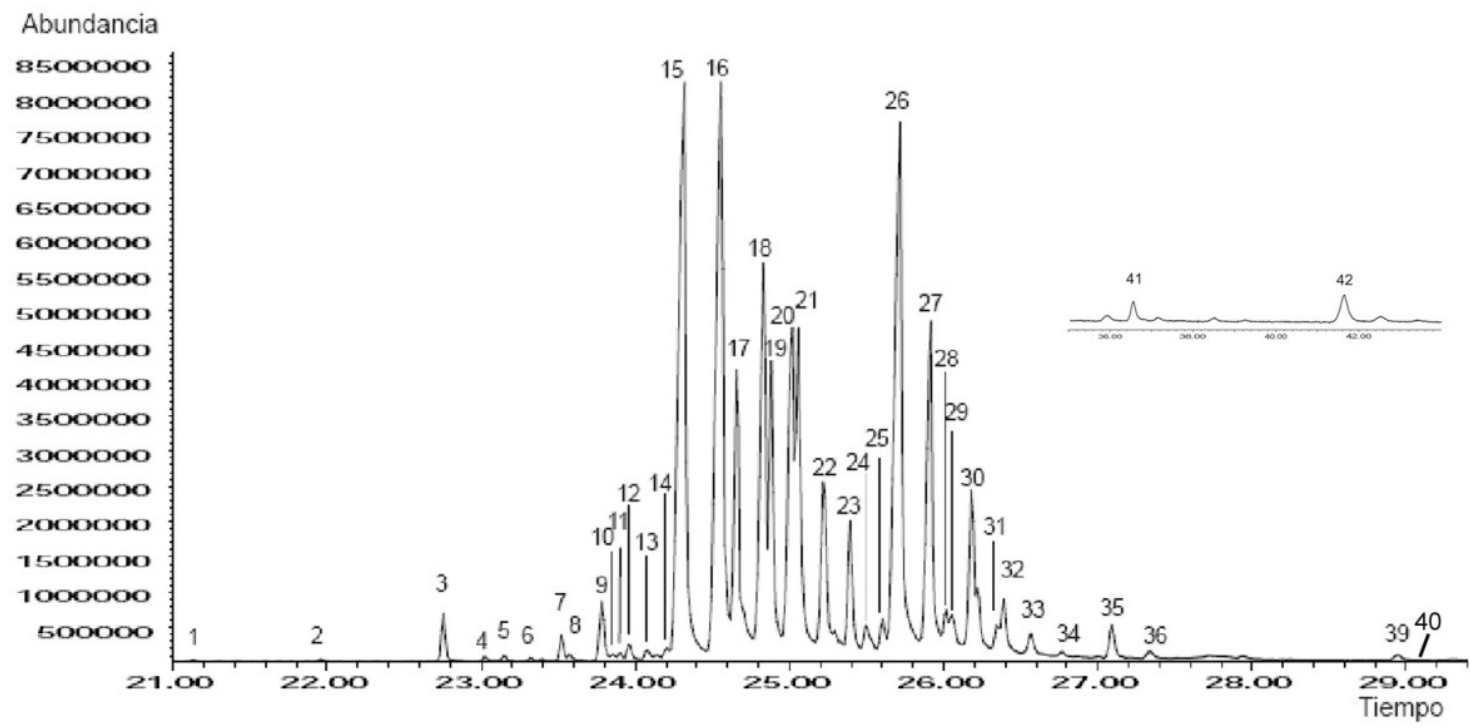

Fig.IV.2.b. Perfil cromatográfico de los HC epicuticulares de T. castaneum.

El análisis de espectrometría de masa (MS), mostró una serie continua de $n$ alcanos de 23 a 33 carbonos, caracterizados por el predominio de cadenas impares sobre todo de 27 y 29 carbonos. En la figura IV.2.c se muestra el espectro del heptacosano ( $n-\mathrm{C} 27)$, compuesto más abundante.

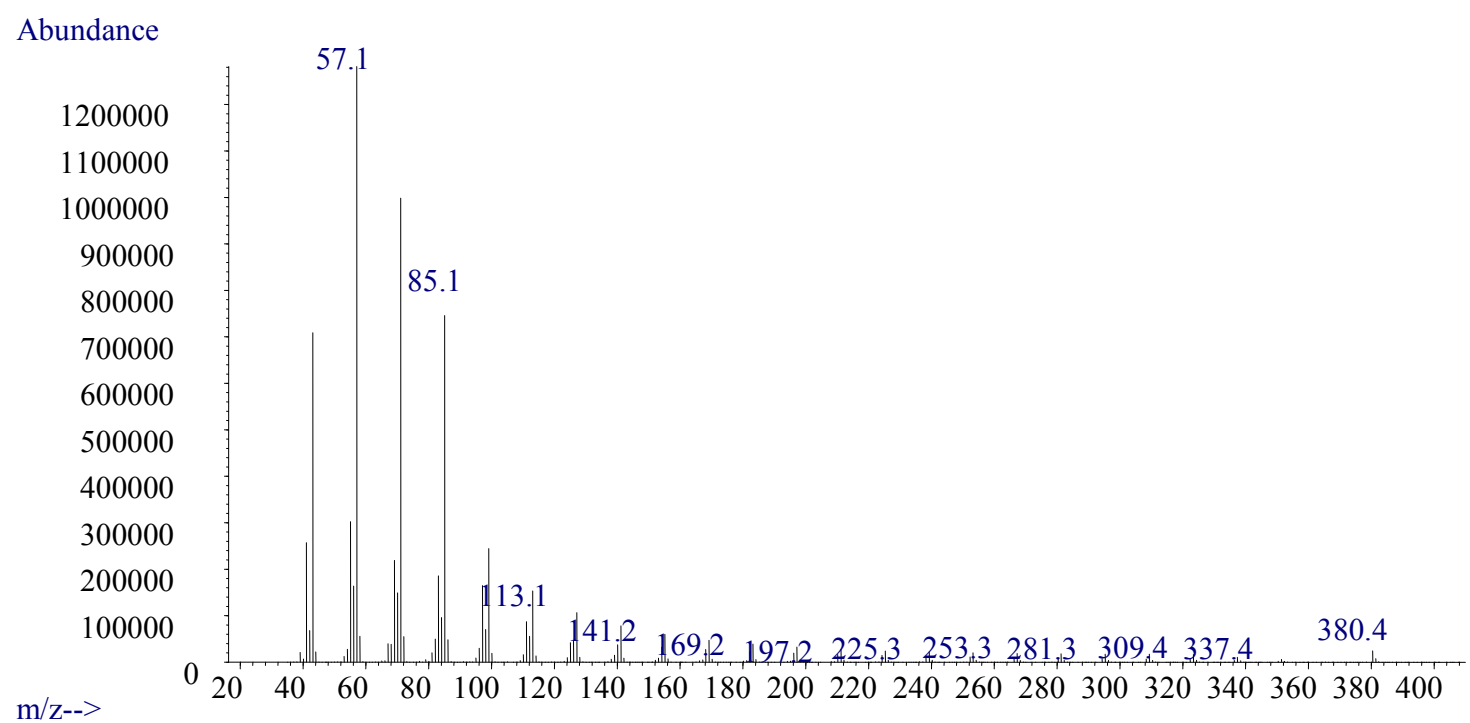

Fig.IV.2.c. Espectro de masa del heptacosano ( $n$-C27) 
En la Fig.IV.2.c, se muestra el espectro del $n$-C27, típico espectro de $\mathrm{HC}$ de cadena lineal, donde la intensidad de los fragmentos disminuye en forma continua, es característico de esa fragmentación la formación de grupos de iones cada catorce unidades de masa, que corresponden al clivaje de las uniones carbono-carbono de la cadena principal. El ion al final de la escala de masas, es el ion molecular $\left(\mathrm{M}^{+}\right)$, que corresponde al hidrocarburo sin fragmentar y mediante el cual es posible determinar su peso molecular, el (M) ${ }^{+}$del $n$-C27 es 380.

La fracción de monometilalcanos, consiste en cadenas principales pares e impares donde las ramificaciones de las cadenas impares se ubican en posición impar, mientras que en las pares se ubica preferencialmente en posición par aunque también impar (p.ej. 5-metil C26, 3-metil C28). Las ramificaciones en posiciones terminales y cercanas a éstas (posiciones 3-6) muestran una abundancia similar a los monometilalcanos internos en cadenas principales de 25 a 29 carbonos, sin embargo en cadenas más largas los monometilalcanos terminales presentan una franca disminución. En las cadenas pares se destacan de manera característica el componente 4-metil en cadenas lineales de 26 a 30 carbonos, también se observan 3metil en cadenas lineales de 26 y 28 carbonos, los isómeros 12-metil como los metilalcanos internos más comunes (en cadenas de 26 a 30 carbonos). En las cadenas impares predominan las ramificaciones terminales 3-metil, 5-metil e internas 11- y 13-metil en cadenas lineales desde 25 a 31 carbonos.

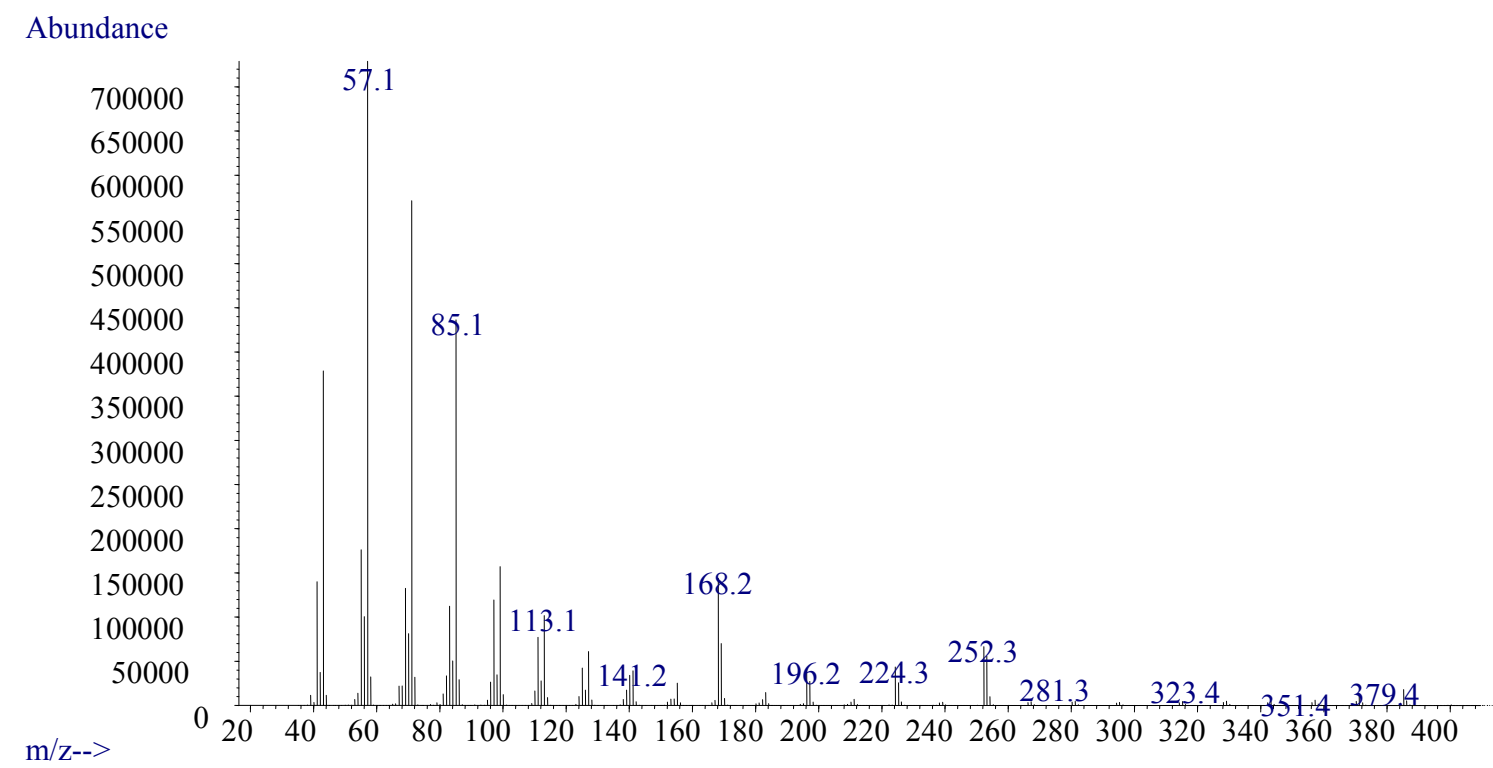

Fig.IV.2.d.Espectro de masa del 11-metil heptacosano 
Fig.IV.2.e. Patrón de fragmentación del 11-metilC27

Las bases de datos disponibles para interpretar los espectros de masa obtenidos, contienen escasos hidrocarburos de la longitud de cadena y de los tipos que se encuentran en insectos (Carlson y col., 1998). No hay disponibles bibliotecas de espectros de $\mathrm{HC}$ ramificados de insectos, y en la mayoría de los casos no es posible visualizar el $\mathrm{M}^{+}$, por lo cual es necesario interpretar cada espectro individualmente. Una medida adicional y de gran utilidad, que provee una aproximación a la estructura del compuesto y que da una identificación tentativa del mismo es el Índice de Kovats (KI) o Índice de Retención (Kovats 1965), el cual da una medida de la cantidad de carbonos en la cadena y contribuye a determinar la identidad del compuesto. En el caso de los hidrocarburos lineales saturados los KIs tienen valores de centenas enteros (ej: $n \mathrm{C} 23=\mathrm{KI} 2300, n \mathrm{C} 29=\mathrm{KI} 2900, n \mathrm{C} 32=\mathrm{KI} 3200$ ). En los monometilalcanos, la presencia de una ramificación metilo en la cadena alquílica suele acortar su tiempo de retención comparado al de una cadena normal con el mismo número de carbonos. La posición de la ramificación determina la magnitud de la reducción, de tal manera que los isómeros con la ramificación en el centro tienen los tiempos de retención más cortos (aproximadamente 70 unidades $\mathrm{KI}$ menos), mientras que a medida que la ramificación se ubica cerca del extremo de la cadena, el valor de $\mathrm{KI}$ se aproxima al del correspondiente $n$-alcano con el mismo número de carbonos (Blomquist y col., 1987; Lockey, 1988; Juárez, 1993; Carlson y col., 1998; Juárez y col.,2001).

En los dimetilalcanos las ramificaciones se ubican comúnmente en posiciones pares o impares dependiendo si la cadena lineal tiene número par o impar de carbonos respectivamente. En cadenas impares son comunes los isómeros 3,X-dimetil en cadenas de 25 a 31 carbonos, con la segunda ramificación en posición interna (3,11-, 3,13-); los dimetilalcanos impares internos consisten generalmente en cadenas con ramificaciones $11, X$ - En cadenas pares son comunes las ramificaciones $12, \mathrm{X}$-, $6, X-$ y $4, X$ en cadenas de 26 y 28 carbonos. 


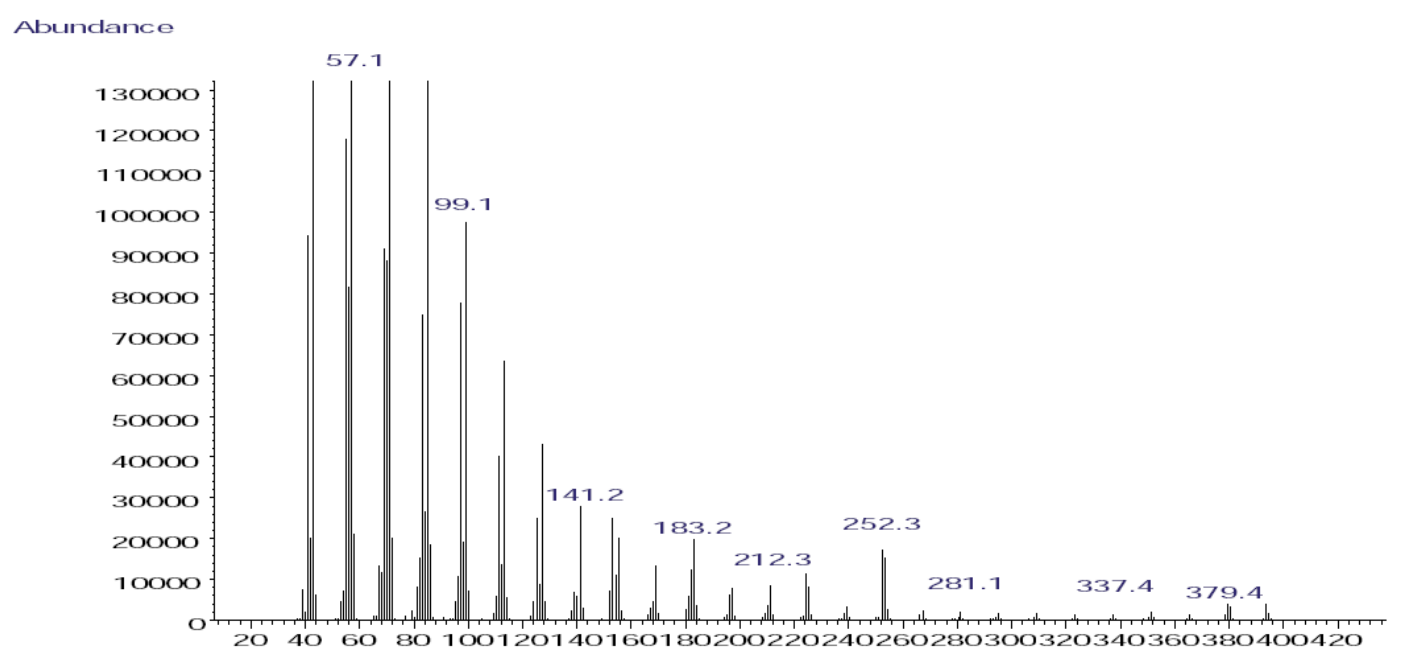

Fig.IV.2.f. Espectro de masa del 3,11-dimetil heptacosano

Fig.IV.2.g. Patrón de fragmentación del isómero 3,11-dimetilC27

En los dimetilalcanos, la presencia de una ramificación metilo extra, aproximadamente duplica el efecto sobre el tiempo de retención por lo que el $\mathrm{KI}$ es entre 90 a 160 unidades menor que el correspondiente al $n$-alcano con el mismo número de carbonos; el menor desplazamiento del $\mathrm{KI}$ se obtiene cuando una de las ramificaciones se encuentra en posición terminal o subterminal de la cadena (ej: $3, X-$ diMe-C33 KI 3403 a 3409, 5,X-diMe-C33 KI 3379 a 3382, 13,X-diMe-C33 KI 3340 a 3362) (Blomquist y col., 1987, Lockey, 1988, Carlson y col., 1998; Juárez y col., 2001). Una identificación confiable de la estructura de los hidrocarburos resulta de la interpretación de los espectros de masa junto con el análisis de los valores de índices de retención y la factibilidad biosintética de las estructuras propuestas (Blomquist y col., 1987).

IV.3. Análisis de compuestos volátiles orgánicos (VOC) emitidos por insectos plaga de granos almacenados

\section{IV.3.a. Tribolium castaneum}


Los adultos de $T$. castaneum poseen glándulas defensivas que secretan metil1,4-benzoquinona (MBQ) y etil-1,4-benzoquinona $(\mathrm{EBQ})$, conocidas comúnmente como benzoquinonas (BQ), liberadas junto con el $\mathrm{HC}$, 1-pentadeceno ( $n$-C15:1). Un adulto de $T$. castaneum puede secretar en el grano o harina hasta aproximadamente 0,5 mg de BQ (Yezerski y col., 2000, 2004). Los insectos pueden colonizar rápidamente granos almacenados y derivados, liberando las secreciones volátiles, modificando las propiedades, otorgándole un olor desagradable y modificando su color (Fig.IV.3.a.1.B)

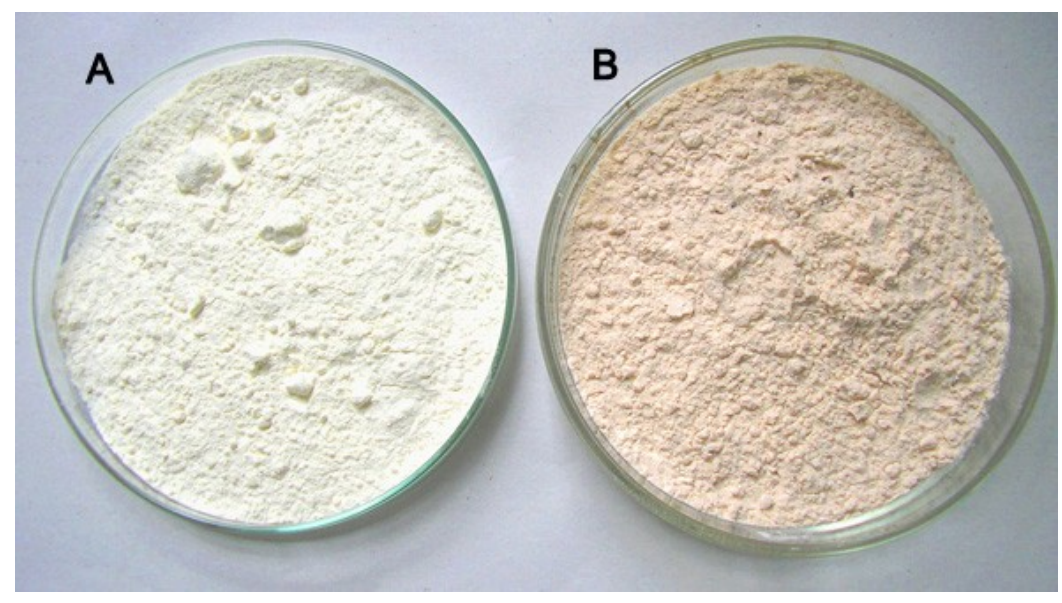

Fig.IV.3.a.1.A: Harina sin contaminar; B: Harina contaminada con los VOC de T. castaneum.

Con el fin de identificar/analizar cuali y cuantitativamente la composición de los VOC, principalmente las $B Q$, liberadas por adultos vivos de T. castaneum, se empleó para la extracción la técnica de SPME-CGC, también se comparó la capacidad de captación de las fibras polidimetilsiloxano/ divinilbenceno (PDMS/DVB), carboxen/polidimetilsiloxano (CAR/PDMS), y polidimetilsiloxano (PDMS) de SPME para los VOC de T. castaneum.

El análisis de los VOC liberados por un grupo de adultos estresados por agitación de $T$. castaneum mediante SPME-CGC-MS mostró la presencia de tres compuestos principales: metil-1,4-benzoquinona (MBQ), etil-1,4-benzoquinona (EBQ) y 1-pentadeceno ( $n-\mathrm{C} 15: 1)$, obteniendo los siguientes iones moleculares $\mathrm{MBQ}\left(\mathrm{M}^{+}\right.$: $122,94,82,66,54,39)$, EBQ $\left(\mathrm{M}^{+}: 136,108,79,54,39\right)$ y $n-\mathrm{C} 15: 1\left(\mathrm{M}^{+}: 210\right)$; estos compuestos representan más del $90 \%$ de la mezcla volátil y son fácilmente detectables con cualquiera de los tres fibras utilizadas (Fig.IV.3.a.2). La fibra CAR/PDMS fue más eficiente en la extracción de compuestos minoritarios, como acetofenona $\left(\mathrm{M}^{+}: 120,105,77,51\right), m$-cresol $\left(\mathrm{M}^{+}: 108,90,77,51\right)$, metilhidroquinona $\left(\mathrm{M}^{+}: 124,95,77,67,65,39\right)$, tetradeceno $\left(\mathrm{M}^{+}: 196\right)$, tetradecano $\left(\mathrm{M}^{+}: 198\right)$, metoxi-1,4- 
benzoquinona $\left(\mathrm{M}^{+}: 138,123,108,95,79,67,65,39\right)$, hidroxi-metilbenzaldehido $\left(\mathrm{M}^{+}\right.$: $175,159,135,105,91,77,65,41,39)$ y pentadecadieno $\left(M^{+}:\right.$208) (Fig. IV.3.a.2.A).
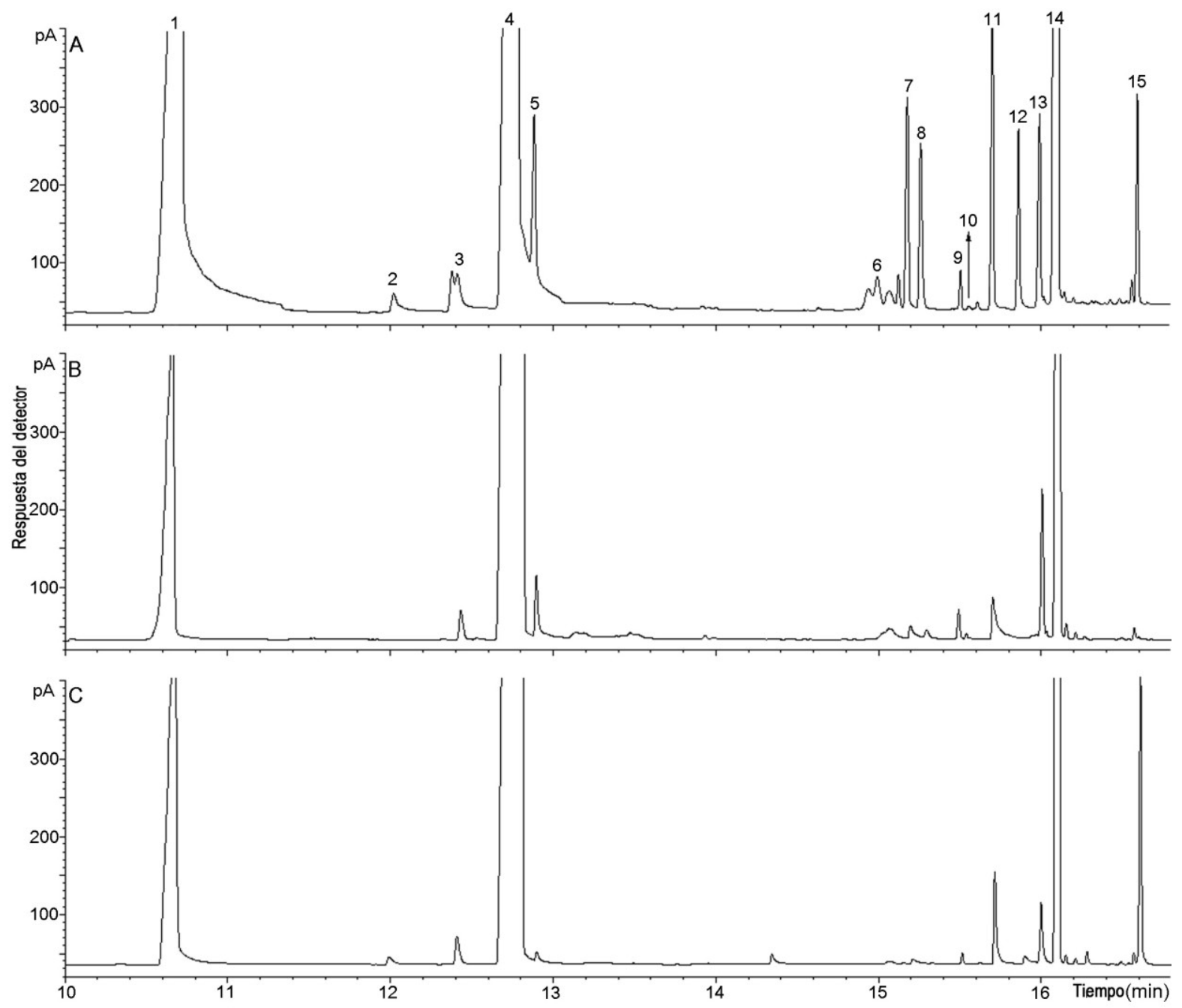

Fig.IV.3.a.2. Perfil cromatográfico de SPME-CGC de los compuestos volátiles (VOC) emitidos por $T$. castaneum captados por 3 diferentes fibras. A: Carboxen/Polidimetilsiloxano (CAR/PDMS). B: PDMS/divinilbenceno (DVB). C: PDMS. Los compuestos mayoritarios fueron identificados por SPME-CGC-MS en las mismas condiciones de SPME-CGC. 1: Metil-1,4 benzoquinona (MBQ), 2: acetofenona, 3: $m$-cresol, 4: etil-1,4 benzoquinona, 5: $\mathrm{NI}$ (no identificado), 6: NI, 7: metilhidroquinona, 8: NI, 9: tetradeceno, 10: tetradecano, 11: metoxi-1,4 benzoquinona, 12: hidroxi-metilbenzaldehido, 13: 1,6-pentadecadieno, 14:1-pentadeceno, 15: NI.

En los insectos sin estresar (tratamiento 1), el único compuesto detectado en pequeñas cantidades fue $n$-C15: 1 (1-4 ng/insecto) Fig. IV.3.a.3.A 


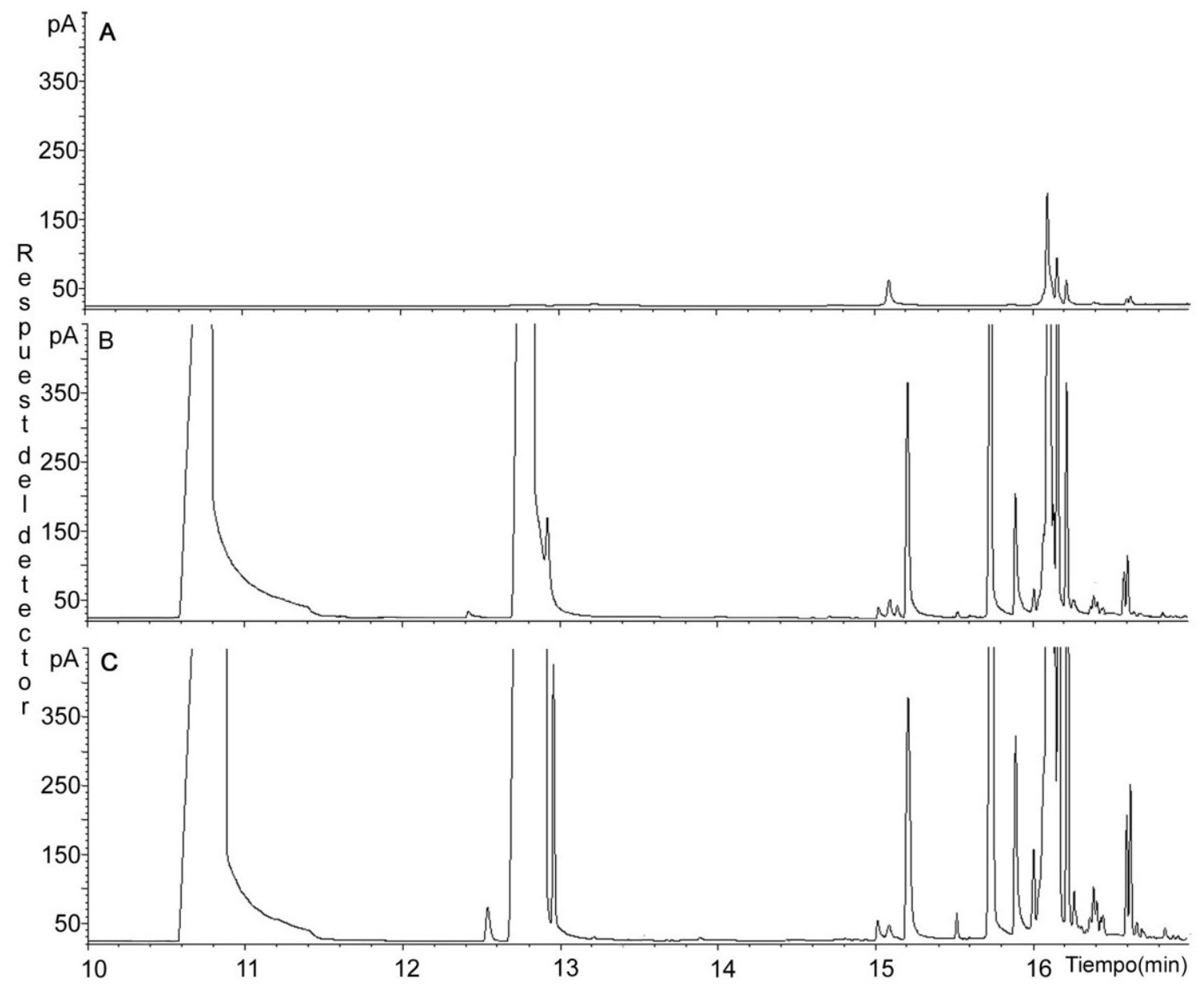

Fig.IV.3.a.3. Perfil cromatográfico de SPME-CGC de T. castaneum, utilizando la fibra CAR/PDMS con los tres tratamientos. A: temperatura ambiente sin estresar, B: agitados fuertemente durante $30 \mathrm{seg}$., C: calentados a $90^{\circ} \mathrm{C}$ durante $15 \mathrm{~min}$.

Se compararon las cantidades relativas obtenidas con las 3 fibras utilizadas, si bien la fibra CAR/PDMS y PDMS/DVB son de polaridad intermedia, y la fibra PDMS es no polar, las 3 fibras son recomendadas para la captación de compuestos volátiles. En los insectos estresados por la agitación, las benzoquinonas $(B Q=M B Q+E B Q)$ representan un $81,5 \pm 7,8 \%$ de las secreciones volátiles adsorbidas con la fibra CAR/PDMS, este porcentaje relativo es significativamente diferente $(P<0,01)$ del obtenido con la fibra PDMS (44,8 $\pm 7,6 \%$ ) (Tabla IV.3.a). Con la fibra PDMS/DVB las $\mathrm{BQ}$ mostraron valores intermedios. Se comparó la relación entre los principales compuestos, la relación BQ: $n$-C15:1 varió entre 4 con CAR/PDMS $(P<0,001)$ y 1 con la fibra PDMS $(P<0,05)$. 
Tabla IV.3.a. Cantidades relativas $(\% \pm$ E.E) de los tres principales VOC detectados por SPMECGC en adultos de $T$. castaneum ${ }^{a}$

\begin{tabular}{ccccc}
\hline & \multicolumn{3}{c}{ Cantidades relativas $(\% \pm \mathrm{E} . \mathrm{E})^{\mathrm{c}}$} \\
\hline Fibras & $N^{\mathrm{b}}$ & $\mathrm{MBQ}$ & $\mathrm{EBQ}$ & $n-\mathrm{C} 15: 1$ \\
\hline CAR/PDMS & 8 & $26,6 \pm 2,7^{\mathrm{a}}$ & $54,9 \pm 5,1^{\mathrm{a}}$ & $18,4 \pm 6,7^{\mathrm{a}}$ \\
PDMS/DVB & 7 & $17,5 \pm 2,1^{\mathrm{b}}$ & $44,2 \pm 5,6^{\mathrm{a}}$ & $38,3 \pm 5,5^{\mathrm{ab}}$ \\
PDMS & 9 & $8,30 \pm 1,7^{\mathrm{c}}$ & $36,5 \pm 5,9^{\mathrm{a}}$ & $54,2 \pm 7,3^{\mathrm{b}}$ \\
\hline
\end{tabular}

${ }^{a}$ Insectos agitados (30 seg.) mantenidos a temperatura ambiente. Los VOC fueron colectados por SPME, durante $15 \mathrm{~min}$.

${ }^{b} N=$ Número de ensayos, con cinco insectos por vial.

${ }^{c}$ Los valores de cada columna seguidos de letras diferentes son significativamente diferentes (ANOVA seguido por Prueba de Tukey, $P<0,05$ )

Comparando los componentes individuales, la cantidad relativa adsorbida de MBQ fue significativamente diferente con las tres fibras $(P<0,05$ y 0,001$)$, con la fibra PDMS se observa la menor afinidad; mientras que las cantidades detectadas de $n$ C15:1 mostraron diferencias significativas entre las fibras CAR/PDMS y PDMS $(P<$ $0,01)$. Las cantidades relativas de EBQ fueron similares con las tres fibras utilizadas.

Con el fin de estimar la cantidad máxima detectable de VOC por este método, los viales que contienen los insectos ya expuesto a las sucesivas extracciones, bajo las condiciones de temperatura ambiente sin estresar y agitados, fueron sometidos a un tratamiento térmico para liberar la mayor cantidad de VOC internos. Las cantidades relativas de VOC liberados con calor no fueron significativamente diferentes de los obtenidos por agitación a temperatura ambiente (datos no mostrados). Sin embargo, la cantidad relativa de $B Q$ total extraída con la fibra CAR/PDMS fue tres veces más que la de $n$-C15:1 $(P<0,001)$; mientras que la fibra de PDMS $(P<0,001)$ detectó relativamente más $n-C 15: 1(71,9 \pm 5,5 \%)$ que BQ. Similares cantidades relativas de BQ y $n-C 15: 1$ fueron detectados con la fibra de PDMS/DVB.

Las cantidades de VOC (ng/insecto) liberadas después del tratamiento de agitación se muestran en la figura IV.3.a.4.A. 

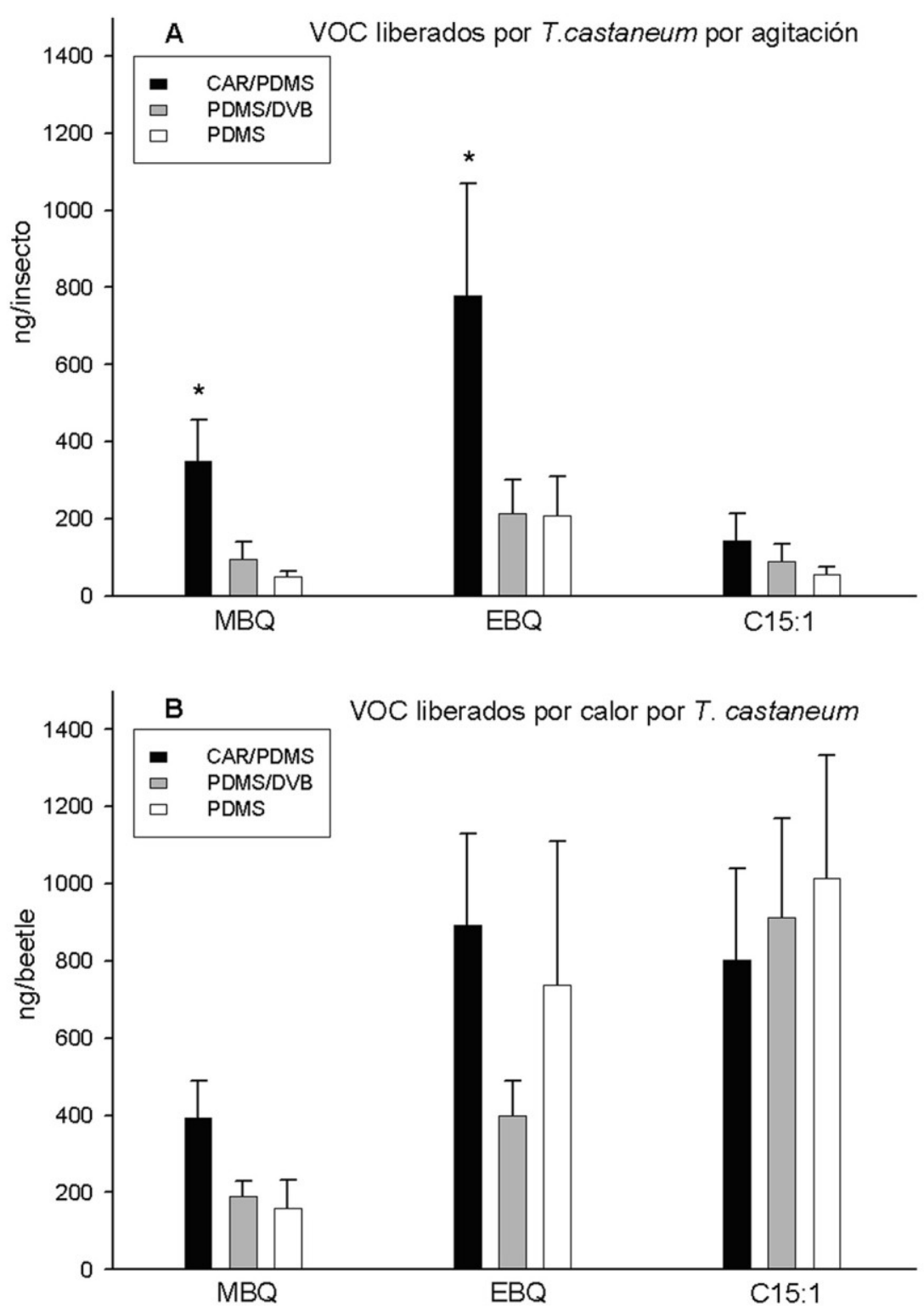

Fig.IV.3.a.4. Cantidades (ng/insecto) de VOC captados por SPME-CGC de T. castaneum. A: las barras representan las medias ( \pm E.E) de los volátiles liberados por agitación. * Los valores de $M B Q$ y $E B Q$ con la fibra CAR/PDMS difieren significativamente con los valores de las fibras PDMS/DVB y PDMS (ANOVA, seguido de Prueba de Tukey, $P<0,05$ ). B: las barras representan los medias $( \pm$ E.E) de los VOC liberados por calor.

La mayor recuperación de los tres principales VOC liberados por agitación, se obtuvo con la fibra CAR/PDMS, con 349,1 \pm 107,5 ng/insecto de MBQ, 779,5 \pm 290,0 ng/insecto para EBQ y 143,8 $\pm 69,9 \mathrm{ng} /$ insecto de $n-C 15: 1$. Las cantidades de MBQ y EBQ captadas con la fibra CAR/PDMS fueron significativamente diferentes de las obtenidas con las restantes fibras $(P<0,05)$, cantidades de $n-C 15: 1$ detectadas no fueron significativamente diferentes con las tres fibras utilizadas. 
Las cantidades de $B Q$ detectadas sin y con tratamiento térmico no fueron significativamente diferentes (Fig.IV.3.a.4.A, B), aunque los valores de $n$-C15: 1 fueron significativamente diferentes $(P<0,05)$.

Las cantidades de los VOC liberados luego del tratamiento por calor con la fibra CAR/PDMS fueron de $393 \pm 96 \mathrm{ng} /$ insecto (MBQ), $893 \pm 238 \mathrm{ng} /$ insecto (EBQ) y $802 \pm$ 235 ng/insecto (n-C15:1) (Fig. IV.3.a.4.B). No se detectaron diferencias significativas entre en las cantidades de los VOC adsorbidos con las tres fibras.

Las cantidades totales promedio de los principales VOC extraídos con la fibra CAR/PDMS después del período de agitación seguido del tratamiento térmico (Fig. IV.3.d.A + B) fueron de $742 \pm 93 \mathrm{ng} /$ insecto de $\mathrm{MBQ}, 1672 \pm 244 \mathrm{ng} / \mathrm{insecto}$ de $\mathrm{EBQ}$ más $946 \pm 237 \mathrm{ng} /$ insecto de $n$-C15:1. Sin embargo, para calcular el total de VOC extraíbles por calor se realizaron sucesivas mediciones de un mismo vial; una sola extracción con calor extrae un $82,7 \pm 1,0 \%$ del total de VOC extraíbles. Por lo tanto, los volátiles totales promedio extraídos por HS-SPME en las condiciones ensayadas fueron estimados por la adición de la cantidad de VOC liberados por agitación más los VOC liberados por calor, resultando $810 \pm 100$ ng/insecto de MBQ,1827 \pm 258 ng/insecto y $1085 \pm 276$ ng/insecto de $n$-C15: 1 .

\section{IV.3.b.Ulomoides dermestoides}

Los principales VOC liberados por los machos y hembras adultos vivos de $U$. dermestoides fueron analizados mediante SPME-CGC-MS en condiciones similares a las descriptas para $T$. castaneum con el tratamiento de agitación, utilizando la fibra bipolar PDMS/DVB y colocando un insecto por vial. El análisis mostró la presencia de cuatro componentes principales: $\mathrm{MBQ}\left(\mathrm{M}^{+}: 122\right)$, EBQ $\left(\mathrm{M}^{+}: 136\right), n-\mathrm{C} 13: 1\left(\mathrm{M}^{+}: 182\right)$ y $n$-C15:1 ( $\mathrm{M}^{+}:$210), que representa más del $90 \%$ de la mezcla de volátiles. Los componentes menores fueron identificados como limoneno (KI: 1036, $\mathrm{M}^{+}$: 136), y 1,6pentadecadieno (C15:2) (KI: 1479, $\mathrm{M}^{+}:$208) (Fig.IV.3.b.1). También se detectaron trazas de hidrocarburos saturados de cadena lineal de 10 (KI: 1000, M +: 142), 12 (KI: 1200, $\left.\mathrm{M}^{+}: 170\right), 14\left(\mathrm{Kl}: 1400, \mathrm{M}^{+}: 198\right), 15\left(\mathrm{Kl}: 1500, \mathrm{M}^{+}:\right.$212) y 16 átomos de carbonos (KI: 1600, $\left.\mathrm{M}^{+}: 226\right)$ (datos no mostrados). 


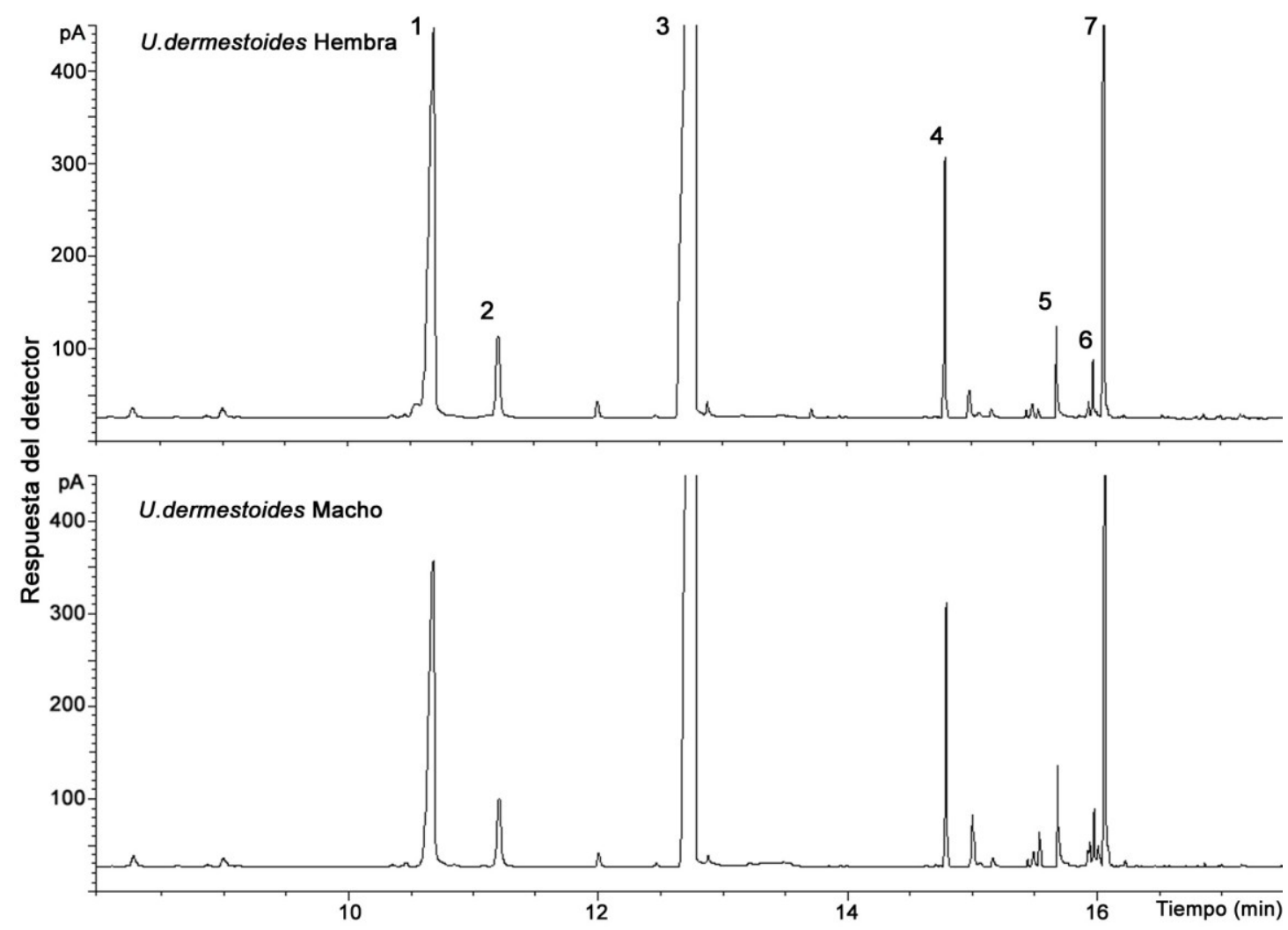

Fig.IV.3.b.1. Perfil cromatográfico de hembra y macho de $U$. dermestoides, mediante SPMECGC utilizando la fibra PDMS/DVB. Los insectos fueron agitados durante 30 segundos. 1: metil-1,4 benzoquinona, 2: limoneno, 3: etil-1,4 benzoquinona, 4: 1-trideceno, 5: NI, 6:1,6 pentadecadieno, 7: 1-pentadeceno.

Tabla IV.3.b. Cantidades relativas $(\% \pm$ E.E) de los cuatro principales VOC detectados por SPME-CGC en hembra y macho adultos de $U$. dermestoides ${ }^{a}$

\begin{tabular}{ccccc}
\hline & & \multicolumn{3}{c}{ Cantidades relativas $(\% \pm \mathrm{E} . \mathrm{E})^{b}$} \\
\hline Sexo & MBQ & EBQ & $n$-C13:1 & $n$-C15:1 \\
\hline hembra & $14,3 \pm 1,1$ & $64,0 \pm 2,8$ & $3,0 \pm 0,5$ & $18,2 \pm 1,9$ \\
macho & $15,7 \pm 1,5$ & $68,5 \pm 2,2$ & $3,3 \pm 0,5$ & $12,1 \pm 1,8$ \\
\hline
\end{tabular}

${ }^{a}$ Insectos agitados (30 seg.) mantenidos a temperatura ambiente. Los VOC fueron colectados por SPME, durante $15 \mathrm{~min}$.

${ }^{b}$ Los valores de cada columna no difieren significativamente (Prueba de Student, $P<0,05$ ). Se realizaron 20 ensayos por cada sexo.

No hubo diferencias significativas en los principales VOC en función del sexo. Al igual que en $T$. castaneum las $B Q$ representan alrededor del $80 \%$ de los VOC liberados cuando los insectos son estresados por agitación. 


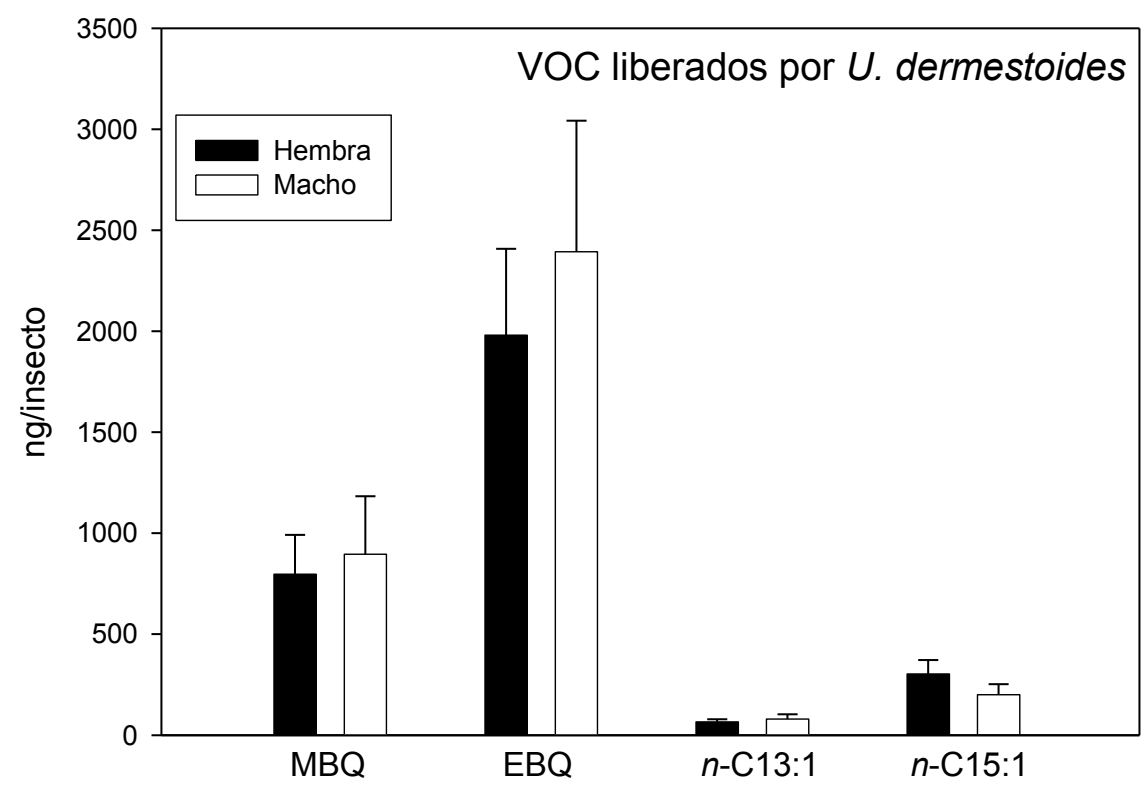

Fig.IV.3.b.2. Cantidades (ng/insecto) de VOC captadas por SPME-CGC de U. dermestoides. Las barras representan las medias de 20 repeticiones $( \pm E$ E.E) de los VOC liberados por agitación.

Las cantidades (ng/insecto) de VOC detectados se muestran en la figura IV.3.b.2. No se observaron diferencias significativas entre los sexos (Prueba de Student, $P<0,05)$. Sin embargo las cantidades de los tres compuestos mayoritarios liberados individualmente por cada adulto de $U$. dermestoides, fue significativamente diferente $(P<0,05)$ de las cantidades estimadas para $T$. castaneum (Fig. IV.3.a.3.A), en iguales condiciones.

IV.3.c. Análisis de las secreciones volátiles por extracción con solventes de $U$. dermestoides

La extracción mediante SPME no da información sobre la cantidad de compuestos producidos por las glándulas, para estimar la cantidad total de VOC se realizó la extracción con solvente, los VOC de $U$. dermestoides fueron extraídos con diclorometano (DCM), en el mismo período de tiempo (15 min, como se realizó por SPME). Estos extractos fueron utilizados por otro grupo de trabajo para realizar ensayos de citotoxicidad en la línea celular tumoral A549 (causante de adenocarcinoma de pulmón). Se establece 1 equivalente $=$ a la extracción de los compuestos de $U$. dermestoides con DCM, durante $15 \mathrm{~min}$ ). En la tabla IV.3.c, se muestra la cantidad de VOC extraídos con DCM, en comparación con los VOC extraídos con la técnica de SPME (Fig.IV.3.c.1), la cantidad de BQ es 
aproximadamente 5 veces mayor, mientras que la cantidad de $n$-C15:1 extraído es 25 veces mayor.

Para estimar la cantidad total (o extracción exhaustiva) de los compuestos, se utilizó un período mayor de tiempo (48 h), mostrando valores significativamente superiores $(P<0,0001)$ que los obtenidos con 15 min de extracción (Tabla IV.3.c).

Tabla.IV.3.c. Cantidades ( $\mu \mathrm{g} / \mathrm{insecto} \pm \mathrm{E}$.E) de las principales secreciones liberadas por adultos de $U$. dermestoides mediante extracción con DCM.

\section{Cantidades $(\mu \mathrm{g} / \mathrm{insecto} \pm \mathrm{E} . \mathrm{E})$}

\begin{tabular}{cccc}
\hline Tiempo & MBQ & EBQ & $n-C 15: 1$ \\
\hline 15 min & $5,6 \pm 2,3 \mathrm{a}$ & $16,6 \pm 6,0 \mathrm{a}$ & $12,5 \pm 1,6 \mathrm{a}$ \\
$48 \mathrm{hs}$ & $13,5 \pm 1,1 \mathrm{~b}$ & $39,5 \pm 0,4 \mathrm{~b}$ & $34,0 \pm 1,5 \mathrm{~b}$ \\
\hline
\end{tabular}

Valores seguidos por la misma letra no difieren estadísticamente entre sí entre cada columna. Prueba de Tukey $(P<0,05) \cdot N=8$

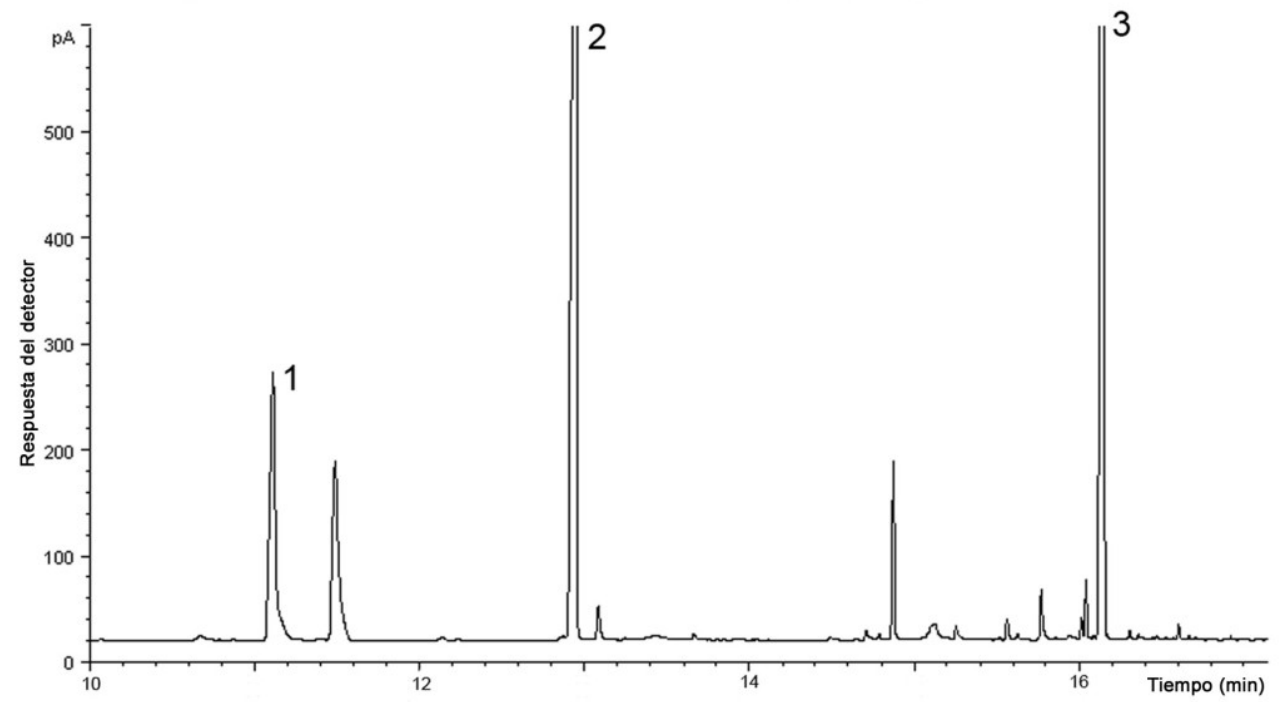

Fig.IV.3.c.1. Perfil cromatográfico de las principales secreciones volátiles de U. dermestoides, utilizando DCM, durante 15 min. 1: MBQ, 2: EBQ, 3: n-C15:1.

\section{IV.4. Biosíntesis de novo de lípidos y secreciones volátiles}

\section{IV.4.a. Tribolium castaneum}

Se iniciaron estudios de la biosíntesis de lípidos en insecto entero a partir de [1-

${ }^{14} \mathrm{C}$ ] acetato. Se emplearon hembras y machos adultos de 30 días de $T$. castaneum, 
alimentados con harina conteniendo $\left[1-{ }^{14} \mathrm{C}\right]$ acetato durante 10 días. Al finalizar ese período, se extrajeron los lípidos epicuticulares, los VOC y los lípidos internos.

En la tabla IV.4.a.1 se muestra la distribución de la radiactividad en las distintas clases de lípidos de los adultos de $T$. castaneum; en los lípidos internos la marcación radiactiva se incorporó principalmente en los TG $(72,4 \pm 4,0 \%)$, seguido de HC, AGL y lípidos polares. Los lípidos sintetizados y transportados a la superficie epicuticular se concentran principalmente en la fracción de $\mathrm{HC}(>80 \%)$, encontrándose el resto de la marcación en TG, AGL y en el punto de siembra, siguiendo un patrón similar a la composición lipídica. En la fracción de VOC la marcación radiactiva se distribuyó en $\mathrm{HC}$ (principalmente $n$-C15:1) y BQ. La incorporación total de radiactividad fue de $3 \%$ en los lípidos internos, $0,38 \%$ en epicuticulares y $0,2 \%$ en VOC (Tabla IV.4.a.2)

Tabla IV.4.a.1. Incorporación de la radiactividad (\% \pm E.E) en las distintas clases de lípidos en T. castaneum ${ }^{a}$.

\begin{tabular}{cccc}
\hline Lípidos & VOC & Epicuticulares & Internos \\
\hline HC & $48,3 \pm 2,0$ & $80,6 \pm 1,3$ & $10,5 \pm 2,9$ \\
TG & ND & $6,2 \pm 1,1$ & $72,4 \pm 4,0$ \\
BQ & $47,7 \pm 3,6$ & trazas & ND \\
AGL & ND & trazas & $10,1 \pm 1,2$ \\
L Polares & ND & trazas & $6,6 \pm 0,9$
\end{tabular}

${ }^{a}$ Los insectos fueron alimentados durante 10 días con $\left[1-{ }^{14} \mathrm{C}\right]$ acetato. Los valores representan la media $\pm \mathrm{E}$.E de 4 repeticiones. $\mathrm{HC}$ : hidrocarburos, TG: triglicéridos, $\mathrm{BQ}$ : benzoquinonas, AGL: ácidos grasos, LP: lípidos polares ND: No detectable

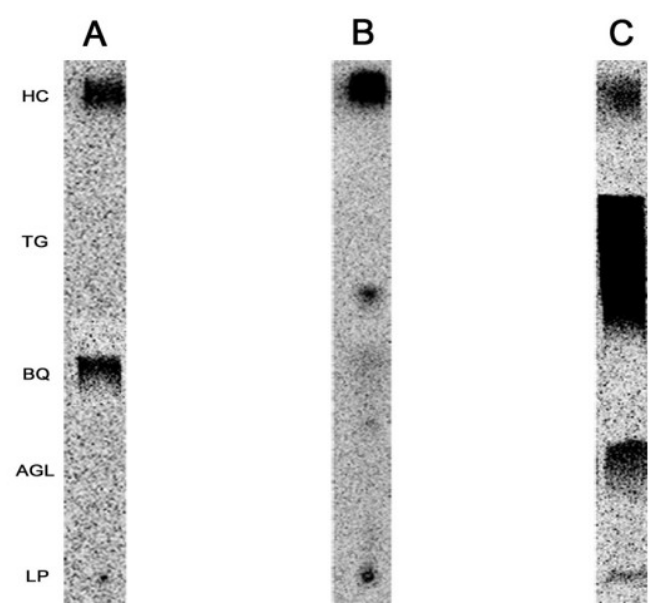

Fig. IV.4.a.1. Radio-TLC de las distintas clases lipídicas en T. castaneum. A: VOC, B: Epicuticulares, C: Internos. HC: hidrocarburos, TG: triglicéridos, BQ: benzoquinonas, $A G L$ : ácidos grasos, LP: lípidos polares. 
La fracción de hidrocarburos fue purificada de lípidos epicuticulares en una mini columna de Biosil y analizados por radio-TLC. La marcación radiactiva se distribuyó en un $55 \pm 1,4 \%$ en la fracción de $\mathrm{HC}$ insaturados y un $40 \pm 2,3 \%$ en la fracción de $\mathrm{HC}$ saturados (Fig.IV.4.a.2.).

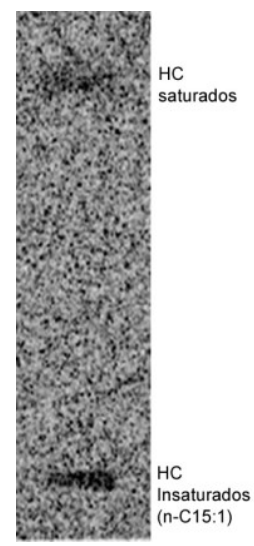

Fig.IV.4.a.2. Radio-TLC de los hidrocarburos epicuticulares de T. castaneum. La placa de sílica gel fue previamente impregnada con $\mathrm{AgNO}_{3}$ (20\% de acetonitrilo) y luego desarrollada en 95:5 (hexano: éter etílico). Los componentes se identificaron corriendo en la misma placa los estándares de $n$-C28, $n$-C15:1 y $n$-C23:1.

En un ensayo similar se estudio el efecto de un inhibidor de la FAS, el PHEP (2 $\mathrm{mM}$ ) en la biosíntesis de lípidos. No se observaron diferencias significativas con los controles, ni entre sexos (Tabla IV.4.a.2). La dosis de PHEP (2 mM) utilizada, coincide con la dosis ensayada para el estudio de la liberación de VOC (inciso IV.5).

Tabla IV.4.a.2. Distribución de la radiactividad ( $\% \pm$ E.E) en los distintos extractos de lípidos de machos y hembras de T. castaneum ${ }^{a}$

Incorporación de radiactividad (\% \pm E.E)

\begin{tabular}{ccccc}
\hline & \multicolumn{2}{c}{ Control } & \multicolumn{2}{c}{ PHEP (2mM) } \\
& Macho & Hembra & Macho & Hembra \\
\hline VOC & $0,22 \pm 0,07$ & $0,20 \pm 0,07$ & $0,16 \pm 0,02$ & $0,17 \pm 0,03$ \\
Epicuticulares & $0,38 \pm 0,08$ & $0,20 \pm 0.04$ & $0,21 \pm 0,05$ & $0,18 \pm 0,02$ \\
Internos & $3,0 \pm 1,0$ & $3,4 \pm 0,9$ & $1,97 \pm 0,63$ & $2,1 \pm 0,8$
\end{tabular}

a Los insectos separados por sexo fueron alimentados durante 10 días con $\left[1-{ }^{14} \mathrm{C}\right]$ acetato. Los insectos control fueron topicados con $1 \mu \mathrm{l}$ de etanol, los insectos tratados fueron topicados con $1 \mu \mathrm{l}$ de PHEP. (ANOVA seguido por Prueba de Tukey, $P<0,05$ ). Los valores representan la media \pm E.E de cuatro repeticiones 


\section{IV.4.b. Glándulas abdominales de U. dermestoides}

Las glándulas abdominales de adultos de $U$. dermestoides se incubaron con [1${ }^{14} \mathrm{C}$ ] acetato en medio acuoso, la extracción de los lípidos y la distribución de la radiactividad por Radio-TLC.

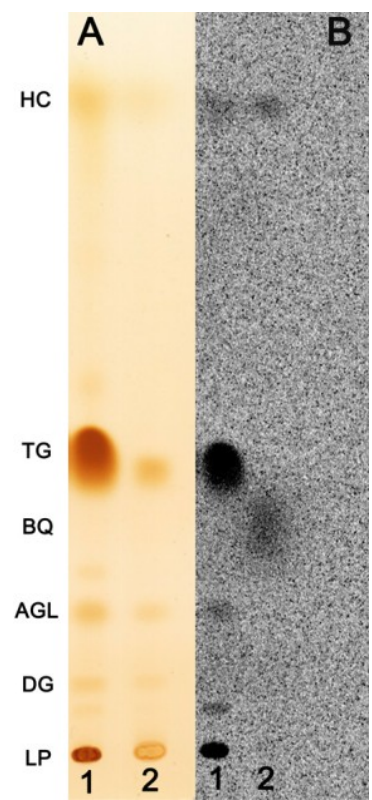

Fig.IV.4.b.A. TLC de los lípidos totales extraídos de cuerpo (columna 1), glándulas abdominales y reservorios glandulares $(R G)$ (columna 2 ) de $U$. dermestoides luego de incubación con $\left[1{ }^{14} \mathrm{C}\right]$ acetato.

Fig.IV.4.b.B: Radio-TLC de cuerpo (columna 1) y glándulas abdominales y RG (columna 2) de $U$. dermestoides. $\mathrm{HC}$ : hidrocarburos, TG: triacilglicéridos, $\mathrm{BQ}$ : benzoquinona, $\mathrm{AGL}$ : ácidos grasos libres; DG: Diacilglicéridos; LP: lípidos polares. 1: Cuerpo; 2: Glándulas + RG.

En la Fig. IV.4.b.A, se muestra una TLC de los lípidos totales de $U$. dermestoides (cuerpos sin glándulas $\mathrm{C}-\mathrm{G}$ ) (columna 1), donde se observa un patrón similar al observado en T. castaneum (Fig.IV.1.c.B), siendo los TG los componentes mayoritarios, seguidos de LP (principalmente fosfolípidos), HC, AGL y DG; en la columna 2 (glándulas + RG), se observa la presencia de TG, HC, AGL y LP, posiblemente debida a restos de cuerpo graso.

La Fig.IV.4.b.B en la columna 1 (C-G) la marcación radiactiva se distribuyó en TG $(54,4 \pm 5,0 \%), A G L(7,6 \pm 0,07 \%), H C(9,5 \pm 2,9 \%)$, DG $(7,2 \pm 0,2 \%)$ y en el punto de siembra, fracción de lípidos polares $(21,4 \pm 1,5 \%)$; en la columna 2 (glándulas + $\mathrm{RG})$ la radiactividad se distribuyó en los principales componentes de sus secreciones, $\mathrm{HC}(42,3 \pm 2,0 \%)$ y $\mathrm{BQ}(56,2 \pm 3,1 \%)$. Dada la escasa cantidad de muestra, en la fracción de $\mathrm{HC}$ no se pudo posteriormente analizar la distribución en HC saturados/ insaturados. 
Para investigar la etapa final de producción de $\mathrm{HC}$, en otro experimento, se incubaron glándulas $+R G$ de $U$. dermestoides con $\left[1-{ }^{14} \mathrm{C}\right]$-palmitato durante $2 \mathrm{~h}$ a 30 ${ }^{\circ} \mathrm{C}$; el $\left[{ }^{14} \mathrm{C}\right] \mathrm{CO}_{2}$ producido fue capturado por arrastre en minicolumnas con $\mathrm{K}(\mathrm{OH})$, obteniendo un $0,65 \pm 0,32 \%$ de radiactividad en el homogenato de glándula $(N=6)$.

IV.5. Efecto de inhibidores de la ácido graso sintasa (FAS) en la liberación de VOC en insectos plaga de granos almacenados

Se analizaron los VOC liberados por insectos adultos tratados (PHEP $2 \mathrm{mM} \mathrm{y}$ octanoico $20 \mathrm{mM}$ ) como se explica en el inciso III.7, se compararon cuantitativamente con los respectivos controles, mediante la técnica de SPME-CGC utilizando la fibra de CAR/PDMS.

\section{IV.5.a. Tribolium castaneum}

Tabla IV.5.a. Cantidades relativas $(\% \pm$ E.E) de los principales VOC de $T$. castaneum detectados por SPME-CGC.

\begin{tabular}{cccc}
\hline \multicolumn{4}{c}{ Cantidades relativas(\% \pm E.E) T. castaneum } \\
\\
Hembra & MBQ & EBQ & $n$-C15:1 \\
\hline Control & $28,5 \pm 2,4 \mathrm{a}$ & $62,2 \pm 1,8 \mathrm{a}$ & $9,7 \pm 2,5 \mathrm{a}$ \\
PHEP & $29,3 \pm 3,4 \mathrm{a}$ & $64,9 \pm 2,8 \mathrm{a}$ & $5,1 \pm 1,3 \mathrm{a}$ \\
octanoico & $27,7 \pm 4,0 \mathrm{a}$ & $63,1 \pm 1,3 \mathrm{a}$ & $7,0 \pm 1,1 \mathrm{a}$ \\
\hline Macho & $\mathrm{MBQ}$ & $\mathrm{EBQ}$ & $n-\mathrm{C} 15: 1$ \\
\hline Control & $30,8 \pm 1,8 \mathrm{a}$ & $63,6 \pm 1,5 \mathrm{a}$ & $5,5 \pm 1,1 \mathrm{a}$ \\
PHEP & $29,7 \pm 1,6 \mathrm{a}$ & $58,7 \pm 2,1 \mathrm{a}$ & $11,5 \pm 1,7 \mathrm{~b}$ \\
octanoico & $29,5 \pm 1,7 \mathrm{a}$ & $60,7 \pm 3,0 \mathrm{a}$ & $8,1 \pm 2,3 \mathrm{ab}$ \\
\hline
\end{tabular}

adultos hembras y machos tratados y control (cinco insectos/vial). $N=$ seis repeticiones. Valores seguidos por la misma letra en la columna no difieren significativamente entre sí. (Prueba de Tukey, $P<0,05$ ).

El tratamiento con PHEP produjo variaciones significativas en la cantidad relativa de $n-C 15: 1$ en machos $(P<0,05)$; no se observaron otros efectos. 


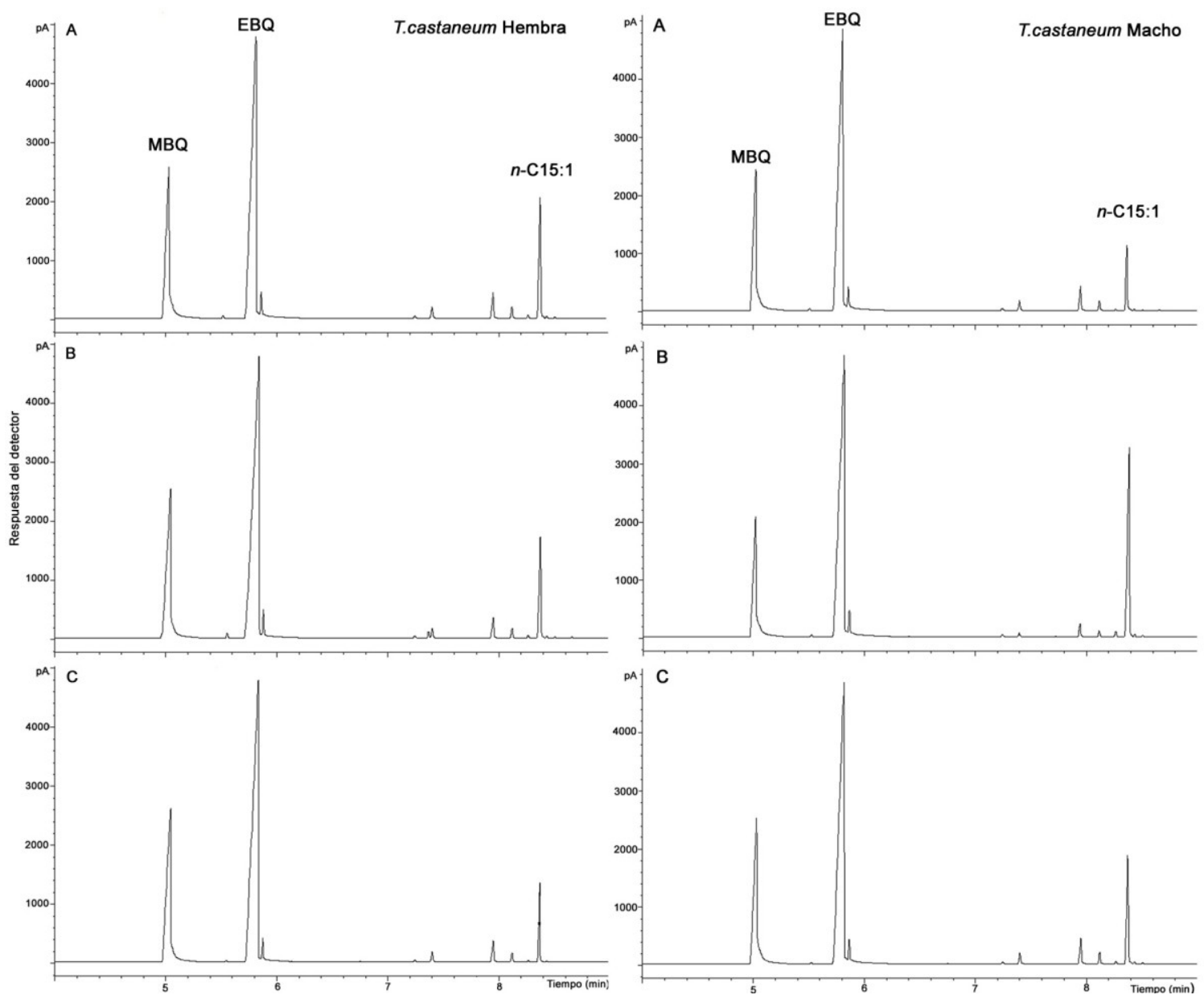

Fig.IV.5.a.1. Perfil cromatográfico de SPME-CGC de hembras y machos de T. castaneum, utilizando la fibra CAR/PDMS. Los insectos fueron agitados fuertemente durante $30 \mathrm{seg}$. A: Insectos topicados con Etanol (Control), B: Insectos topicados con PHEP, C: Insectos topicados con octanoico. MBQ: metil1,4-benzoquinona, EBQ:etil1,4-benzquinona, $n$-C15:1:pentadeceno
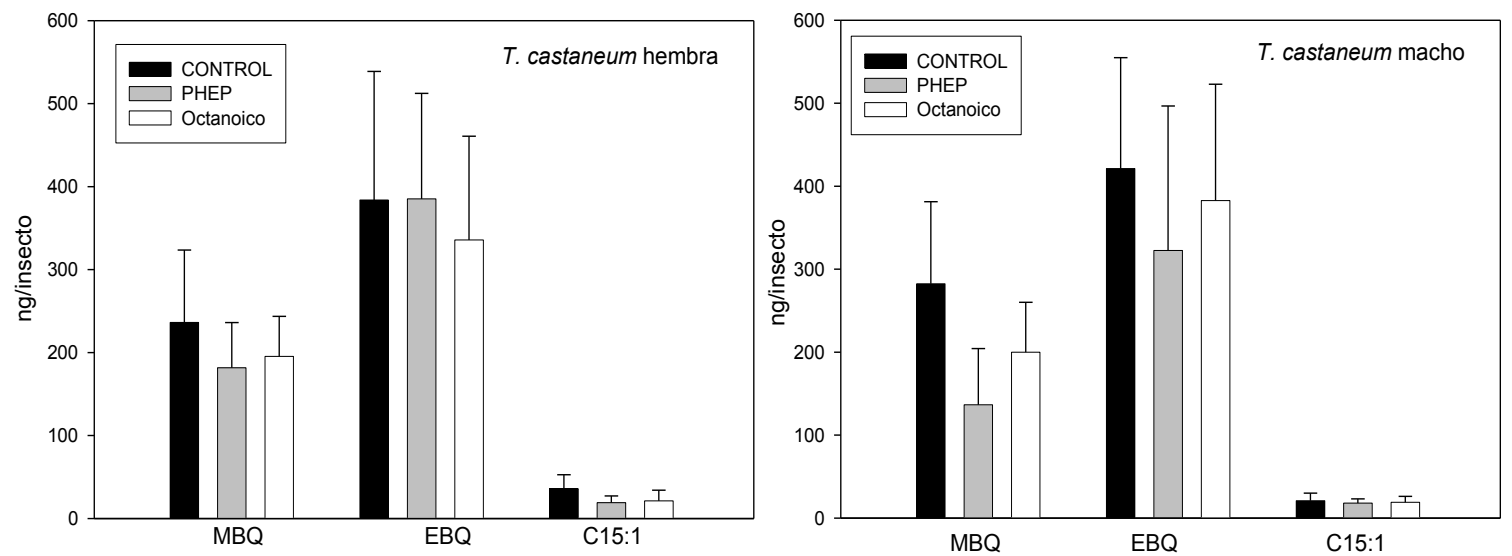

Fig.IV.5.a.2. Cantidades (ng/insecto) de VOC captados por SPME-CGC de hembras y machos de $T$. castaneum. Las barras representan las medias de seis repeticiones ( \pm E.E) de los volátiles liberados por agitación. ANOVA seguido por Prueba de Tukey, $P<0,05$ ) 
Las cantidades (ng/insecto) de VOC detectados se muestran en la Fig. IV.5.a.3. No se observaron diferencias significativas con los controles, ni entre sexos.

\section{IV.5.b. Ulomoides dermestoides}

Se efectuaron ensayos similares a los realizados en $T$. castaneum en un pool de adultos de $U$. dermestoides. En presencia de octanoico las cantidades relativas del $n$-C15:1 fueron significativamente mayor, en comparación con los controles $(P<0,01)$ y el PHEP $(P<0,001)$ y la de MBQ significativamente menor, en comparación con los insectos tratados con PHEP $(P<0,001)$ y los insectos controles $(P<0,01)$ (Tabla IV.5.b.2)

Tabla IV.5.b. Cantidades relativas ( $\% \pm$ E.E) de los principales VOC detectados por SPMECGC en $U$. dermestoides ${ }^{a}$ control y tratados con PHEP y octanoico.

\begin{tabular}{ccccc}
\hline & \multicolumn{4}{c}{ Cantidades relativas $(\% \pm \mathrm{E} . \mathrm{E})^{b}$} \\
\cline { 2 - 5 } & $\mathrm{MBQ}$ & $\mathrm{EBQ}$ & $n-\mathrm{C} 13: 1$ & $n$-C15:1 \\
\hline Control & $29,9 \pm 3,4 \mathrm{a}$ & $38,3 \pm 3,5 \mathrm{a}$ & $2,2 \pm 0,3 \mathrm{a}$ & $29,6 \pm 4,4 \mathrm{a}$ \\
PHEP & $33,9 \pm 3,3 \mathrm{a}$ & $44,3 \pm 4,1 \mathrm{a}$ & $4,6 \pm 1,0 \mathrm{a}$ & $17,7 \pm 4,6 \mathrm{a}$ \\
octanoico & $13,9 \pm 2,4 \mathrm{~b}$ & $31,0 \pm 4,6 \mathrm{a}$ & $2,9 \pm 0,4 \mathrm{a}$ & $52,1 \pm 6,5 \mathrm{~b}$ \\
\hline
\end{tabular}

a Pool de adultos de $U$. dermestoides agitados (30 seg) mantenidos a temperatura ambiente. Los VOC fueron colectados, durante $15 \mathrm{~min} . \mathrm{N}=$ catorce repeticiones.

${ }^{b}$ Los valores seguidos por la misma letra en cada columna no difieren estadísticamente entre sí. ANOVA seguido de Prueba de Tukey $(P<0,05)$. 


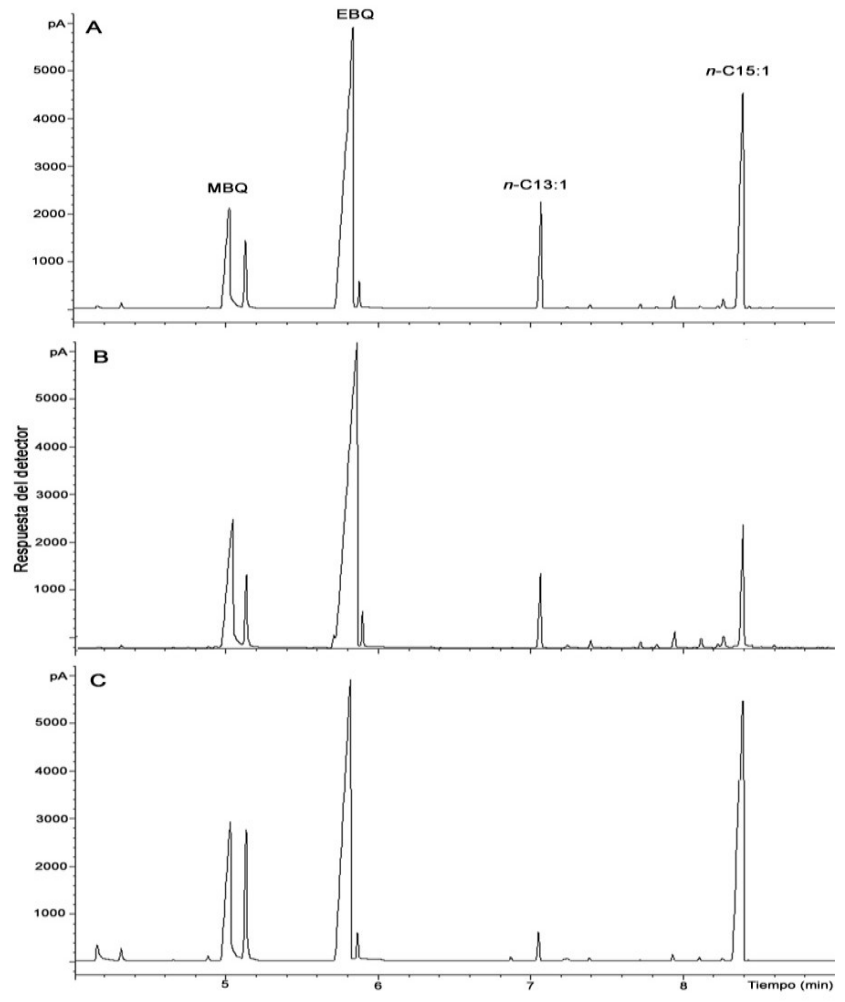

Fig.IV.5.b.1. Perfil cromatográfico de SPME-CGC de pool de adultos de $U$. dermestoides utilizando la fibras CAR/PDMS. Los insectos fueron agitados durante $30 \mathrm{seg}$. A: insectos topicados con etanol (control), B: insectos topicados con PHEP, C: insectos topicados con octanoico.

Las cantidades (ng/insecto) de VOC detectados se muestran en la figura IV.5.b.2. Sólo se observan diferencias significativas entre la cantidad de $n$-C15:1 de los insectos control con los tratados con PHEP y octanoico $(P<0,01)$.

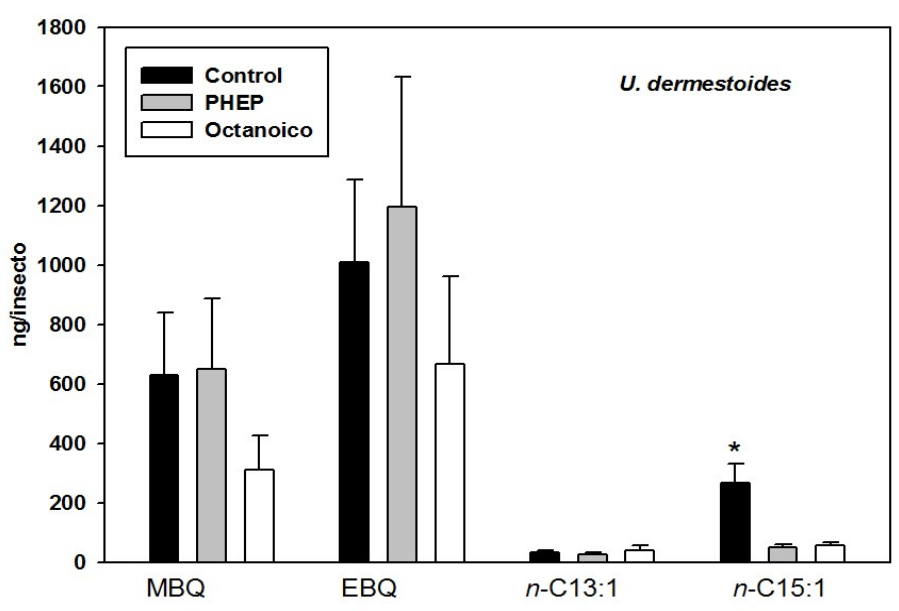

Fig.IV.5.b.2. Cantidades (ng/insecto) de VOC captados por SPME-CGC de pool de adultos de $U$. dermestoides. Las barras representan las medias de catorce repeticiones ( \pm E.E). ${ }^{*}$ Los valores de $n$-C15:1 de los insectos control difieren significativamente de los insectos tratados (ANOVA, seguido de Prueba de Tukey, $P<0,05$ ). 


\section{IV.6. Efecto de agentes naturales y biológicos en la supervivencia y ciclo de vida de insectos plaga de granos almacenados}

\section{IV.6.a. Bioensayos con agentes naturales (Tierra de Diatomeas)}

Se analizó la capacidad insecticida de TD obtenidas de tres yacimientos locales (LJ, RN 1 y RN 2) y dos TD comerciales (San Juan (local) y Permaguard (USA)), los bioensayos se realizaron comparando dos concentraciones de TD (700 y 1500 ppm), y evaluando la mortalidad a los 7 y 14 días de exposición.

Para $T$. castaneum, con la dosis de $700 \mathrm{ppm}$ no se detectaron diferencias significativas entre las TD ensayadas, con valores de mortalidad que no superaron el 14\% (Permaguard) a los 7 días. Luego de 14 días de exposición a las TD, los valores de mortalidad fueron significativamente diferentes para Permaguard $(82 \%)(P<0,001)$ y LJ $(34 \%)(P<0,001)$, los valores obtenidos con las otras TD no variaron significativamente en función del tiempo (Tabla IV.6.a.1). A dosis más alta (1500 ppm), a los 7 días se logró un 58\% de mortalidad con Permaguard, en tanto que con las TD locales los porcentajes de mortalidad fueron muy bajos. Sin embargo, el porcentaje de mortalidad con LJ se elevó a 98\% a los 14 días, similar al alcanzado con Permaguard (100\%); las restantes TD no incrementaron significativamente su eficacia con mayor tiempo de exposición (Tabla IV.6.a.2).

Los valores de mortalidad para $R$. dominica superaron el $85 \%$ a los 7 días, tanto con LJ como con Permaguard (700 ppm), sin diferencias significativas entre ambas TD ni en función del tiempo. Estos valores fueron significativamente diferentes para las otras TD en ambos períodos de ensayo $(P<0,001$ y $P<0,01)$. Valores intermedios de mortalidad se obtuvieron para RN 1, con diferencias significativas a los 7 y 14 días $(P<0,001)$ (Tabla IV.6.a.1). A mayor dosis no se observaron diferencias significativas a los 14 días en la mortalidad entre LJ y Permaguard; ambas fueron significativamente diferentes del resto de las TD $(P<0,001)$ (Tabla IV.6.a.2). No se observaron diferencias significativas en la mortalidad de $R$. dominica en función del tiempo de exposición, con ninguna de las TD ensayadas (Tabla IV.6.a.2).

En cuanto a la especie más susceptible, $S$. oryzae, a los 7 días se logró más de $80 \%$ de mortalidad a la dosis más baja, tanto con Permaguard como con LJ, llegando a $100 \%$ a los 14 días. A los 7 días, se obtuvieron resultados significativamente diferentes con las otras TD $(P<0,05, P<0,01$ y $P<0,001)$, que a su vez mostraron incrementos significativos en la mortalidad a los 14 días $(P<0,001)$ (excepto RN 1$)$, sin diferencias significativas con Permaguard y LJ a los 14 días (Tabla IV.6.a.1). A 1500 ppm, no se observaron diferencias significativas a los 7 días entre las TD. A mayor 
tiempo de exposición, se alcanzaron valores aproximados al $100 \%$, excepto para RN 1.

Tabla IV.6.a.1. Porcentaje de mortalidad (media \pm E.E) de las especies $T$. castaneum, $R$. dominica y $S$. oryzae a los 7 y 14 días del tratamiento de exposición a granos de trigo tratados con 700 ppm de TD.

\begin{tabular}{lcccccc}
\hline & \multicolumn{2}{c}{$T$. castaneum } & \multicolumn{2}{c}{$R$. dominica } & \multicolumn{2}{c}{ S. oryzae } \\
\cline { 2 - 7 } \multicolumn{1}{c}{ TD } & 7 días & 14 días & 7 días & 14 días & 7 días & 14 días \\
\hline Permaguard \& & $14,0 \pm 4,0$ a A & $82,0 \pm 3,7$ a B & $93,6 \pm 4,3$ a A & $97,8 \pm 2,2$ a A & $83,3 \pm 4,7$ a A & $100,0 \pm 0,0$ a B \\
La Josefina & $4,0 \pm 2,4$ a A & $34,0 \pm 2,4$ b B & $85,1 \pm 6,4$ a A & $93,3 \pm 4,4$ a A & $85,7 \pm 8,7$ a A & $100,0 \pm 0,0$ a A \\
RN. 1 & $4,9 \pm 2,0$ a A & $4,9 \pm 2,0$ c A & $40,4 \pm 2,6$ b A & $57,8 \pm 2,2$ b B & $42,8 \pm 10,2$ b A & $60,0 \pm 12,3$ b A \\
RN. 2 & $10,6 \pm 4,7$ a A & $12,6 \pm 4,9$ c A & $14,9 \pm 3,4$ c A & $28,9 \pm 4,4$ c B & $30,9 \pm 4,4$ b A & $85,7 \pm 7,8$ a B \\
San Juan & $1,6 \pm 1,6$ a A & $3,3 \pm 2,0$ c A & $8,93 \pm 3,6$ c A & $19,9 \pm 6,5$ c A & $35,7 \pm 10,4$ b A & $71,4 \pm 9,0$ a B
\end{tabular}

Valores seguidos por la misma letra en la columna no difieren estadísticamente entre sí. Diferentes letras mayúsculas en cada fila indican diferencias significativas en la mortalidad producida por la TD a los 7 y a los 14 días de exposición. Prueba de Tukey $(P<0,05)$.

Tabla IV.6.a.2. Porcentaje de mortalidad (media \pm E.E) de las especies $T$. castaneum, $R$. dominica y $S$. oryzae a los 7 y 14 días del tratamiento de exposición a granos de trigo tratados con 1500 ppm de TD.

\begin{tabular}{|c|c|c|c|c|c|c|}
\hline \multirow[b]{2}{*}{ TD } & \multicolumn{2}{|c|}{ T. castaneum } & \multicolumn{2}{|c|}{ R. dominica } & \multicolumn{2}{|c|}{ S. oryzae } \\
\hline & 7 días & 14 días & 7 días & 14 días & 7 días & 14 días \\
\hline \multicolumn{7}{|l|}{ Permaguard } \\
\hline 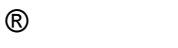 & $58,0 \pm 11,1 \mathrm{a} A$ & $100,0 \pm 0,0$ a $B$ & $91,5 \pm 6,2$ a $A$ & $95,5 \pm 4,4$ a $A$ & $85,7 \pm 4,4$ a A & $100,0 \pm 0,0$ a $A$ \\
\hline La Josefina & $16,0 \pm 6,0 \mathrm{~b} \mathrm{~A}$ & $98,0 \pm 2,0$ a $B$ & $78,7 \pm 3,4$ a $A$ & $88,9 \pm 3,5$ a $A$ & $88,1 \pm 3,8$ a $A$ & $100,0 \pm 0,0$ a $A$ \\
\hline RN. 1 & $3,6 \pm 3,6 \mathrm{~b} \mathrm{~A}$ & $6,9 \pm 3,4 \mathrm{~b} \mathrm{~A}$ & $29,8 \pm 7,2$ b A & $42,2 \pm 8,1 \mathrm{~b} \mathrm{~A}$ & $66,6 \pm 4,4$ a $A$ & $82,8 \pm 5,3$ b B \\
\hline RN. 2 & $5,3 \pm 3,6 b \mathrm{~b}$ & $16,3 \pm 3,8 \mathrm{~b} \mathrm{~A}$ & $10,6 \pm 4,2 \mathrm{~b} \mathrm{~A}$ & $17,7 \pm 8,3 \mathrm{~b} \mathrm{~A}$ & $76,2 \pm 8,4$ a $A$ & $97,1 \pm 2,8$ a $A$ \\
\hline San Juan & $6,9 \pm 3,4 \mathrm{~b} \mathrm{~A}$ & $8,6 \pm 2,9 \mathrm{~b} \mathrm{~A}$ & $17,1 \pm 6,2 \mathrm{~b} \mathrm{~A}$ & $31,1 \pm 5,4 \mathrm{~b} \mathrm{~A}$ & $83,3 \pm 2,9$ a $A$ & $100,0 \pm 0,0$ a $B$ \\
\hline
\end{tabular}

\section{IV.6.b. Bioensayos con el agente biológico Beauveria bassiana}

Se estudió el efecto en el ciclo de desarrollo de $T$. castaneum y $U$. dermestoides por infección con el hongo entomopatógeno, B. bassiana. Los adultos de sexo conocido fueron tratados y colocados en frasco de vidrio con la dieta 
correspondiente. A los 15 días se separaron los adultos y se realizó el conteo de la descendencia (pupas y adultos) cada 4 días, durante 3 meses.

Tabla IV.6.b. Desarrollo de la colonia de T. castaneum y U. dermestoides luego del tratamiento con B. bassiana ( $1 \times 10^{9}$ conidios $\left./ \mathrm{ml}\right)$

\begin{tabular}{lllll}
\hline \multirow{2}{*}{ Insecto $^{\mathrm{a}}$} & & \multicolumn{2}{c}{$\mathrm{N}^{\circ}$ de insecto $\left(\mathrm{F}_{1}\right)$ por hembra $\left(\mathrm{P}_{1}\right)$} & \multirow{2}{*}{$P$} \\
\cline { 3 - 4 } & Estado & \multicolumn{1}{c}{ Control } & Tratados con B.b GHA & 0,0029 \\
\hline T. castaneum & Pupa & $2,97 \pm 0,24$ & $1,21 \pm 0,38$ & 0,0020 \\
\multirow{3}{*}{ U. dermestoides } & Adulto & $2,5 \pm 0,05$ & $0,95 \pm 0,37$ & 0,0210 \\
& Pupa & $3,34 \pm 0,41$ & $1,55 \pm 0,51$ & 0,0558 \\
& Adulto & $2,12 \pm 0,29$ & $1,12 \pm 0,36$ & 0 \\
\hline
\end{tabular}

${ }^{a}$ Para cada grupo de insectos, cada colonia se inició con ocho machos y ocho hembras. El número de insectos emergente se contabilizaban cada 4 días durante 3 meses. Los valores representan las medias \pm de seis repeticiones. Prueba de Student, $P<0,05$

El desarrollo de las colonias de ambas especies se alteró tras el tratamiento con $B$. bassiana, mostrando una disminución significativa en la progenie $(P<0,05$ y $P$ $<0,005)$. Se registró una disminución significativa $(P<0,005)$ en la tasa de reproducción para $T$. castaneum, siendo de 2,97 $\pm 0,24$ pupas por hembra para la colonia control y de 1,21 \pm 0,38 para la colonia tratada con el hongo (Tabla IV.6.b). La colonia de $U$. dermestoides, también mostró una disminución significativa $(P<0,05)$ en la tasa de reproducción, siendo de 3,34 $\pm 0,41$ y 1,55 $\pm 0,51$ pupas por hembra para las colonias control y tratada con B. bassiana respectivamente (Tabla IV.6.b). Con respecto a los adultos, se obtuvo 2,50 \pm 0,05 adultos por hembra para la colonia control de $T$. castaneum, mientras que sólo $0,95 \pm 0,37$ adultos surgieron por hembra en las colonias tratadas con hongo $(P<0,005)$ (Tabla IV.6.b). Sin embargo, la transición entre pupa y adultos no parece ser afectada por la infección con el hongo, aproximadamente el $80 \%$ de las pupas fueron capaces de mudar a adulto tanto en las colonias tratadas como en las control. La producción de adultos en $U$. dermestoides fue menor en las colonias tratadas con $B$. bassiana $(1,12 \pm 0,36$ adultos por hembra) en comparación con las colonias control (2,12 $\pm 0,29$ adultos por hembra), pero no se mostraron diferencias significativas (Tabla IV.6.b). La eficacia de muda a adulto fue del 60 a $70 \%$ para esta especie. La infección con $B$. bassiana muestra baja mortalidad, pero la presencia del hongo afecta significativamente la progenie. 


\section{V.1. Hidrocarburos epicuticulares de T. castaneum}

Los hidrocarburos $(\mathrm{HC})$ son constituyentes característicos de los lípidos cuticulares de insectos (Blomquist y Dillwith, 1985; Blomquist y Bagnéres, 2010). Dado que carecen de grupos reactivos y la alta estabilidad, los $\mathrm{HC}$ juegan un papel fundamental en las principales funciones de la cutícula, restringiendo la pérdida de agua, actuando en procesos de comunicación química (Blomquist y Howard, 2003; Blomquist y Bagnéres, 2010) y en la resistencia a insecticidas (Pedrini y col., 2009; Juárez y col., 2010).

Los HC de T. castaneum fueron analizados por Baker y col. (1978) empleando la tecnología disponible en ese momento (CG con columnas empacadas, de baja resolución). Estos autores reportaron 2 grupos de HC; un grupo formado por HC de bajo PM y otro grupo formado por componentes estructurales de la cutícula de mayor PM, de cadenas lineales y ramificadas de 25 hasta 31 carbonos.

En este trabajo se efectuó el análisis de los HC epicuticulares de adultos de $T$. castaneum. Empleando CGC de alta resolución, logrando detectar 22 nuevos componentes metilramificados (Tabla IV.2, composición porcentual de HC epicuticulares de $T$. castaneum). Los $n$-alcanos representan el $40 \%$ de los HC epicuticulares totales, con longitud de cadena entre los 23 y 39 carbonos, siendo los principales componentes el $n$-C27:0 (15.60 $\pm 0.51 \%)$ y el $n$-C29:0 $(14.91 \pm 0.82 \%)$.

En la fracción de $\mathrm{HC}$ ramificados predominan los monometilalcanos de cadenas impares (38\% de los $\mathrm{HC}$ epicuticulares totales), siendo el componente principal el isómero 11-; 13- metilC27; seguido de los isómeros 11-; 13-; 15-metilC29, del 3-metilC27 y 3-metilC29 (Tabla IV.2); en la fracción de HC ramificados de cadenas pares $(10,2 \%$ de los HC epicuticulares totales) el componente mayoritario es el 4metilC28 (Tabla IV.2). Dentro de los monometilalcanos podemos mencionar que la ramificación en posición 4- está presente en cadenas pares de 26 a 30 carbonos y la ramificación terminal 3-metil tanto en cadenas pares como impares. En la mayoría de los insectos con $\mathrm{HC}$ ramificados es característica la presencia de múltiples isómeros posicionales; aún con la tecnología actual, estos isómeros coeluyen en un único pico (p.ej. 11- y 13-metilC27; 11-; 13- y 15-metilC29) y no son separables por CGC. Sin embargo, estos $\mathrm{HC}$ son identificables por sus patrones de fragmentación de masa y por los valores de IK, como se explica en las secciones anteriores.

En la fracción de dimetilalcanos ( $12 \%$ de los $\mathrm{HC}$ epicuticulares) las ramificaciones se ubican comúnmente en posiciones pares o impares dependiendo si la cadena lineal tiene número par o impar de carbonos, respectivamente, el componente principal es el isómero 3,11-; 3,13-dimetilC27. No se detectaron tri ni 
tetrametilderivados. En general la composición de $\mathrm{HC}$ de $T$. castaneum es relativamente simple con el casi $80 \%$ del total de $\mathrm{HC}$ epicuticulares representado por 10 compuestos de cadenas de 27 hasta 29 átomos de carbono. En general, la composición de $\mathrm{HC}$ de insectos es más compleja y, a veces, consta de más de 100 compuestos y en algunos casos se reportaron HC de alto PM de 70 carbonos (Cvačka y col., 2006).

Suzuki y col. (1975) analizaron por primera vez la fracción de HC de bajo PM de $T$. castaneum, siendo el compuesto mayoritario el 1-pentadeceno ( $n$-C15:1), junto con 1-tretadeceno ( $n$-C14:1), 1-hexadeceno ( $n-\mathrm{C} 16: 1)$, 1-heptadeceno ( $n$-C17:1), 1,6pentadecadieno ( $n$-C15:2), 1,8- heptadecadieno ( $n$-C17:2) y heptadecatrieno ( $n$ C17:3).

La presencia conjunta de $\mathrm{HC}$ de bajo y alto PM fue también detectada en otro tenebriónido estudiado en este laboratorio, U. dermestoides. La fracción de bajo PM es similar a la de $T$. castaneum, con predominio de HC insaturados de 13-17 carbonos, siendo el $n$-C15:1 el componente mayoritario. En el grupo de mayor PM, las cadenas lineales mayoritarias son similares; sin embargo, la composición de la fracción ramificada es muy diferente, predomina un $\mathrm{HC}$ de 25 carbonos diinsaturado, el 9,11-dimetilC25:2 (Pedrini, 2006; Villaverde y col., 2009). En Tenebrio obscurus y $T$. molitor, el C25:0 y C25:1 representan aproximadamente el 40\% de la fracción de HC (Lockey, 1978), en contraste, la epicutícula de otros coleópteros plaga de granos almacenados, como Sitophilus sp. tiene en su composición grandes cantidades de HC insaturados de largas cadenas. En S. oryzae predominan alquenos, alcadienos y alcatrienos de altos PM (Baker y col., 1984).

Dada la importancia de los HC epicuticulares es extenso el estudio de los mismos, de unos 130 trabajos relacionados con hidrocarburos de insectos citados en una revisión de 1982 (Howard y Blomquist, 1982) actualmente se pueden hallar varios miles y este campo sigue creciendo rápidamente (Howard y Blomquist, 2005, Blomquist y Bagnères, 2010). Los $n$-alcanos se encuentran en casi la totalidad de los más de 100 órdenes analizados (Blomquist y Bagnères, 2010), representando más del 90\% en algunos coleópteros (Baker y col., 1978; Lockey, 1985). La longitud de la cadena oscila entre 21 y 35 átomos de carbono, predominando las cadenas impares. Los $n$-alquenos predominan fundamentalmente en los órdenes Coleoptera, Diptera e Himenoptera, donde se encuentran como mezclas de isómeros y la posición del doble enlace es variable (de Renobales y col., 1991; Buckner y col., 2009; Martin y Drifjhout, 2009; Villaverde y col., 2009). En el orden Hemiptera son abundantes los trimetil y tetrametil-derivados de cadenas impares y pares en Triatoma sp. y Rhodnius prolixus (Juárez y Blomquist, 1993; Juárez y col., 2001; Juárez y Calderón , 2007; Calderón y 
col., 2012). En el orden Lepidoptera, Girotti y col. (2012) estudiaron los HC epicuticulares de Diatraea saccharalis, detectando en la larva HC de muy larga cadena insaturados, con longitudes de 37-53 átomos de carbono y hasta cuatro dobles enlaces, siendo el componente principal el C49:3 (Girotti y col., 2012).

El conocimiento de la estructura de los $\mathrm{HC}$ es importante para avanzar en la comprensión de los mecanismos regulatorios bioquímicos y genéticos que participan en su formación; así como el desarrollo de inhibidores específicos de su formación (Juárez, 1994a; Juárez, 1996; Tittiger y Blomquist, 2009; Qui, y col., 2012).

\section{V.2. Compuestos orgánicos volátiles (VOC) de T. castaneum y U. dermestoides}

\section{Análisis cuali-cuantitativo}

En los últimos años, la SPME acoplada a CGC-MS ha sido ampliamente utilizada para estudiar las secreciones volátiles en Coleópteros, por ejemplo, el aislamiento y la identificación de la feromona de los escarabajos rinocerontes (Rochat y col., 2000) y cerambícidos (Lacey y col., 2004; Seitz y Ram, 2004; Ginzel y Hanks, 2005, Rodstein y col., 2009; Spikes y col., 2010; Maki y col., 2011), también fue utilizada para detectar la feromona de agregación y otros metabolitos volátiles menores del barrenador de los granos, R. dominica (Seitz y Ram, 2004) y de $T$. castaneum (Arnaud y col., 2002).

El empleo de esta técnica para detectar compuestos sin utilizar solventes durante el inicio de la presente tesis en 2004 fue novedoso en el país; asimismo fue novedosa su utilización para el análisis de las secreciones volátiles liberadas por uno o más insectos vivos. En este trabajo se evaluó el potencial de un método sin solventes para detectar VOC de insectos plaga en muestras de granos almacenados, que podría ser de utilidad como indicador de contaminación insectil.

Las secreciones volátiles liberadas por adultos vivos de $T$. castaneum fueron analizados empleando la técnica de SPME-CGC-MS, utilizando 3 fibras de diferente polaridad y tres tipos tratamientos. Las cantidades relativas de los 3 principales VOC variaron significativamente dependiendo de la polaridad de la fibra utilizada, la fibra CAR/PDMS captó alrededor del $75 \%$ de las BQ del total de los VOC liberados, mientras que la fibra PDMS solo detectó alrededor del $45 \%$ de $B Q$, la fibra PDMS/DVB mostró una afinidad intermedia (Tabla.IV.3.a).

En este sentido, se pudo optimizar un método libre de solvente para detectar estos VOC, a pesar de que las cantidades absolutas de BQ extraíbles por SPME son muy inferiores a las reportadas por extracción con solventes, las señales obtenidas en el análisis por SPME-CGC son suficientes y permiten confirmar la presencia de BQ en la muestra. En una extracción de $15 \mathrm{~min}$, empleando la fibra CAR/PDMS, las 
cantidades de $B Q$ que se detectaron fueron de $349 \pm 107 \mathrm{ng} /$ insecto de MBQ y $780 \pm$ 290 ng/insecto de EBQ en insectos sometidos a estrés por agitación (Fig.IV.3.a.4).

Sin embargo, cantidades mucho mayores de $B Q$ están internamente almacenadas en los reservorios glandulares y no se detectan por este método. Los niveles reportados de las secreciones defensivas son muy variables, dependiendo no sólo de la edad y el sexo, sino también de la disponibilidad de alimentos, fotoperíodo, densidad de los insectos, etc. (Unruh y col., 1998); también dependen del método de extracción. Estudios previos p.ej., detectaron 300-1000 ng de BQ (Pappas y Wardrop, 1996, Yezerski y col., 2000); sin embargo, los niveles más altos estimados por extracción con solventes y análisis por HPLC fueron de 15-21 $\mu \mathrm{g}$ de MBQ y 22-32 $\mu \mathrm{g}$ por adulto de T. castaneum (Unruh y col., 1998).

La cantidad de analito extraído por SPME es proporcional a su concentración en la muestra. Con el fin de estimar la cantidad máxima extraíble de VOC por este método, los viales que contienen insectos ya expuestos a las sucesivas extracciones bajo las condiciones de temperatura ambiente sin estresar y agitados, fueron sometidos a un tratamiento térmico $\left(90^{\circ} \mathrm{C}\right.$ durante $15 \mathrm{~min}$ ) para liberar la mayor parte de la VOC internos. Las cantidades totales liberadas de matrices inertes pueden ser calculadas mediante la realización de varias extracciones consecutivas de HS-SPME (múltiple HS-SPME) de la misma muestra, la sumatoria de las áreas de extracciones sucesivas individuales es igual a la superficie total del compuesto en estudio (Ezquerro, y col, 2003; Ezquerro y Tena, 2005; Martínez- Uruñuela y col., 2005). Sin embargo, no había reportes de un método para estimar la cantidad total de VOC de un organismo vivo; extracciones consecutivas no parecían apropiadas porque la síntesis de volátiles probablemente continúa durante el período de muestreo. Por lo tanto, la extracción múltiple HS-SPME fue sustituida por una extracción luego de un periodo de tratamiento térmico. En SPME, el aumento de la temperatura de extracción puede tener efectos opuestos a lo esperado, debido a que los coeficientes de difusión se incrementan, aunque los coeficientes de partición a la fase de extracción se reducen, por lo que la cantidad de VOC extraídos puede disminuir a mayor temperatura (Lord y Pawliszyn, 2000). El efecto de la temperatura de extracción se estimó como la diferencia de lecturas entre las repeticiones efectuadas a $90{ }^{\circ} \mathrm{C}$ y a temperatura ambiente. Empleando SPME-CGC-MS en estas condiciones, las cantidades totales detectadas de $\mathrm{BQ}$ fueron de 2,3 $\mu \mathrm{g} /$ insecto junto con $1 \mu \mathrm{g} /$ insecto de $n$-C15:1 en $T$. castaneum.

Mediante SPME-CGC-MS también fueron analizados los VOC de adultos macho y hembra de $U$. dermestoides por separado, utilizando la fibra PDMS/DVB; los principales VOC liberados cuando los insectos son estresados por agitación fueron 
MBQ, EBQ, 1-trideceno (n-C13:1) y $n$-C15.1 (Fig.IV.3.b.1), similares a los descriptos en T. castaneum y otros tenebriónidos (Blum, 1981; Eisner y col., 1998; Wahrendorf y Wink, 2006; Geiselhardt y col., 2006; Villaverde y col., 2007). Sin embargo, las cantidades de los tres principales compuestos liberados post-agitación (MBQ, EBQ y $n$-C15:1) por individuos adultos fue significativamente mayor que las estimadas en $T$. castaneum utilizando la misma metodología SPME (Villaverde y col., 2007); siendo la cantidad de MBQ de $1 \mu \mathrm{g} /$ insecto, de EBQ de 2,5 $\mu \mathrm{g} /$ insecto y de $n$-C15:1 de 0,5 $\mu \mathrm{g} /$ insecto (Fig. IV.3.b.2). Al igual que en $T$. castaneum, las BQ representan alrededor del $80 \%$ de los VOC liberados por los insectos cuando son estresados. El análisis SPME-CGC-MS no reveló dimorfismo sexual, descartando un rol sexual del $n$-C13:1 como se informó en el escarabajo Parastizopus transgariepinus (Geiselhardt y col., 2008). Sin embargo, estudios posteriores realizados en este laboratorio, a través de una modificación de la técnica de la captación de los VOC, demostró diferencias cualitativas en los compuestos liberados por machos de $T$. castaneum y $U$. dermestoides identificando nuevos componentes (un aldehído y sesquiterpenos, respectivamente) con posible rol sexual (Girotti y Juárez, no publicado).

Para evaluar las cantidades absolutas de los VOC de $U$. dermestoides, las secreciones volátiles fueron extraídas durante $48 \mathrm{~h}$ en DCM, obteniendo 39,5 $\pm 0,4$ $\mu \mathrm{g} /$ insecto (EBQ), 13,5 $\pm 1,1 \mu \mathrm{g} /$ insecto (MBQ), y 34,0 $\pm 1,5 \mu \mathrm{g} /$ insecto ( $n$-C15:1) (Tabla IV.3.C). Las cantidades totales de $B Q$ detectadas en $U$. dermestoides fueron similares o superiores a los reportados para $T$. castaneum y $T$. confusum por métodos análogos (Unruh y col., 1998; Wirtz y col., 1978; Yezerski y col, 2000).

Los resultados presentados mostraron la utilidad de la técnica de SPME empleada para el análisis de las secreciones volátiles liberadas por $T$. castaneum y $U$. dermestoides. Además se demostró que SPME acoplada a CGC es un método suficientemente sensible como para detectar las secreciones volátiles de insectos individuales. El análisis no daña a los insectos, y diferentes tratamientos se pueden aplicar a una misma muestra. La detección de insectos plaga en productos almacenados sigue siendo un problema muy importante en el sector agrario. Se aplica una variedad de métodos de análisis para la detección de insectos y fragmentos de insectos en granos enteros y harina; entre ellos, inspección visual, monitoreo de temperatura y humedad, sensores del movimiento de los insectos, trampas de feromonas, inmunoensayos, métodos basados en flotación, en espectroscopía infrarroja, etc. Sin embargo, la mayoría de ellos implican mano de obra intensiva y costosa, o no tienen suficiente sensibilidad. 
Biosíntesis de lípidos y secreciones volátiles en tenebrionidos

Los HC cuticulares de insecto son sintetizados en los oenocitos, asociados al integumento o cuerpo graso ( $\mathrm{Gu}$ y col., 1993, Juárez y Calderón F, 2007). Sin embargo, no hay evidencias concluyentes sobre el origen de $\mathrm{HC}$ de relativamente bajo PM (n-C13:1, n-C15:1). El sitio de síntesis más probable de estos alquenos serían las glándulas de secreción específicas en tenebriónidos (Blum, 1981; Attygalle y col, 1991, 1993; Eisner y col, 1998; Geiselhardt y col, 2008). El n-C15:1 cumpliría un importante rol como señal de alerta per se y como carrier de las BQ (Happ, 1968). El conocimiento sobre la ruta de síntesis del $n$-C15:1 es aún incompleto; la etapa final en la formación del $n$-C15:1 ocurriría a partir de la decarboxilación oxidativa de palmitato (Fig.V.2.a) (Görgen y col., 1990), aunque no existe información sobre el sitio de síntesis.

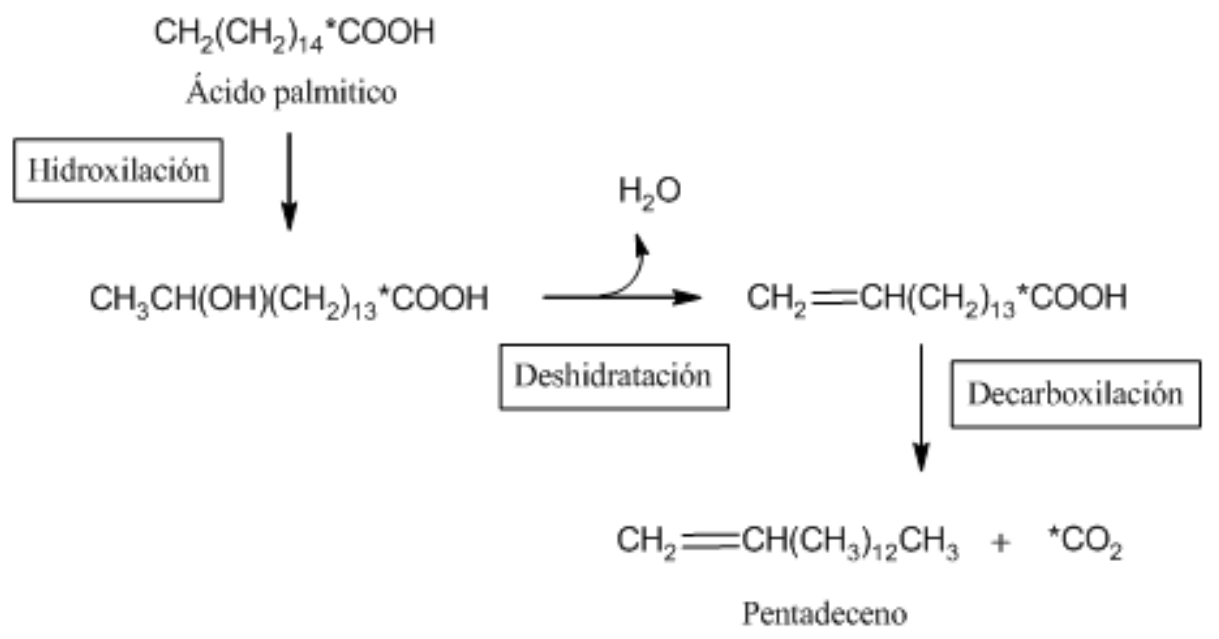

Fig.V.2.a. Etapa final de la biosíntesis de $n$-C15:1. *: $\left[1{ }^{14}\right]$

El análisis de la distribución relativa de radiactividad en los ensayos in vivo a partir de $\left[1-{ }^{14} \mathrm{C}\right]$ acetato mostró que $\sim 50 \%$ de la marcación tanto en la cutícula como en los VOC liberados por T. castaneum, correspondió a $\left[1-{ }^{14} \mathrm{C}\right] n-\mathrm{C} 15: 1$ (Tabla IV.4.a.1 y Fig.IV.4.a.2). En cuanto a la incorporación total en $\left[1-{ }^{14} \mathrm{C}\right] n-\mathrm{C} 15: 1$, se observó $\sim 1 \%$ en la fracción de las secreciones volátiles y $2 \%$ en la fracción de lípidos epicuticulares. La ruta más probable de síntesis sería vía palmitato y posterior conversión a pentadeceno (Fig.V.1).

Para investigar el sitio de síntesis de los VOC, se incubaron glándulas abdominales de $U$. dermestoides, logrando evidenciar síntesis de novo de $n-C 15: 1$ a partir $\left[1-{ }^{14} \mathrm{C}\right]$ acetato (Fig.IV.4.b); en tanto que se observó liberación de $\left[{ }^{14} \mathrm{C}\right] \mathrm{CO}_{2}$ como producto de la decarboxilación de $\left[1{ }^{14} \mathrm{C}\right]$ palmitato (Fig.V.1). 
Se ha descripto la síntesis de palmitato en insectos, a través de la acción de ácido graso sintasas (FASs) tanto de cuerpo graso como de integumento (de Renobales y col., 1987; Stanley-Samuelson y col., 1988; Juárez y col., 1992; Juárez y col. 1996).

De acuerdo a estos resultados la síntesis de $n$-C15:1 podría ocurrir vía de novo en la glándula, o a partir de palmitato exógeno incorporado a través del alimento, o sintetizado en integumento y cuerpo graso. Aunque no hay otros estudios del metabolismo lipídico en tenebriónidos, se ha reportado recientemente la identificación de al menos 5 genes codificantes para FAS en el genoma de $T$. castaneum (www.beetlebase.org).

En estos experimentos también se observó síntesis de novo de $B Q$ tanto en insecto entero como en incubaciones de glándulas (Fig. IV.4.b).

Las $B Q$ son producidas por diversos organismos a través de diferentes rutas biosintéticas. Se especula que más de un sistema estaría involucrado en la síntesis de diferentes $B Q$ con distintas funciones celulares (Pankewitz y Hilker, 2008). En este sentido, se ha demostrado que en el tenebriónido Eleodes longicollis la 1,4-BQ es sintetizada utilizando como precursor el aminoácido aromático tirosina (Meinwald y col., 1966; Blum, 1987). Sin embargo, se desconoce el origen de otras dos BQ detectadas en este insecto (2-metil y 2-etil-1,4-BQ); aunque se ha sugerido que una FAS participaría en la síntesis de estos compuestos (Pankewitz y Hilker, 2008). Recientemente, en un estudio del transcriptoma de las glándulas de defensa de $T$. castaneum, se detectaron genes específicos que codifican para glucosidasas, peroxidasas y fenoloxidasas, los que estarían involucrados en la síntesis de BQ (Li y col., 2013).

Dada la importancia de la FAS en el metabolismo de las secreciones defensivas producidas por $T$. castaneum, se evaluó el efecto de inhibidores específicos de su actividad. Estudios previos en insectos demostraron que la actividad de la FAS es inhibida de manera dosis dependiente en presencia de un ácido graso fenilsustituido (PHEP), así como también de un ácido graso de cadena corta (octanoico); esto se correlacionó con alteraciones importantes en los parámetros de supervivencia (Juárez y Napolitano, 2000). Luego de $24 \mathrm{~h}$ de tratamiento con ambos inhibidores, la cantidad de $n$-C15:1 liberada fue similar a la de insectos $T$. castaneum no tratados, pero fue significativamente reducida en $U$. dermestoides (Fig.IV.5.a.2 y b.2). En T. castaneum, ensayos de metabolismo in vivo similares a los mencionados (Juárez y Napolitano, 2000), no permitieron detectar modificaciones en la biosíntesis de lípidos (Tabla IV.4.a.2). Sin embargo, estos resultados no son concluyentes debido a que las dificultades en la aplicación de estos compuestos en insectos de tamaño tan reducido, la escasez de insectos durante esa etapa de investigación y la dificultad de 
estandarizar el estado alimentario de los insectos, impidieron la obtención de un número importante de réplicas, así como ensayo a diferentes dosis.

\section{V.3. Control físico y biológico de insectos plaga de granos almacenados}

\section{Tierras de Diatomeas}

El uso de las TD se encuentra entre uno de los métodos de control físico (Korunic, 1997, 1998; Arthur, 2000; Lord, 2001; Dal Bello y Padín, 2006; Dal Bello y col., 2011). Los primeros casos documentados sobre el empleo de polvos inertes para el control de insectos datan de alrededor del año 2000 A.C. y se refieren al control de plagas con tierra de diatomeas (TD) en China (Allen, 1972).

Las TD para el control físico de insectos plaga son un insumo de alto valor agregado y están registradas como insecticidas en diferentes países, principalmente, para la protección de granos almacenados, para uso doméstico y en cultivos protegidos (Golob, 1997; Korunic, 1998; Athanassiou y Korunic, 2007).

La producción mundial de TD durante el año 2011 fue de 1.800 .000 Tm, de las cuales $50.000 \mathrm{Tm}$ corresponden a la Argentina (United State Geological Survey Minerals Yearbook, 2011).

Para evaluar la capacidad insecticida de TDs extraídas de yacimientos locales comparamos los resultados de bioensayos de mortalidad con parámetros fisicoquímicos de las TDs (densidad aparente compactada, reducción del peso hectolítrico, adherencia al grano y $\mathrm{pH}$ ), previamente propuestos como parámetros predictivos para la evaluación de la eficacia insecticida (Korunic, 1997). Los resultados obtenidos por ambos métodos fueron concordantes y variaron en función del yacimiento y de la especie de insecto en estudio. Las muestras del yacimiento LJ mostraron un potencial insecticida semejante al del producto comercial Permaguard $₫$, en tanto que las restantes TDs ensayadas mostraron una capacidad inferior (Fusé y col., 2012). El análisis de la mortalidad (Tabla IV.6.a.1 y 2) evidencia que la TD Permaguard $®$ y la extraída del yacimiento $L J$, poseen una actividad semejante sobre las tres especies estudiadas, excepto a la dosis más baja (700 ppm) de LJ en $T$. castaneum. En los ensayos con $R$. dominica, los mayores porcentajes de mortalidad se obtuvieron con Permaguard $®$ y LJ, con resultados similares a 700 y 1500 ppm que son valores significativamente diferentes de los obtenidos con las restantes TDs. Sólo RN 1 presentó actividad insecticida intermedia, que tampoco varió con la concentración. S. oryzae, resultó la especie más susceptible, todas las TDs fueron efectivas a $700 \mathrm{ppm}$, excepto RN 1. En concordancia con los resultados de otros autores (Aldryhim, 1990; Mewis y Ulrichs, 2001; Korunic y Fields, 2006), R. dominica, 
S. oryzae y $T$. castaneum muestran diferente susceptibilidad a la TD; $T$. castaneum es la especie más tolerante, $R$. dominica presenta valores intermedios de susceptibilidad, en tanto que $S$. oryzae es la especie más susceptible.

La baja eficacia de las TDs restantes no se modificó con la dosis; es importante destacar que las TDs locales provenían directamente del yacimiento (sin etapa de purificación previa) y contenían abundante cantidad de arcilla (De Giusto, comunicación personal).

La predicción del potencial insecticida de TD obtenidas de yacimientos locales es sencilla, rápida y de bajo costo; esta metodología también sería útil para determinar las etapas de purificación necesarias.

La explotación de yacimientos locales de TD se beneficiaría con un importante valor agregado incorporando la utilización de este producto para el control de insectos. Dada la gran variabilidad en la susceptibilidad reportada para diferentes poblaciones de insectos, la selección de la TD o mezcla de TD óptima a utilizar, debería evaluarse empleando ejemplares de la población a controlar. Asimismo, es probable que la combinación de una TD con alta capacidad de absorción/adsorción, junto con otra por ejemplo, de menor tamaño de partícula, resulte en una mayor eficacia insecticida. El avance en estas investigaciones contribuirá a reducir el empleo de insecticidas químicos, lo que es de especial importancia en el mercado de productos orgánicos.

\section{Hongos entomopatógenos}

La cutícula de insectos es la principal barrera de defensa contra la penetración de hongos entomopatógenos. La infección fúngica comienza por la germinación de conidios y posterior penetración a través de la cutícula del insecto; el hongo crece en el medio interno, llevando a la muerte del insecto (Roberts, 1989). Se ha demostrado en este laboratorio la capacidad de los hongos entomopatógenos para degradar los HC epicuticulares de insectos y utilizarlos para la producción de energía y la incorporación a componentes celulares (Napolitano y Juárez, 1997). En los HC de insectos susceptibles a hongos entomopatógenos predominan cadenas saturadas lineales y ramificadas; contrariamente, una baja susceptibilidad coincide con la presencia de $\mathrm{HC}$ insaturados y de derivados de quinonas presentes en sus secreciones volátiles, como es el caso de $T$. castaneum y $U$. dermestoides (Villaverde y col., 2007; 2009; Pedrini y col., 2010). No se han detectado hasta el momento cepas de hongos entomopatógenos efectivas contra adultos de $T$. castaneum y $U$. dermestoides; los índices de mortalidad son menores al $10 \%$ cuando se utilizan formulados comerciales a las dosis usualmente útiles para la mayoría de los insectos 
susceptibles (Akbar y col., 2004; Pedrini y col., 2010). Sin embargo, se ha reportado $50 \%$ de mortalidad en larvas de $T$. castaneum tratadas en similares condiciones (Akbar y col., 2004). Las larvas exhiben un perfil de HC más simple que los adultos, y tanto el $n-\mathrm{C} 15: 1$ como las $\mathrm{BQ}$ están ausentes de los extractos de las secreciones volátiles (Girotti y Juárez, no publicado), además de presentar una cutícula menos esclerotizada.

En este estudio se ha determinado que la infección fúngica produce un estado de aislamiento e inanición que alteraría en forma importante el desarrollo de las colonias (Tabla IV.6.b). Otros experimentos desarrollados en este laboratorio mostraron que la infección con Beauveria bassiana no altera el contenido total de $B Q$ (comparado con insectos no infectados), pero afecta adversamente la liberación de los VOC alterando el comportamiento de ambos tenebriónidos (Pedrini, 2006; Pedrini y col., 2010). Es probable que la infección fúngica afecte al sistema nervioso dificultando a su vez el mecanismo de secreción glandular de estas sustancias tóxicas.

Por otra parte, se ha descripto que las $B Q$ presentan actividad antimicrobiana (Ruther y col., 2001), lo cual podría explicar la baja susceptibilidad de estos coleópteros a los hongos entomopatógenos. Estos compuestos protegerían al insecto de infecciones fúngicas, inhibiendo el desarrollo del hongo sobre la cutícula. Se ha detectado en este laboratorio que extractos de las secreciones de $T$. castaneum y $U$. dermestoides inhiben el crecimiento in vitro de B. bassiana (Pedrini, 2006). Estas investigaciones, condujeron al desarrollo de una nueva línea de trabajo en el mejoramiento de una cepa de $B$. bassiana para el control de tenebriónidos secretores de $B Q$. Se estudia el gen codificante para 1,4-benzoquinona reductasa fúngica. Mediante la eliminación de este gen específico se ha comprobado su función en la degradación de $B Q$, obteniendo un fenotipo alterado tanto en la tolerancia a la $B Q$ como a la virulencia frente a $T$. castaneum (Pedrini y Juárez, no publicado).

Es evidente entonces que tanto la comprensión de aspectos bioquímicos y metabólicos de las secreciones de defensa de estos insectos, así como de los mecanismos de interacción con hongos entomopatógenos, abre un importante panorama para el desarrollo de mejores estrategias de manejo de estos insectos. 
-Se avanzó en el conocimiento de la estructura y composición de los HC epicuticulares de Tribolium castaneum, identificando 22 nuevos componentes metilramificados.

-Se identificó y determinó la composición de las secreciones de defensa de Ulomoides dermestoides, empleando la técnica de HS-SPME acoplada a CGC-MS. Los principales compuestos volátiles orgánicos (VOC) identificados fueron: metil-1,4benzoquinona (MBQ), etil-1,4-benzoquinona (EBQ), 1-trideceno ( $n$-C13:1) y 1pentadeceno ( $n$-C15:1). En las condiciones de análisis utilizadas, no fue posible detectar dimorfismo sexual evidente en los VOC de U. dermestoides.

-Se estableció un nuevo método libre de solventes y basado en el empleo de técnicas de HS-SPME-CGC-MS, para la detección de los VOC liberados por adultos de $T$. castaneum y $U$. dermestoides.

-Este es el primer método químico que propone la detección de quinonas volátiles como un indicador de contaminación con tenebriónidos en granos almacenados.

-El mecanismo de síntesis del $n$-C15:1 en las glándulas abdominales de estos tenebriónidos ocurriría tanto por la vía de novo, como a partir de palmitato exógeno incorporado a través del alimento. Los datos obtenidos no permiten descartar su síntesis en otros tejidos (integumento y cuerpo graso). Asimismo se demostró síntesis de novo de $\mathrm{BQ}$ en glándulas abdominales de $U$. dermestoides.

-Se seleccionaron tierras de diatomeas (TDs) de yacimientos argentinos en base a la determinación de su capacidad insecticida contribuyendo a la evaluación del potencial económico de yacimientos de TDs.

-La infección con Beauveria bassiana afecta significativamente la secreción de los VOC y el ciclo de vida de T. castaneum y U. dermestoides.

Los resultados obtenidos en esta tesis dieron origen a nuevas líneas de investigación, que emplean distintas herramientas bioquímicas y moleculares para avanzar en la comprensión de los mecanismos involucrados en la vía de síntesis de las secreciones volátiles de estos insectos. A largo plazo se espera que contribuyan al desarrollo/mejoramiento de estrategias ecológicas para el control de plagas. 
Bibliografía 
Adane, K., Moore, D., Archer, S.A. 1996. Preliminary studies on the use of Beauveria bassiana to control Sitophilus zeamais (Coleoptera: Curculionidae) in the laboratory. J. Stored Prod. Res. 32: 105-113.

Akbar, W., Lord, J., Nechols, J., Howard, W. 2004. Diatomaceous earth increases the efficacy of Beauveria bassiana against Tribolium castaneum larvae and increases conidia attachment. J. Econ. Entomol. 97: 273-280.

Aldryhim, Y.N. 1990. Efficacy of the amorphous silica dust, Dryacide, against Tribolium confusum Duv. and Sitophilus granarius (L.). (Coleoptera: Tenebrionidae and Curculionidae). J. Stored Prod. Res. 26: 207-210.

Alexander, P., Barton, H.R. 1943. The excretion of ethylquinone by the flour beetle. Biochem. J. 37: 463-465.

Allen, F. 1972. A natural earth that controls insects. Org. Gard.\& Farm. 19: 50-56.

Arnaud, L., Lognay, G., Verscheure, M., Leenaers, L., Gaspar, C., Haubruge, E. 2002. Is dimethyldecanal a common aggregation pheromone of Tribolium flour beetles? J. Chem. Ecol. 28: 523-532.

Arthur, F.H. 2000. Toxicity of diatomaceous earth to red flour beetles and confused flour beetles (Coleoptera: Tenebrionidae): Effects of temperature and relative humidity. J. Econ. Entomol.93: 526-532.

Athanassiou, C.G., Korunic, Y.Z. 2007. Evaluation of two new diatomaceous earth formulations, enhanced with abamectin and bitterbarkomycin, against four stored-grain beetle species. J. Stored Prod. Res. 43, 468-473.

Attygalle, A.B., Blankespoor, C.L., Meinwald, J., Eisner, T. 1991. Defensive secretion of Tenebrio molitor (Coleoptera: Tenebrionidae). J. Chem. Ecol. 17: 805-809.

Attygalle, A.B., Xu, S.C., Meinwald, J., Eisner, T. 1993. Defensive secretion of the millipede Floridobolus penneri. J. Nat. Prod. 56: 1700-1706.

Augustynowicz M., Malinski E., Warnke Z., Szafranek J., Nawrot J. 1987. Cuticular hydrocarbons of the German cockroach, Blattella germanica L. Comp. Biochem. Physiol. 86B:519-523.

Baker, J.E., Sukkestad, D.R., Woo, S.M., Nelson, D.R. 1978. Cuticular hydrocarbons of Tribolium castaneum: effects of the food additive tricalcium phosphate. Insect Biochem. 8: 159-167.

Baker, J.E., Woo, S.M., Nelson, D.R., Fatland, C.L. 1984. Olefins as major components of epicuticular lipids of three Sitophilus weevils. Comp. Biochem. Physiol. 77B: 877-884.

Bartelt, R.J., Schaner, A.M., Jackson, L.L. 1985. Cis-vaccenyl acetate as an aggregation pheromone in Drosophila melanogaster. J. Chem. Ecol. 11:1747-1756.

Bartelt, R.J., Arnold, M.T., Schaner, A.M. Jackson, L.L. 1986. Comparative analysis of cuticular hydrocarbons in the Drosophila virilis species group. Comp. Biochem. Physiol. 83: 731742.

Beamont, J.W.L. 1945. The cuticular lipids of insects. J. Exp. Biol. 21: 115-131. 
Beeman, R.W., Nanis, S.M. 1986. Malathion resistance alleles and their fitness in the red flour beetle (Coleoptera: Tenebrionidae). J. Econ. Entomol. 79: 580-587

Beeman, R.W., Stuart, J.J. 1990. A gene for lindane + cyclodiene resistance in the red flour beetle (Coleoptera: Tenebrionidae). J. Econ. Entomol. 83: 1745-1751

Beeman, R.W., Stuart, J.J., Denell, R.E., McGaughey, W.H., Dover, B.A. 1992. Tribolium as a model insect for study of resistance mechanisms. Molecular Mechanisms of Insecticide Resistance, Am. Chem. Soc., Washington, DC. pp. 202-208.

Beeman, R.W., Arakane, Y., Phillips, T.W., Muthukrishnan, S. 2010. Implications of the Tribolium genome project for pest biology. Proceedings of the $10^{\text {th }}$ International Working Conference on Stored Product Protection, Portugal: pp 63-71.

Belardi, R.P., Pawliszyn, J. 1989. The application of chemically modified fused silica fibers in the extraction of organics from water matrix samples and their rapid transfer to capillary columns, Water Pollut. Res. J. Canada, 24: 179.

Bloch Qazi, M.C., Boake, C.R.B., Lewis, S.M. 1998. The femoral setiferous glands of Tribolium castaneum males and production of the pheromone 4,8-dimethyldecanal. Entomol. Exp. Appl. 89: 313-317.

Blomquist, G.J., Jackson, L.L. 1979. Chemistry and biochemistry of insect waxes. Prog. Lipid Res. 17: 319-345.

Blomquist G.J., Dillwith J.W. 1985. Cuticular lipids. En: Comprehensive Insect Physiology, Biochemistry and Pharmacology, editado por Kerkut G.A. y Gilbert L.I., $1^{\text {a }}$ edición, pag. 117-154. Pergamon Press, Oxford.

Blomquist G.J., Nelson D.R., de Renobales M. 1987. Chemistry, biochemistry and physiology of insect cuticular lipids. Arch. Insect Biochem. Physiol. 6: 227-265.

Blomquist, G.J., Howard, R.W. 2003. Pheromone biosynthesis in social insects. En: Blomquist, G.J., Vogt, R.G. (Eds.), Insect Pheromone Biochemistry and Molecular Biology. The biosynthesis and detection of pheromones and plan volatiles. Elsevier Academic Press, London: 323-340.

Blomquist, G.J., Vogt, R.G. 2003. Biosynthesis and detection of pheromones and plant volatilesintroduction and overview. En: Blomquist, G.J., Vogt, R.G. (Eds.), Insect Pheromone Biochemistry and Molecular Biology. Elsevier Academic Press, London: 3-18.

Blomquist, G.J., Bagnéres, A.-G. 2010. Introduction: History and overview of insect hydrocarbons In: Blomquist G.J., Bagnéres A.-G.(Eds) Insect Hydrocarbons: Biology, Biochemistry, and Chemical Ecology. Cambridge University Press, 3-18.

Blum, M.S. 1969. Alarm pheromones. Annu. Re. Entomol. 14: 57-80.

Blum, M.S. 1981. Chemical Defenses of Arthropods. Academic Press,New York, NY, USA.

Blum, M.S. 1987. Biosynthesis of arthropod exocrine compounds. Ann. Rev. Entomol. 32: 381 413.

Bolton, J.L., Trush, M.A., Penning, T.M., Dryhurst, G., Monks, T.J. 2000. Role of quinones in toxicology. Chem. Res. Toxicol. 13, 135-160.

Brown, W.V., Doyen, J.T., Moore, B.P., Lawrence, J.F. 1992. Chemical-composition and 
taxonomic significance of defensive secretions of some Australian Tenebrionidae (Coleoptera). J. Aust. Entomol. Soc. 31: 79-89

Buckner, J.S., Pitts-Singer, T.L., Guédot, C. y col. 2009. Cuticular lipids of female solitary bees, Osmia lignaria Say and Megachile rotundata (F.) (Hymenoptera: Megachilidae). Comp. Biochem. Physiol. 153B: 200-205.

Butenandt ,von A., Beckmann, R., Stamm, D., Hecker, E. 1959. Über den sexuallockstoff des seidenspinners Bombyx mori. Reindarstellung und konstitution. Z. Naturforsch. B. 14: 283-284

Buzzi, Z.J., Miyazaki, R.D. 1999. Entomologia didática, Editora da Universidade Federal do Paraná. Curitiba, Paraná, Brazil. 308 pp., (3 Ed.).

Calderón Fernández, G., Juárez, M.P., Ramsey, J., Salazar Schettino, P.M., Monroy, M.C., Ordoñez, R., Cabrera, M. 2005. Cuticular hydrocarbon variability among Triatoma dimidiata (Hemiptera: Reduviidae) populations from Mexico and Guatemala. J. Med. Entomol. 42: 780-788.

Calderón Fernández, G., Girotti, J.R., Juárez, M.P. 2011a. Cuticular hydrocarbons of Triatoma dimidiata (Hemiptera: Reduviidae): intraspecific variation and chemotaxonomy. J. Med. Entomol. 48: 262-271.

Calderón Fernández, G., Girotti, J.R., Juárez M.P. 2011b. The cuticular hydrocarbon pattern as chemotaxonomy marker to assess the intraspecific variability in Triatoma infestans, a major Chagas disease vector. Med. Vet. Entomol. 26: 201-209.

Caputo, B., Dani, F.R, Horne, G.L, Petrarca, V., Turillazzi, F., Coluzzi, M., Priestman, A.A., della Torre, A. 2005. Identification and composition of cuticular hydrocarbons of the major Afrotropical malaria vector Anopheles gambiae s.s. (Diptera: Culicidae): analysis of sexual dimorphism and age-related changes. J. Mass Spectrom. 40: 1595-604.

Caputo, B., Dani F.R., Horne, G.L., N'Fale S., Diabate, A. 2007. Comparative analysis of epicuticular lipid profiles of sympatric and allopatric field populations of Anopheles gambiae s.s. molecular forms and An. arabiensis from Burkina Faso (West Africa). Insect Biochem. Molec. Biol. 37: 389-398.

Carlson D.A., Mayer M.S., Sillhacek D.L., James J.D., Beroza M., Bierl B.A. 1971 Sex attractant pheromone of the housefly: isolation, identification and synthesis. Science 174: 76-78.

Carlson D.A., Service M.W. 1979. Differentiation between species of the Anopheles gambiae Giles complex (Diptera: Culicidae) by analysis of cuticular hydrocarbons. Ann.Trop. Med. Parasit. 73: 589-592.

Carlson D.A., Milstrey S.K., Narang S.K. 1993. Classification of tsetse Glossina spp. (Diptera: Glossinidae) by gas chromatographic analysis of cuticular components. Bull. Entomol. Res. 83: 507-515.

Carlson D.A., Bernier U.R., Sutton B.D. 1998. Elution patterns from capillary GC for methylbranched alkenes. J. Chem. Ecol. 24: 1845-1865. 
Cassini, C., Rodríguez, J., Bartosik, R., Peiretti, J., Cabral, G. 2005. Trigo Eficiencia de Cosecha y Postcosecha de granos. Manual Técnico Nº1. Sección Postcosecha. Ediciones INTA. 120 pp.r

Charnley, A.K. 1991. Microbial pathogens and insect pest control. Lett. Appl. Microbiol. 12: 149157.

Chase, J., Jurenka, R.J., Schal, C, Halarnkar, P.P., Blomquist, G.J. 1990. Biosynthesis of methyl branched hydrocarbons in the German cockroach Blattella germanica (L.) (Orthoptera, Blattellidae). Insect Biochem. 20: 149-156.

Cobb, M., Jallon, J.M. 1990. Pheromones, mate recognition and courtship stimulation in the Drosophila melanogaster species subgroup. Anim. Behav. 39: 1058-1067.

Cocchiararo Bastías, L.M., Mijailovsky, S., Calderón Fernández, G., Lorenzo Figueiras, A., Juárez, M.P. 2011. Epicuticle lipids mediate mate recognition in T. infestans (Hemiptera, Reduviidae). J. Chem. Ecol. 37: 246-252.

Costa, J.J., Margheritis, A.E., Mársico, O.J. 1974. Introducción a la Terapéutica Vegetal. Editorial Hemisferio Sur. Primera Edición. 534 pp.

Costa-Neto, E.M. 2002. The use of insects in folk medicine in the state of Bahia, northeastern Brazil, with notes on insects reported elsewhere in Brazilian folk medicine. Human Ecol. 30: 245-263.

Crespo R., Juárez M.P., Cafferatta L.R.F. 2000. Biochemistry of the interaction between entomopathogenous fungi and their insect host-like hydrocarbons. Mycologia 92: 528536.

Crespo R., Juárez M.P., Dal Bello G., Padín S., Calderón Fernández G., Pedrini N. 2002. Increased mortality of Acanthoscelides obtectus by alkane-grown Beauveria bassiana. BioControl 47: 685-696.

Crespo, R. 2006. Bioquímica de la interacción hongo entomopatógeno-cutícula de triatomino. Tesis de la Facultad de Ciencias Naturales y Museo, UNLP

Crespo, R., Villaverde, M.L., Girotti, J.R., Güerci, A., de Bravo M.G., Juárez, M.P. 2011. Cytotoxic and genotoxic effects of defence secretion of Ulomoides dermestoides on A549 cells. J. Ethnopharm. 36: 204-209.

Cvačka, J., Jiroš, P., Šobotník, J., Hanus, R. Svatoš, A. 2006. Analysis of insect cuticular hydrocarbons using matrix-assisted laser desorption/ionization mass spectrometry. J. Chem. Ecol. 32: 409-434.

Dal Bello, G., Padín, S., López Lastra, C., Fabricio, M. 2001. Laboratory evaluation of chemicalbiological control of the rice weevil (Sitophilus oryzae L.) in stored grains. J. Stored Prod. Res. 37: 77-84.

Dal Bello, G., Padín, S. 2006. Olfatómetro simple para evaluar la actividad biológica de aleloquímicos vegetales en Tribolium castaneum Herbst (Coleoptera: Tenebrionidae). Agrociencia 10: 23-26 
Dal Bello, G., Padín, S., Juárez, M.P., Pedrini, N., De Giusto, M. 2006. Biocontrol of Acanthoscelides obtectus and Sitophilus oryzae with diatomaceous earth and Beauveria bassiana on stored grains. Biocontrol Sci.Technol. 16: 215-220.

Dal Bello, G., Fusé, C., Juárez, M.P., Pedrini, N., Imaz, A., Padín, S. 2011. Insecticidal effect of fenitrothion, diatomaceous earth and Beauveria bassiana against Coleopteran pests on stored grain. Integrated Protection of Stored Products IOBC/wprs Bulletin 69: 175-180

Dallerac, R., C. Labeur, J. M. Jallon, D. C. Knipple, W. L. Roelofs, and C. Wicker-Thomas. 2000. A 9 desaturase gene with different substrate specificity is responsible for the cuticular diene hydrocarbon polymorphism in Drosophila melanogaster. Proc. Natl. Acad. Sci. USA 97: 9449-9454.

Dapporto, L., Liebert, A.E., Starks, P.T., Turillazzi, S. 2009. The relationships between cuticular hydrocarbon composition, faunal assemblages, inter-island distance, and population genetic variation in Tuscan Archipelago wasps. Biochem. Syst. Ecol. 37: 341-348

de Renobales, M., Cripps, C., Stanley-Samuelson, D.W., Jurenka, R.A., Blomquist, G.J. 1987. Biosynthesis of linoleic acid in insects. Trends Biochem. Sci. 12: 364-366.

de Renobales, M., Nelson, D.R., Zamboni, A.C, Mackay, M.E., Dwyer, L.A., Theisen, M.O., Blomquist, G.J. 1989. Biosynthesis of very long-chain methyl branched alcohols during pupal development in the cabbage looper, Trichoplusia ni. Insect Biochem. 19: 209-214.

de Renobales, M., Nelson, D.R., Blomquist, G.J. 1991. Cuticular lipids. The Physiology of the Insect Epidermis (ed. por K. Binnington and A. Retnakaran), pp. 240-251. CSIRO Publications, Australia.

Deschamps, L.R., Reviriego, M.E., Suárez, A.A., Ferrero, A.A. 2004. Reproducción de Sitophilus oryzae L. (Coleoptera: Curculionidae) y de Tribolium castaneum Herbst. (Coleoptera: Tenebrionidae) en cultivares de trigo argentinos. Bol. San. Veg. Plagas.30: 171-176.

Dillwith, J.W., Nelson, J.H., Pomonis, J.G., Nelson, D.R., Blomquist, G.J. 1982. A ${ }^{13}$ C-NMR study of methyl-branched hydrocarbon biosynthesis in the housefly. J. Biol. Chem. 257: 11305-11314.

Eisner, T. 1966. Beetle's spray discourages predators. Nat. History 75: 42-47.

Eisner, T., Eisner, M., Attygalle, A.B., Deyrup, M., Meinwald, J. 1998. Rendering the inedible edible: circumvention of a millipede's chemical defense by a predaceous beetle larva (Phengodidae). Proc. Natl. Acad Sci. USA 95: 1108-1113.

Etges, W.J., Jackson, L.L. 2001. Epicuticular Hydrocarbon Variation in Drosophila mojavensis Cluster Species. J. Chem. Ecol. 27: 2125-2149.

Ezquerro, O., Pons, B., Tena, M.T. 2003. Multiple headspace solid-phase microextraction for the quantitative determination of volatile organic compounds in multilayer packaging. J. Chromatogr. A 999: 155-164.

Ezquerro, O., Tena, M.T. 2005. Determination of odour-causing volatile organic compounds in cork stoppers by multiple headspace solid-phase microextraction. J. Chromatogr. A 1068: 201-208. 
Faustini, D.L., Burkholder, W.E., Laub, R.J. 1981. Sexually dimorphic setiferous sex patch in the male red flour beetle, Tribolium castaneum (Herbst) (Coleoptera: Tenebrionidae): Site of aggregation pheromone production. J. Chem. Ecol. 7: 465-480.

Fedina, T.Y., Lewis, S.M. 2007. Effect of Tribolium castaneum (Coleoptera: Tenebrionidae) nutritional environment, sex and mating status on response to commercial pheromone traps. J. Econ. Entom. 100: 1924-1927.

Fields, P.G. 1992. The control of stored products insects and mites with extreme temperaturas. J. Stored Prod. Res. 28: 89-118.

Flores, G.E., Padín, S.B., Stetson, E. 2002. First record of the Oriental species of Ulomoides dermestoides (Coleoptera: Tenebrionidae) in Argentina. Rev. Soc. Entomol. Argent. 61: 48-50.

Fontán, A., González Audino, P., Martínez, A., Alzogaray, R.A., Zerba, E.N., Camps, F., Cork, A. 2002. Attractant volatiles released by female and male Triatoma infestans (Hemiptera: Reduviidae), a vector of Chagas disease: chemical analysis and behavioral bioassay. J. Med. Entomol. 39: 191-197.

Free, J.B., Ferguson, A.W., Pickett, J.A. 1981: Evaluation of the various components of the Nasonov pheromone used by clustering honeybees. Physiol. Entomol. 6: 263-268.

Geiselhardt, S., Szepat, T., Rasa, O.A.E., Peschke, K. 2006. Defensive secretion components of the host Parastizopus armaticeps as kairomones for the cleptoparasite Eremostibes opacus. J. Chem. Ecol. 32:767-778

Geiselhardt, S., Ockenfels, P., Peschke, K. 2008. 1-Tridecene male-produced sex pheromone of the tenebrionid beetle Parastizopus transgariepinus. Naturwissenschaften 95: 247-251.

Gibbs, A.G. 1995. Physical properties of insect cuticular hydrocarbons: model mixtures and lipid interactions. Comp. Biochem. Physiol. 112B: 667-672.

Ginzel, M.D., Hanks, L.M. 2005. Role of host plant volatiles in mate location for three species of long-horned beetles. J. Chem. Ecol. 31: 213-217.

Girotti, J.R., Mijailovsky, S.J., Juárez, M.P. 2012. Epicuticular hydrocarbons of the sugarcane borer Diatraea saccharalis (Lepidoptera: Crambidae). Physiol. Entomol. 37: 266-277.

Golob, P. 1997. Current Status and Future Inert Dusts for Control of Insects J. Stored Prod. Res. 33: 69-79.

Görgen, G. Frobl, C., Boland, W, Dettner, K. 1990. Biosynthesis of 1-alkenes in the defensive secretions of the beetle Tribolium confusum (Tenebrionidae); stereochemical implications. Experientia 46: 700-704.

Gu, P., Welch, W.H., Blomquist, G.J.1993. Methyl-branched fatty acid biosynthesis in the German cockroach, Blattella germanica: kinetic studies comparing microsomal and soluble fatty acid synthetases. Insect Biochem. Mol. Biol. 23: 263-271.

Hackman, R.H. 1971. The integument of Arthropoda. In Florkin, M. y Scheer, B.T. (eds), Chemical Zoology, Vol. 6, pp.1-62. Academic Press, NY. 
Hadley, N.E. 1984. Cuticle: Ecological significance. In Bereiter-Hahn, J., Matoltsy, A.G., y Richards, K.S. (eds.), Biology of the integument, Vol. 1, pp. 685-702. Spring-Verlag, Berlin.

Happ, G.M. 1968. Quinone and hydrocarbon production in the defensive glands of Eleodes longicollis and Tribolium castaneum (Coleoptera, Tenebrionidae). J. Insect Physiol. 14: 1821-1837.

Hatami, P., Imani, S., Larijani, K. 2011. Isolation and Identification of volatiles compounds from Rice Weevil, Sitophilus oryzae (Coleoptera: Curculionidae) in Iran with Solid Phase Micro Extraction (SPME) and Headspace Chromatography. Ann. Biol. Res. 2: 528-531.

Haverty, M.I., Grace, J.K., Nelson, L.J., Yamamoto, R.T. 1996. Intercaste, intercolony, and temporal variation in cuticular hydrocarbons of Coptotermes formosanus shiraki (Isoptera: Rhinotermitidae). J. Chem. Ecol. 22: 1813-1834.

Hebanowska, E., Maliñski, E., Nawrot, J., Ruszkowska, M, Pihlaja, K., Szafranek, J. 1989. The composition of cuticular hydrocarbons of the cereal aphids Sitobion avenae $\mathrm{F}$. (Homoptera, aphididae). Comp. Biochem. Physiol. 94B:723-727.

Hidalgo, E., Moore, D., Le Patourel, G. 1998. The effect of different formulations of Beauveria bassiana on Sitophilus zeamais in stored maize. J. Stored Prod. Res. 34:171-179.

Hodges, R.J., Robinson, R., Hall, D.R. 1996. Quinone contamination of dehusked rice by Tribolium castaneum (Herbst) (Coleoptera: Tenebrionidae). J. Stored Prod. Res 32: 3137.

Hölldobler, B., Michener, C. 1980. Mechanisms of identification and discrimination in social Hymenoptera. In: Markl H, (ed). Evolution of social behavior: hypotheses and empirical tests. Verlag Chemie; Weinheim, Germany: 35-58.

Horne, G.L., Priestman, A.A. 2002. The chemical characterization of the epicuticular hydrocarbons of Aedes aegypti (Diptera: Culicidae). Bull. Entomol. Res. 92: 287-294.

Howard, R.W., McDaniel C.A., Blomquist G.J. 1978. Cuticular hydrocarbons of the Eastern subterranean termite Recticulitermes flavipes (Kollar) (Isoptera: Rhinotermitidae). J. Chem. Ecol. 4: 233-245.

Howard, R.W., Blomquist, G.J. 1982. Chemical ecology and biochemistry of insect hydrocarbons. Annu. Rev. Entomol. 27: 149-72.

Howard, R.W. 1987. Chemosystematic Studies of the Triboliini (Coleoptera: Tenebrionidae): Phylogenetic Inferences from the Defensive Chemicals of Eight Tribolium spp., Palorus ratzeburgi (Wissmann), and Latheticus oryzae Waterhouse. Ann. Entomol. Soc. Am. 80: 398-405.

Howard, R.W., Liang, Y. 1993. Cuticular hydrocarbons of winged and wingles morphs of the ectoparasitoid Choetospila elegans westwood (Hymenoptera: Pteromalidae) and its host, larval lesser grain borer (Rhyzopertha dominica) (Coleoptera: Bostrichidae). Comp. Biochem. Physiol. 106B: 407-414.

Howard, R.W., Blomquist, G.J. 2005. Ecological, behavioral, and biochemical aspects of insect hydrocarbons. Annu. Rev. 50: 371-393. 
Hu, J., 2006. Application of PCA Method on Pest Information Detection of Electronic Nose. International Conference on Information Acquisition. Shandong, P.R. China.

Islam, N., Bacala, R., Moore, A., Vanderwel, D. 1999. Biosynthesis of 4-methyl-1-nonanol: Female-produced sex pheromone of the yellow mealworm beetle, Tenebrio molitor (Coleoptera: Tenebrionidae). Insect Biochem Mol Biol. 29: 201-208.

Ivarsson, P., Schlyter, F., Birgersson, G. 1993. Demonstration of de novo pheromone biosynthesis in Ips duplicatus (Coleoptera: Scolytidae): inhibition of ipsdienol and Emyrcenol production by compactin. Insect Biochem Mol Biol. 23: 655-662

Jackson, L.L., Bartelt, R.J. 1986. Cuticular hydrocarbons of Drosophila virilis: comparison by age and sex. Insect Biochem. 16: 433-439.

Jallon, J.M., David, J.R. 1987. Variations in cuticular hydrocarbons among the eight species of the Drosophila melanogaster subgroup. Evolution. 41: 294-302.

Juárez M.P., Brenner R.R., Gros E.G. 1984. The epicuticular lipids of Triatoma infestans. I. Glycerides. Comp. Biochem. Physiol. 78B: 427-431.

Juárez M.P., Brenner R.R. 1985. The epicuticular lipids of Triatoma infestans, II. Hydrocarbon dynamics. Comp. Biochem. Physiol. 82B: 793-803.

Juárez M.P., Brenner R.R. 1986. Bioquímica del ciclo evolutivo de Triatoma infestans. IX. Composición de los hidrocarburos cuticulares comparada con otros triatominos. Acta Physiol. Pharmacol. Latinoam. 36: 47-57.

Juárez, M.P., Brenner R.R. 1989. Fatty acid biosynthesis in the integument tissues of Triatoma infestans. Comp. Biochem. Physiol. 93B: 763-772.

Juárez, M.P., Chase, J., Blomquist, G.J. 1992. A microsomal fatty acid synthetase from the integument of Blattella germanica synthesizes methyl-branched fatty acids, precursors to hydrocarbon and contact sex pheromone. Arch. Biochem. Biophys. 293: 333-341.

Juárez, M.P., Blomquist, G.J. 1993. Cuticular hydrocarbons of Triatoma infestans and T. mazzottii. Comp. Biochem. Physiol. 106B: 667-674.

Juárez, M.P. 1994a. Inhibition of cuticular lipid synthesis and its effect on insect survival. Arch. Insect Biochem. Physiol. 25:177-191.

Juárez, M.P. 1994b. Hydrocarbons biosynthesis in Triatoma infestans eggs. Arch. Insect Biochem. Physiol. 25:193-206.

Juárez, M.P. 1995. The effect of sublethal doses of insecticides on Triatoma infestans cuticular lipids synthesis. Pestic. Biochem. Physiol. 52:81-89.

Juárez, M.P. 1996. Composición de efecto insecticida. In: \# 249780, Argentina.

Juárez, M.P., Ayala, S., Brenner, R.R. 1996. Methyl-branched fatty acid biosynthesis in Triatoma infestans. Insect Biochem. Molec. Biol. 26: 593-598.

Juárez, M.P., Napolitano, R. 2000. Effects of organic acids on lipid synthesis and ecdysis in Triatoma infestans eggs. Comp. Biochem. Physiol. 125B: 503-510.

Juárez, M.P, Crespo, R., Calderón Fernández, G., Lecouna, R., and Cafferata, L.F.R. 2000. Characterization and carbon metabolism in fungi pathogenic to Triatoma infestans, a Chagas Disease Vector. J. Invertebr. Pathol. 76: 198-207. 
Juárez, M.P., Blomquist, G.J., Schofield, C.J. 2001. Hydrocarbons of Rhodnius prolixus, a Chagas disease vector. Comp. Biochem. Physiol. 129B: 733-746.

Juárez, M.P., Carlson D.A., Salazar-Schettino P.M., Mijailovsky S., Rojas G. 2002. Cuticular hydrocarbons of Chagas disease vectors in Mexico. Mem. Inst. Oswaldo Cruz. 97: 819827.

Juárez, M.P. 2004. Elongation reactions involved in the formation of hydrocarbons in Blatella germanica integument. Arch. Insect Biochem. Physiol. 56: 170-178

Juárez, M.P., Calderón Fernández, G.M. 2007. Cuticular hydrocarbons of triatomines. Comp. Biochem. Physiol. 147A: 711-730.

Juárez M.P., Pedrini N., Girotti J.R., Mijailovsky S.J. 2010. Pyrethroid resistence in Chagas disease vectors: The case of Triatoma infestans cuticle. Resistance Pest Managnment Newsletter, 19: 59-61.

Jurenka, R.A., Subchev, M. 2000. Identification of cuticular hydrocarbons and the alkene precursor to the pheromone in hemolymph of the female gypsy moth, Lymantria dispar. Arch. Insect Biochem. Physiol. 43:108-115.

Karlson, P., Butenandt, A. 1959. Pheromones (ectohormones) in insects. Annu Rev Entomol 4: 49-58.

Khorramshahi, A., Burkholder, W.E. 1981. Behavior of the lesser grain borer Rhyzopertha dominica (Coleoptera: Bostrichidae) male produced aggregation pheromone attracts both sexes. J. Chem. Ecol. 7: 33-38.

Kim, J, Matsumaya, S., Suzuki, T. 2005 4,8-dimethyldecanal, the aggregation pheromone of Tribolium castaneum, is biosynthesized through the fatty acid pathway. J. Chem. Ecol. 31: $1381-1400$.

Kolattukudy, P.E., Croteau, R., Bruckner, J.S. 1976. Biochemistry of plant waxes. En: Chemistry and Biochemistry of Natural Waxes, editado por Kolattukudy P.E., pp. 201-233, Elsevier, Amsterdam.

Korunic, Z. 1997. Rapid assessment of the insecticidal value of diatomaceous earths without conducting bioassays. J. Stored Prod. Res. 33: 219-229.

Korunic, Z. 1998. Diatomaceous earths, a group of natural insecticides. J. Stored Prod. Res. 34: 87-97.

Korunic, Z., Fields, P. 2006. Susceptibility of three species of Sitophilus to diatomaceous earth. 9th International Working Conference on Stored Product Protection. pp 681-685.

Kovats, E. 1965. Gas chromatographic comparison of organic substances in the retention index system. Adv. Chromatogr. 1: 229-247.

Lacey, L.A, Frutos, R., Kaya, H.K., Vail, P. 2001. Insect pathogens as biological control agents: do they have a future? Biol. Control. 21: 230-248.

Lacey, E.S., Ginzel, M.D., Millar, J.C., Hanks, L.M. 2004. Male production aggregation pheromone of the cerambycid beetle Neoclytus acuminatus acuminatus. J. Chem. Ecol. 30: $1493-1507$. 
Le Conte, Y., Arnold, G., Trouiller, J., Masson, C. 1990. Identification of a brood pheromone in honeybees. Naturwissenschaften. 81: 462-465.

Li, J., Lehmann, S., Bernhard, G.J., Wimmer, E.A. 2013. Odoriferous Defensive Stink Gland Transcriptome to Identify Novel Genes Necessary for Quinone Synthesis in the Red Flour Beetle, Tribolium castaneum. PloS Genet. 9: e1003596.

Lima, I.S., House, P.E, do Nascimento, R.R. 2001. Volatile Substances from Male Anastrepha fraterculus Wied. (Diptera: Tephritidae): Identification and Behavioural Activity. J. Braz. Chem. Soc. 12: 196-201.

Locke, M. 1965. Permeability of the insect cuticle to water and lipids. Science. 147: 295-298.

Lockey, K.H. 1976. Cuticular hydrocarbons of Locusta, Schistocerca and Periplaneta, and their role in waterproofing. Insect Biochem. 6: 457-472.

Lockey, K.H. 1978. The adult cuticular hydrocarbons of Tenebrio molitor L. and Tenebrio obscurus F. (Coleoptera: Tenebrionidae). Insect Biochem. 8: 237-250

Lockey, K.H. 1985. Insect cuticular lipids. Comp. Biochem. Physiol. 81B: 263-273.

Lockey, K.H. 1988. Lipids of the insect cuticle: origin, composition and function. Comp. Biochem. Physiol. 89B: 595-645.

Loconti, J.D., Roth, L.M. 1953. Composition of the odorous secretion of Tribolium castaneum. Ann. Entom. Soc. Amer. 46: 281-289.

Lorenzo Figueiras, A.N., Girotti, J.R., Mijailovsky, S.J., Juárez, M.P. 2009. Epicuticular lipids induce aggregation in Chagas disease vectors. Parasit Vectors. 2: 1-7

Lord, H., Pawliszyn, J. 2000. Microextraction of drugs. J. Chromatogr. A. 902: 17-63.

Lord, J.C. 2001. Desiccant dusts synergize the effect of Beauveria bassiana (Hyphomycetes: Moniliales) on stored-grain beetles. J. Econ. Entom. 94: 367-372.

Lord, J.C. 2005. Stored grain and flour insects and their management. En: Encyclopedia of Entomology. Part 19. pp 2133-2138. Springer Netherlands Publishers.

Lord, J.C. 2007. Desiccation increases the efficacy of Beauveria bassiana for stored-grain pest insect control. J. Stored Prod. Res. 43: 535-539.

Lu, Y., Beeman, R.W., Campbell, J.F., Park, Y., Aikins, M.J., Mori, K., Akasaka, K., Tamogami, S., Phillips, T.W. 2011. Anatomical localization and stereoisomeric composition of Tribolium castaneum aggregation pheromones. Naturwissenschaften. 98: 755-761

Maki, E.C., Rodstein, J., Millar, J.G., Barbour, K.S., Hanks, L.M., Barbour, J.D. 2011. Synthesis and Field Tests of Possible Minor Components of the Sex Pheromone of Prionus californicus. J. Chem. Ecol. 37: 714-716.

Marinoni, R.C, Ribero-Costa, C.S. 2001. Influence of temperature and diet on the development of the Ulomoides dermestoides (Fairmaire, 1893) (Coleoptera, Tenebrionidae, Diaperinae). Braz. arch. biol. technol. 44: 129-134.

Martin, S.J., Drijfhout, F.P. 2009. Nestmate and task cues are influenced and encoded differently within ant cuticular hydrocarbon profiles. J. Chem. Ecol. 35: 368-374.

Martinez-Urunuela, A., Gonzalez-Saiz, J.M., Pizarro, C. 2005. Multiple solid-phase microextraction in a non-equilibrium situation. Application in quantitative analysis of 
chlorophenols and chloroanisoles related to cork taint in wine. J. Chromatogr. A. 1089: 31-38.

McCarthy, E.D., Han, J., Calvin, M. 1968. Hydrogen Atom Transfer in Mass Spectrometric Fragmentation Patterns of Saturated Aliphatic Hydrocarbons. Anal. Chem. 40: 14751480.

Meinwald, J., Koch, K. F., Rogers, J. E. Jr., Eisner, T. 1966. Biosynthesis of arthropod secretions. III. Synthesis of simple p-benzoquinones in a beetle (Eleodes longicollis). J. Am. Chem. Soc. 88: 1590-1592.

Merzendorfer, H., Kim, H.S., Chaudhari, S.S., Kumari, M., Specht, C.A., Butcher, S., Brown, S.J., Manak, J.R., Beeman, R.W., Kramer, K.J., Muthukrishnan, S. 2012. Genomic and proteomic studies on the effects of the insect growth regulator diflubenzuron in the model beetle species Tribolium castaneum. Insect Biochem. Mol. Biol. 42: 264-276.

Mewis, I., Ulrichs, M. 2001. Action of amorphous diatomaceous earth against different stages of the stored product pests Tribolium confusum, Tenebrio molitor, Sitophilus granarius and Plodia Interpunctella. J. Stored Prod. Res. 37: 153-164

Moino, J.R.A., Alves, S.B., Pereira, R.M. 1998. Efficacy of Beauveria bassiana (Balsamo) Vuillemin isolates for control of stored-grain pests. J. Appl. Entomol. 122:301-305.

Monks, T.J., Jones, D.C. 2002. The metabolism and toxicity of quinones, quinoneimines, quinone methides, and quinone-thioethers. Current Drug Metabolism 3: 425-438.

Mullen, S.P., Millar, J.G., Schal, C., Shaw K.L. 2007. Identification and Characterization of Cuticular Hydrocarbons from a Rapid Species Radiation of Hawaiian Swordtailed Crickets (Gryllidae: Trigonidiinae: Laupala ). J. Chem. Ecol. 34: 198-204.

Napolitano, R., Juárez, M.P. 1997. Entomopathogenous fungi degrade epicuticular hydrocarbons of Triatoma infestans. Arch. Biochem. Biophys. 344: 208-214.

Nelson, D.R., Fatland, C.L., Howard, R.W., McDaniel, C.A., Blomquist, G. J. 1980. Re-analysis of the cuticular methylalkanes of Solenopsis invicta and S. richteri. Insect Biochem. 10: 409-418.

Nelson, D.R., Dillwith, J.W., Blomquist, G.J. 1981. Cuticular hydrocarbons of the housefly Musca domestica. Insect Biochem. 11: 187-197.

Nelson, D.R., Nunn, N.N., Jackson, L.L. 1984. Re-analysis of the methylalkanes of the grasshoppers Melanoplus differentialis, M. packardii and M. sanguinipes. Insect Biochem. 14: 677-683.

Nelson, D.R., Carlson, D.A. 1986. Cuticular hydrocarbons of the tse-tse flies Glossina morsitans morsitans, G. austeni and G. pallidipes. Insect Biochem. 16: 403-416.

Nelson, D.R., Carlson, D.A., Fatland, C.L. 1988. Cuticular hydrocarbons of tsetse flies II: Glossina fuscipes fuscipes, G. palpalis palpalis, G. p. gambiensis, G. tachinoides, and G. brevipalpis. J. Chem. Ecol. 14: 963-987.

Nelson, D.R., Blomquist, G.J. 1995. Insect Waxes. En: Hamilton, R.J., editor. Waxes: Chemistry, Molecular Biology and Functions. W. W. Christie, The Oily Press: London, pp 1-90. 
Nelson, D.R., Adams, T.S., Fatland, C.L. 2003. Hydrocarbons in the surface wax of eggs and adults of the Colorado potato beetle, Leptinotarsa decemlineata. Comp. Biochem. Physiol. 134B: 447-466.

Nerio, L., Olivero-Verbel, J., Stashenko, E. 2009. Repellent activity of essential oils from seven aromatic plants grown in Colombia against Sitophilus zeamais Motschulsky (Coleóptera). J. Stored Prod. Res. 45: 212-214.

Neville, A. C. 1975. Biology of the Arthropod cuticle. N.Y. Springer.

Nojima, S., C. Schal, F. X. Webster, R. Santangelo, y W. Roelofs. 2005. Identification of sex pheromone of the German cockroach, Blattella germanica. Science 307: 1104-1106.

Nojima, S., Shimomura, K., Honda, H., Yamamoto, I., Ohsawa. K. 2007. Contact sex pheromone components of the cowpea weevil, Callosobruchus maculatus. J. Chem. Ecol. 33: 923-933.

Padín, S., Dal Bello, G., Vasicek, A.L. 1997. Pathogenicity of Beauveria bassiana for adults of Tribolium castaneum (Coleoptera: Tenebrionidae) in stored grains. Entomophaga 42: 569-574.

Padín, S., Dal Bello, G., Fabrizio, M. 2002. Grain loss caused by Tribolium castaneum, Sitophilus oryzae and Acanthoscelides obtectus in stored durum wheat and beans treated with Beauveria bassiana. J. Stored Prod. Res. 38: 69-74.

Page, M., Nelson, L.J., Blomquist, G.J., Seybold, S.J. 1997. Cuticular Hydrocarbons as Chemotaxonomic Characters of Pine Engraver Beetles (Ips spp.) in the grandicollis Subgeneric Group. J. Chem. Ecol. 23: 1053-1099.

Pankewitz, F., Hilker, M. 2008. Polyketides in insects: ecological role of these widespread chemicals and evolutionary aspects of their biogenesis. Biol. Rev. 83: 209-226

Pappas, P.W., Wardrop, S.M. 1996. Quantification of benzoquinones in the flour beetles, Tribolium castaneum and Tribolium confusum. Prep. Biochem. Biotech. 26: 53-66.

Pawliszyn, J. 1997. Solid Phase Microextraction. Theory and Practice. Wiley, New York, NY.

Pedrini, N., Dal Bello, G., Padín, S., Juárez, M.P. 2001. Capacidad insecticida de Beauveria bassiana cultivada en hidrocarburos para el control de coleópteros en granos almacenados. Agrociencia 15(1): 64-69.

Pedrini, N. 2006. Enzimas fúngicas involucradas en el catabolismo de hidrocarburos. Su aplicación a la optimización de bioinsecticidas. Tesis de la Facultad de Ciencias Exactas, UNLP.

Pedrini, N., Juárez, M.P., Crespo, R. 2007. Biochemistry of insect epicuticle degradation by entomopathogenic fungi. Comp. Biochem. Physiol. C 146, 124-137.

Pedrini N., Mijailovsky S.J., Girotti J.R., Stariolo R., Cardozo R.M., Gentile A., Juárez M.P. 2009. Control of pyrethroid-resistant Chagas disease vectors with entomopathogenic fungi. PLoS Negl. Trop. Dis. 3: e434.

Pedrini, N., Villaverde, M.L., Fuse, C.B., Dal Bello, G., Juárez, M.P. 2010. Beauveria bassiana infection alters colony development and defensive secretions of the beetles Tribolium 
castaneum and Ulomoides dermestoides (Coleoptera: Tenebrionidae). J. Econ. Entomol. 103: 1094-1099.

Peschke, K., Eisner, T. 1987. Defensive secretion of the tenebrionid beetle, Blaps mucronata: physical and chemical determinants of effectiveness. J. Comp. Physiol. A: 161: 377-88.

Peschke, K., Metzler, M. 1987. Cuticular hydrocarbons and female sex pheromones of the rove beetle, Aleochara curtula (Goeze) (Coleoptera: Staphylinidae). Insect Biochem. 17:167178

Pfeifer, R.W, Irons, R.D. 1983. Alteration of lymphocyte function by quinones through a sulfhydryl-dependent disruption of microtubule assembly. Int. J. Immunopharmacol. 5:463-470.

Phillips, T.W. 1997. Semiochemicals of Stored-product Insects: Research and Applications. J. Stored Prod. Res. 33: 17-30.

Pierce, A.M., Pierce, H.D.Jr., Oehlschlager, A.C., Borden, J.H. 1985. Macrolide aggregation pheromones in Oryzaephilus surinamensis and Oryzaephilus mercator (Coleoptera: Cucujidae). J. Agric. Food Chem. 33: 848-852.

Qazi, M.C.B., Boake, C.R.B., Lewis, S.M. 1998. The femoral setiferous glands of Tribolium castaneum males and production of the pheromone 4,8-dimethyldecanal. Entomol. Exp. Appl. 89: 313-317.

Quarles, W. 1992. Diatomaceous earth for pest control. IPM Practitiones 14: 1-11.

Qui, Y., Tittiger, C., Wicker-Thomas,C., Le Goff, G., Young, S., Wajnberg, E., Fricaux, T., Taquet, N., Blomquist, G.J., Feyereisen, R. 2012. An insect-specific P450 oxidative decarbonylase for cuticular hydrocarbon biosynthesis. Proc. Natl. Acad. Sci. U.S.A 109: 14858-14863.

Rees, D. 2004. Beetles (Order: Coleoptera) Insects of Stored Products. CSIRO. Australia. 181.

Resolución N¹975/94 2007. De la Secretaría de Agricultura, Ganadería y Pesca de la Nación. Republica Argentina.

Rice, W.C., Cogburn, R.R. 1999. Activity of the entomopathogenic fungus Beauveria bassiana (Deuteromycota: Hyphomycetes) against three Coleopteran pests of stored grain. J. Econ. Entomol. 92: 691-694.

Richards S., Gibbs, R.A., Weinstock, G.M., Brown, S.J., y col. 2008. The genome of the model beetle and pest Tribolium castaneum. Nature 452: 949-955.

Rimoldi, O. J; Peluffo, R. O; González, S.M., Brenner, R.R. 1985. Lipid digestion, absorption and transport in Triatoma infestans. J. Comp. Biochem. Physiol. B: 82: 187-190.

Roberts, D.W. 1989. Picture of biological control of insects by fungi. Mem. Inst. Oswaldo Cruz 84: 89-100.

Rochat, D., Ramirez-Lucas, P., Malosee, C., Aldana, R., Kakul, T., Morin, J-P., 2000. Role of solid-phase microextraction in the identification of highly volatile pheromones of two rhinoceros beetles Scapanes australis and Strategus alous (Coleoptera, Scarabaeidae, Dynastinae). J. Chromatogr A 885, 433-444. 
Rodstein, J., McElfresh, J.S., Barbour, J.D., Ray, A.M., Hanks, L.M., Millar, J.G. 2009. Identification and Synthesis of a Female-Produced Sex Pheromone for the Cerambycid Beetle Prionus Californicus. J. Chem. Ecol. 39: 590-600.

Roth, L.M., Howland, R.B. 1941 Studies on the gaseous secretion of Tribolium confusum Duval. I. Abnormaliteies produced in Tribolium confusum Duval by exposure to a secretion given off by the adults. Ann Entomol Soc Am 34: 151-175.

Roth, L.M. 1943. Studies on the gaseous secretion of Tribolium confusum Duval. Ann. Entomol. Soc. Am. 36: 397-425.

Rudinsky, J., Morgan, M., Libbey, L., Putnam, T. 1977. Limonene released by the scolytid beetle Dendroctonus pseudotsugae Z. angew. Entomol. 82: 376-380.

Ruppert, E.E., Barnes,R.D. 1996. Zoología de los Invertebrados. McGraw - Hill Interamericana.

Ruther, J., Reinecke, A., Tolasch, T., Hilker, M. 2001. Make love not war a common arthropod defence compound as sex pheromone in the forest cockchafer Melolontha hippocastani. Oecologia 128: 44-47.

Schmuff, N.R., Philips, J.K., Burkholder, W.E., Fales, H.M., Chen, C.W., Roller, P.P., Ma, M. 1984. The chemical identification of the rice weevil and maize weeli aggregation pheromone. Tetrahedron Lett. 25:1533-1534.

Seitz, L.M., Ram, M.S., Rengarajan, R., 1999. Volatiles obtained from whole and ground grain samples by supercritical carbon dioxide and direct helium purge methods: observations on 2,3-butanediols and halogenated anisoles. J. Agric. Food Chem. 47: 1051-1061

Seitz, L.M., Ram, M.S. 2004. Metabolites of lesser grain borer in grains. J. Agric. Food Chem. 52: 898-908.

Seybold, S., Quilici, D., Tillman, J., Vanderwel, D.; Wood, D., Blomquist, G.J. 1995. De novo biosynthesis of the aggregation pheromone components ipsenol and ipsdienol by the pine bark beetle Ips paraconfusus Lanier and Ips pini (Say) (Coleoptera: Scolytidae). Proc. Natl. Acad. Sci. USA. 92: 8393-8397.

Seybold, S., Vanderwel, D. 2003. Biosynthesis and endocrine regulation of pheromone production in the Coleoptera. en: Blomquist, G.J., Prestwich, G.D. (Eds.), Pheromone Biochemistry. Academic Press, Orlando, Florida, 137-200.

Smith, S.M., Oduor, G.I., Moore, D. 1998. Preliminary investigations into the potential of entomopathogenic fungi for the control of pests of stored maize. En: Smith, P.H., editor. Insect pathogens and insect parasitic nematodes: Bulletin IOBC/SROP. p 53-60.

Soliday, C.L., Blomquist, G.J., Jackson, L.L. 1974. Cuticular lipids of insects. VI. Cuticular lipids of the grasshoppers Melanoplus sanguinipes and Melanoplus packardii. J. Lipid Res. 15: 399-405.

Sosa-Gómez, D.R., Boucias, D.G., Nation, J.L. 1997. Attachment of Metarhizium anisopliae to de southern green stink bug Nezara viridula cuticle and fungistatic effect of cuticular lipids and aldehydes. J. Invertebr. Pathol. 69:31-39. 
Spikes, A.E., Paschen, M.A., Millar, J.G., Moreira, J.A., Hamel, P.B., Schiff, N.M., Ginzel, M.D. 2010. First Contact Pheromone Identified for a Longhorned Beetle (Coleoptera: Cerambycidae) in the Subfamily Prioninae. J. Chem. Ecol. 36: 943-954.

Sponsler, R.C., Apel, A.G. 1990. Aspects of the water relations of the Formosan and Eastern subterranean termites (Isoptera: Rhinotermitidae). Environ. Entomol. 19: 15-20.

Stanley-Samuelson, D.W., Jurenka, R.A., Cripps, C., Blomquist, G.J., de Renobales, M. 1988. Fatty acids in insects: Composition, metabolism and biological significance. Arch. Insect Biochem. Physiol. 9: 1-33.

Stetter, J.R., Findlay Jr, M.W., Schroeder, K.M., Yue, C., Penrose, W.R., 1993. Quality classification of grain using a sensor array and pattern recognition. Anal. Chim. Acta. 284: $1-11$.

Subramanyam, B.H., Roesli, R. 2000. Inert dusts, pp. 321-380. En: Alternatives to pesticides in stored-product IPM. Subramanyam, B.H., Hagstrum, D.W. (eds.). Kluwer Academic Publishers, Boston, Massachusetts.

Suzuki, T., Suzuki, T., Huynh, V.M., Muto, T. 1975. Hydrocarbon repellents isolated from Tribolium castaneum and T. confusum (Coleoptera: Tenebrionidae). Agric. Biol. Chem. 39: 2207-2211.

Suzuki, T., Sugawara, R. 1979. Isolation of an aggregation pheromone from the flour beetles, Tribolium castaneum and T. confusum (Coleoptera: Tenebrionidae). App. Entomol. Zool. 14: 228-230.

Suzuki, T. 1980. 4,8-Dimethyldecanal: the aggregation pheromone of the flour beetles, Tribolium castaneum and T. confusum (Coleoptera: Tenebrionidae). Agric. Biol. Chem. 44: 2519-2520.

Suzuki, T., Nakakita, H., Kuwahara, Y. 1987. Aggregation pheromone of Tribolium freemani Hinton (Coleoptera, Tenebrionidae): I. Identification of the aggregation pheromone. Appl. Entomol. Zool. 22:340Y347.

Szafranek, B., Maliñski, E., Nawrot, J., Sosnowska, D., Ruszkowska, M., Pihlaja, K., Trumpakaj, Z., Szafranek, J. 2001. In vitro effects of cuticular lipids of the aphids Sitobion avenae, Hyalopterus pruni and Brevicoryne brassicae on growth and sporulation of the Paecilomyces fumosoroseus and Beauveria bassiana. ARKIVOC (iii):81-84.

Takahashi, A., Tsaur, S-C., Coyne, J.A. and Wu, C-L. 2001. The nucleotide changes governing cuticular hydrocarbon variation and their evolution in Drosophila melanogaster. Proc. Natl. Acad. Sci. USA. 98: 3920-3925.

Tanaka, K., Ohsawa, K., Honda, H., Yamamoto, I. 1981. Copulation release pheromone erectin from the azuki bean weevil (Callosobruchus chinensis L.). J. Pestic. Sci. 6: 75-82

Tillman, J.A., Seybold, S.J., Jurenka, R.A., Blomquist, G.J. 1999. Insect pheromones-an overview of biosynthesis and endocrine regulation. Insect Biochem. Mol. Biol. 29:481514.

Tittiger, C., Blomquist, G.J. 2009. Hydrocarbon-forming oxidative decarbonylase enzyme, hydrocarbons produced thereby, and method of use. Patente \#20100136595, EEUU. 
Tschinkel, W.R. 1975a. Unsual occurrence of aldehydes and ketones in the defensive secretion of the tenebrionid beetle, Eleodes beameri. J. Insect Physiol. 21: 659-671.

Tschinkel, W.R. 1975b. A comparative study of the chemical defensive system of tenebrionid beetles: chemistry of the secretions. J. Insect Physiol. 21: 753-783.

Tschinkel, W.R., Doyen, J.T. 1980. Comparative anatomy of the defensive glands, ovipositors and female genital tubes of tenebrionid beetles (Coleoptera). J. Insect Morphol Embryol. 9: 321-368.

Tribolium Genome Sequencing Consortium, Richards S, Gibbs, R.A, Weinstock, G.M, Brown, S.J, y col. 2008. The genome of the model beetle and pest Tribolium castaneum. Nature 452: 949-955. Accessed 1 March 2012.

Unruh, L.M., Xu, R., Kramer, K.J. 1998. Benzoquinone levels as a function of age and gender of the red flour beetle, Tribolium castaneum. Insect Biochem. Mol. Biol. 28: 969-977.

Vanderwel, D., Oehschlager, A. 1987. Biosynthesis of pheromones and endocrine regulation of pheromone production in Coleoptera. In: Blomquist, G.J., Prestwich, G.D. (Eds.), Pheromone Biochemistry. Academic Press, Orlando, Florida, pp. 175-215.

Vas, G., Vékey, K. 2004. Solid-phase microextraction: a powerful sample preparation tool prior to mass spectrometric analysis. J. Mass Spectrom. 39: 233-254.

Viale, J.A. 1995. Conservación de granos en silos-chacra. INTA. Marco Juárez.

Villaverde, M.L., Juárez, M.P., Mijailovsky, S. 2007. Detection of Tribolium castaneum volatile defensive secretions by SPME-CGC analysis. J. Stored Prod. Res. 43: 540-545.

Villaverde, M.L., Girotti, J.R., Mijailovsky, S.J., Pedrini, N., Juárez, M.P. 2009. Volatile secretions and epicuticular hydrocarbons of the beetle Ulomoides dermestoides. Comp. Biochem. Physiol. B 154: 381-386.

Viñuela, E., Adan, A., Del Estal, P., Marco, V., Budia, F. 1993. Plagas de los Productos Almacenados. Hojas Divulgadoras. Ministerio de Agricultura Pesca y Alimentación, Madrid, España.

Von Endt, D.W., Wheeler, J.W. 1971. 1-pentadecene production in Tribolium confusum. Science. 172: 60-61.

Wahrendorf, M.S., Wink, M. 2006. Pharmacologically active natural products in the defence secretion of Palembus ocularis (Tenebrionidae, Coleoptera). J. Ethnopharm. 106: 51-56,

Warthen J.D., Uebel, E.C. 1980. Comparison of the unsaturated cuticular hydrocarbons of the male and female house crickets, Acheta domesticus (L.) (Orthoptera: Gryllidae). Insect Biochem. 10: 435-439.

Wigglesworth, V.B. 1934. The physiology of the cuticle and of ecdysis in Rhodnius prolixus (Triatomidae, Hemiptera); with special reference to the function of the oenocytes and of the dermal glands. Q. J. Microsc. Sci. 76: 269-318.

Wigglesworth, V.B. 1942. Some notes on the integument of insects in relation to the entry of contact insecticides. Bidl. Ent. Res. 33: 205-218.

Wigglesworth, V.B. 1945. Transpiration through the cuticle of insects. J. Exp. Biol. 21: 97-114. 
Wigglesworth, V.B. 1985. Sclerotin and lipid in the waterproofing of the insect cuticle. Tissue Cell 17: 227-248.

Wirtz, R.A., Taylor, S.L., Semey, H.G. 1978. Concentrations of substituted p-benzoquinones and 1-pentadecene in the flour beetles Tribolium confusum (J. du Val) and T. castaneum (Herbst). Comp. Biochem. Physiol. B 61: 25-29.

Yezerski, A., Gilmor, T.P., Stevens, L. 2000. Variation in the production and distribution of substituted benzoquinone compounds among genetic strains of the confused flour beetle, Tribolium confusum. Physiol. Biochem. Zool. 73: 192-199.

Yezerski, A., Gilmor, T.P., Stevens, L. 2004. Genetic analysis of benzoquinone production in Tribolium confusum. J. Chem. Ecol. 30: 1035-1044.

Zhang, H., Wang, J. 2007. Detection of age and insect damage incurred by wheat, with an electronic nose. J. Stored Prod. Res. 43: 489-495

Zhang, H., Wang, J. 2008. Identification of stored-grain age using electronic nose by ANN. Appl. Eng. Agric. 24: 227-23

Zhou, B., Wang, J. 2011. Detection of insect infestations in paddy field using an electronic nose. Int. J. Agric. Biol. 13: 707-712. 